UNIVERSIDADE DE BRASÍLIA

FACULDADE DE TECNOLOGIA

DEPARTAMENTO DE ENGENHARIA ELÉTRICA

CONTRIBUIÇÕES AO ESTUDO DA EXPOSIÇÃO HUMANA

A CAMPOS ELETROMAGNÉTICOS NA FAIXA DE RADIOFREQUÊNCIAS

AGOSTINHO LINHARES DE SOUZA FILHO

ORIENTADOR: ANTONIO JOSÉ MARTINS SOARES

TESE DE DOUTORADO EM ENGENHARIA ELÉTRICA

PUBLICAÇÃO: 091/2015 TD PPGEE

BRASÍLIA/DF: MARÇO - 2015 
UNIVERSIDADE DE BRASÍLIA

FACULDADE DE TECNOLOGIA

DEPARTAMENTO DE ENGENHARIA ELÉTRICA

\section{CONTRIBUIÇÕES AO ESTUDO DA EXPOSIÇÃO HUMANA A CAMPOS ELETROMAGNÉTICOS NA FAIXA DE RADIOFREQUÊNCIAS}

\section{AGOSTINHO LINHARES DE SOUZA FILHO}

TESE DE DOUTORADO SUBMETIDA AO DEPARTAMENTO DE ENGENHARIA ELÉTRICA DA FACULDADE DE TECNOLOGIA DA UNIVERSIDADE DE BRASÍLIA, COMO PARTE DOS REQUISITOS NECESSÁRIOS PARA A OBTENÇÃO DO GRAU DE DOUTOR.

APROVADA POR:

Antruionarticy

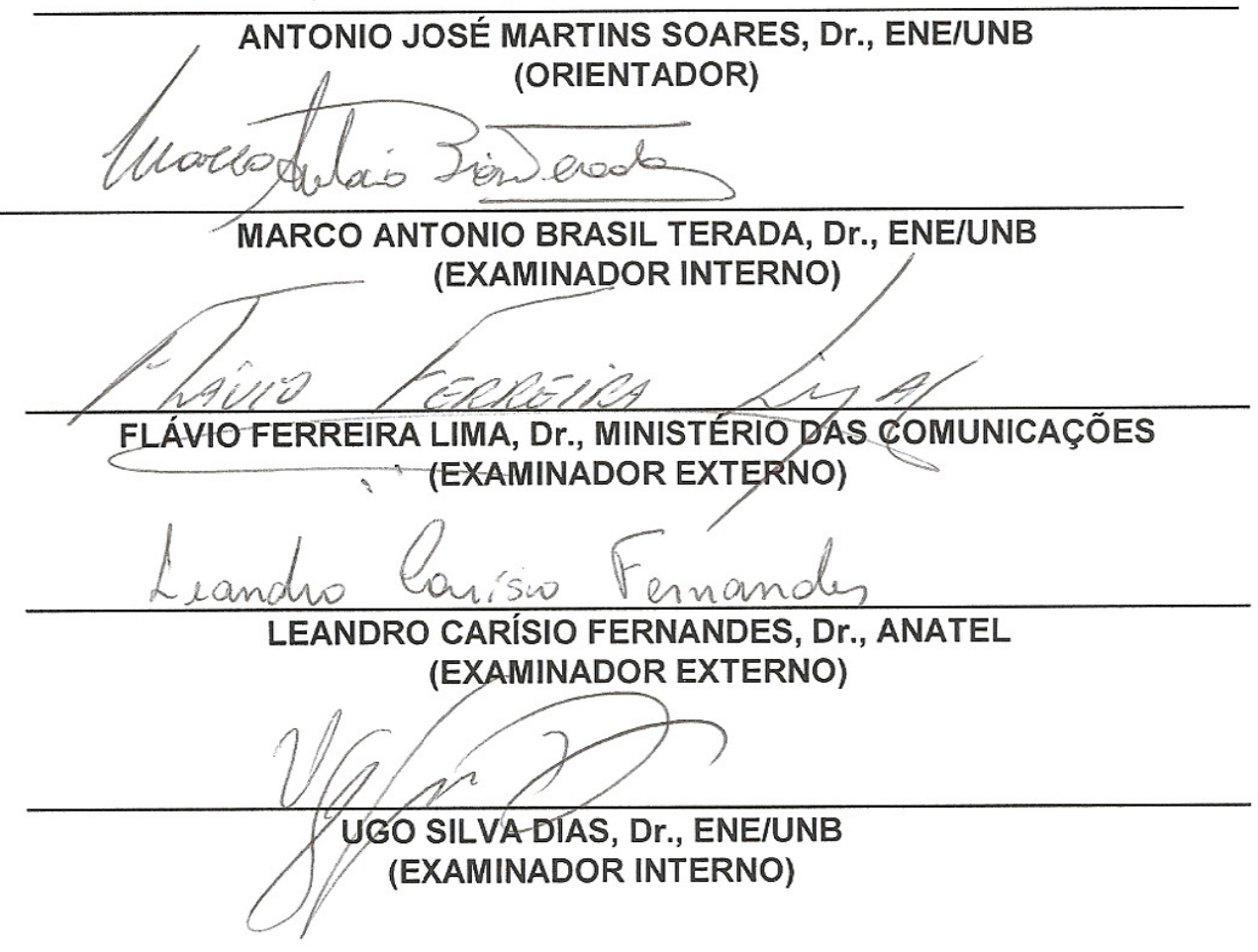

Brasília, 02 de março de 2015. 


\section{FICHA CATALOGRÁFICA}

SOUZA FILHO, AGOSTINHO LINHARES DE

Contribuições ao Estudo da Exposição Humana a Campos Eletromagnéticos na Faixa de Radiofrequências [Distrito Federal] 2015.

xv, 87p., 210 x 297 mm (ENE/FT/UnB, Doutor, Engenharia Elétrica, 2015). Tese de Doutorado - Universidade de Brasília. Faculdade de Tecnologia.

1. Eletromagnetismo aplicado

2. Propagação de ondas

3. Antenas

5. Exposição humana

I. ENE/FT/UnB

4. Campos eletromagnéticos

6. Radiação não ionizante

II. Título (série)

\section{REFERÊNCIA BIBLIOGRÁFICA}

SOUZA FILHO, A. L. (2015). Contribuições ao Estudo da Exposição Humana a Campos Eletromagnéticos na Faixa de Radiofrequências. Tese de Doutorado em Engenharia Elétrica, Publicação 091/2015 TD PPGEE, Departamento de Engenharia Elétrica, Universidade de Brasília, Brasília, DF, 87p.

\section{CESSÃO DE DIREITOS}

AUTOR: Agostinho Linhares de Souza Filho

TÍTULO: Contribuições ao Estudo da Exposição Humana a Campos Eletromagnéticos na Faixa de Radiofrequências

GRAU: Doutor

ANO: 2015

É concedida à Universidade de Brasília permissão para reproduzir cópias desta tese de doutorado e para emprestar ou vender tais cópias somente para propósitos acadêmicos e científicos. O autor reserva outros direitos de publicação e nenhuma parte dessa tese de doutorado pode ser reproduzida sem autorização por escrito do autor.

Agostinho Linhares de Souza Filho

Faculdade de Tecnologia

Departamento de Engenharia Elétrica

70.910-900, Brasília - DF - Brasil. 
À Júlia (in memoriam), com amor.

Ao meu pai (in memoriam) e minha mãe, com respeito e admiração. 


\section{AGRADECIMENTOS}

Toda história tem um começo e minha vontade em obter o maior grau acadêmico começou em minha infância, inspirada em meu pai, que foi Doutor em Matemática e Livre-docente em Matemática Financeira. Assim, não poderia deixar de agradecer aos meus pais e irmãs que sempre foram meus principais incentivadores pelos estudos e amor ao conhecimento. Assim como à minha esposa, Márcia Lemos, pela compreensão, amor, cuidado e companheirismo, tão importantes na vida pessoal, acadêmica e profissional.

Não posso deixar de mencionar também todos os meus professores do PPGEE, em especial, o professor e amigo Martins, que exerceu com excelência o papel de orientador e deu enorme contribuição na pesquisa, profundidade e organização deste trabalho.

Agradeço também aos colegas e amigos da Anatel do GCJV, ORER, UO01 e da antiga RFCE, em especial, a Eng ${ }^{a}$ Maria Aparecida, que como chefa imediata na RFCE me incentivou a especializar-me nos estudos sobre exposição humana a campos eletromagnéticos, tema no qual fui o responsável técnico pela Anatel por seis anos (20072013), além de dar o suporte necessário para o início dos estudos em nível de doutoramento.

Gostaria de mencionar também os engenheiros e pesquisadores da Comissão de Estudos 5 da ITU-T, com os quais tive grande interação no desenvolvimento de normas internacionais nesse tema, assim como, em menor escala, com engenheiros e pesquisadores do IEEE e da IEC. A participação em fóruns internacionais sobre o tema muito me auxiliou no desenvolvimento da expertise necessária para enxergar temas e oportunidades de desenvolvimento de estudos avançados nessa área. Nessa linha, destaco os colegas doutores Haim Mazar (Israel), Fryderyk Lewicki (Polônia) e Andreas Christ (Suíça).

Por fim, e mais importante de tudo, agradeço a Deus, que me deu saúde e força de vontade para concluir este trabalho. 
"Toda nossa ciência, comparada com a realidade, é primitiva e infantil, ainda assim é a coisa mais preciosa que nós temos".

Albert Einstein 


\title{
RESUMO
}

\section{CONTRIBUIÇÕES AO ESTUdO DA EXPOSIÇÃO HUMANA A CAMPOS ELETROMAGNÉTICOS NA FAIXA DE RADIOFREQUÊNCIAS}

\author{
Autor: Agostinho Linhares de Souza Filho \\ Orientador: Antonio José Martins Soares \\ Programa de Pós-graduação em Engenharia Elétrica \\ Brasília, março de 2015
}

A proliferação de estações de radiocomunicação, em especial de estações radiobase, levantou uma preocupação mundial quanto aos possíveis efeitos à saúde associados aos campos eletromagnéticos radiados pelas antenas. Uma estação de radiocomunicação opera em conformidade às normas quando os valores de campos elétrico e magnético observados no ponto de máxima exposição atenderem aos limites estabelecidos. No caso de estação radiobase instalada em área ampla e aberta, esse ponto ocorre na direção de máxima radiação da antena e se localiza, usualmente, entre algumas dezenas a poucas centenas de metros de distância. Em ambientes urbanos que possuem relevante densidade predial, para a determinação do ponto de máxima exposição, é necessário utilizar o modelo que melhor reflita os mecanismos de propagação da onda eletromagnética.

Nesse contexto, o objetivo geral deste trabalho é caracterizar o ambiente, do ponto de vista eletromagnético, de tal forma a auxiliar na avaliação da exposição humana a sinais de radiofrequência. A proposta leva em conta as características da antena do sistema radiante, como ângulo de meia-potência e lóbulos laterais; os mecanismos de propagação da onda eletromagnética, como visada direta, multipercurso e difração; e a representação da pessoa exposta. O objetivo específico é apresentar uma metodologia consistente, que identifique o local de máxima exposição, a fim de auxiliar na avaliação da conformidade de uma estação de radiocomunicação em relação aos limites de exposição humana a campos eletromagnéticos. O propósito é definir criteriosamente os pontos de medições em qualquer ambiente, urbano ou não, para que seja realizada a adequada avaliação da conformidade. A precisão da técnica é demonstrada por meio da aplicação da proposta em cenários simulados e reais. Embora o foco do trabalho seja as estações radiobase, a metodologia é geral e pode ser utilizada, por exemplo, na avaliação de sistemas de radiodifusão. O estudo sobre possíveis efeitos adversos à saúde está fora do escopo deste trabalho. 
ABSTRACT

CONTRIBUTIONS TO THE STUDY OF HUMAN EXPOSURE TO RADIOFREQUENCY ELECTROMAGNETIC FIELDS

\author{
Author: Agostinho Linhares de Souza Filho \\ Supervisor: Antonio José Martins Soares \\ Programa de Pós-graduação em Engenharia Elétrica \\ Brasília, March of 2015
}

The proliferation of radiocommunication stations, mainly base stations, raised a worldwide concern about possible adverse health effects of people exposed to electromagnetic fields radiated by the antennas. A radiocommunication station operates in accordance with the regulation when the electric and magnetic fields observed in the maximum exposure location are compliant with the established limits. In the case of a base station installed in a wide open area that location occurs in the direction of maximum radiation intensity of the antenna, usually, between a few dozen to a few hundred meters away. In urban environments, which have relevant building density, the propagation model should be adjusted to better reflect the mechanisms of propagation of the electromagnetic wave.

In this context, the general objective of this thesis is to present the characterization of the electromagnetic environment in such a way to assist in the exposure assessment. The proposal takes into account the characteristics of the radiating antenna, such as half-power angle and the side lobes; the propagation mechanisms of the electromagnetic waves, as line-of-sight, multipath and diffraction; and the representation of the person exposed. The specific objective is to provide a consistent methodology, to identify the maximum exposure location, in order to assist in the compliance assessment of the radiocommunication station with the limits of human exposure to electromagnetic fields. The purpose is to carefully define the points of measurements in any environment, urban or not, so that the appropriate assessment is performed. The accuracy of the methodology is demonstrated in simulated and real scenarios. Despite the focus of this work is base stations, the methodology is general and can be applied, for instance, in the assessment of broadcasting stations. The study on possible adverse health effects is beyond the scope of this work. 


\section{SUMÁRIO}

1 INTRODUÇÃO

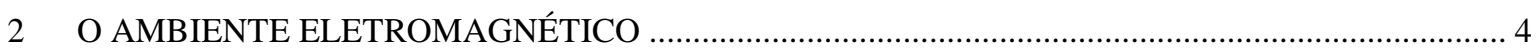

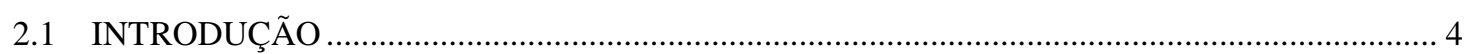

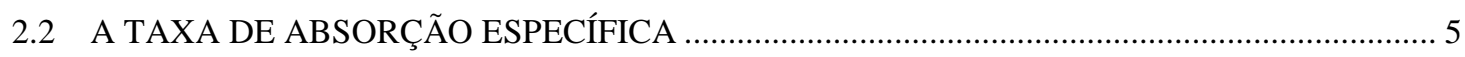

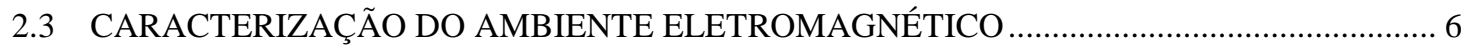

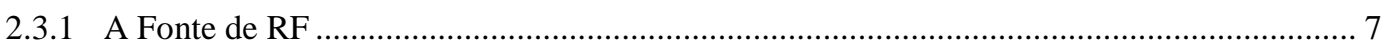

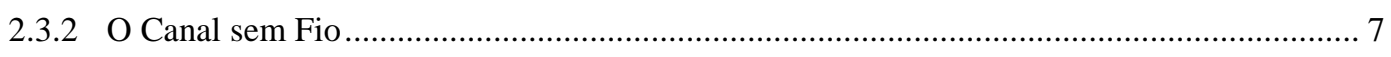

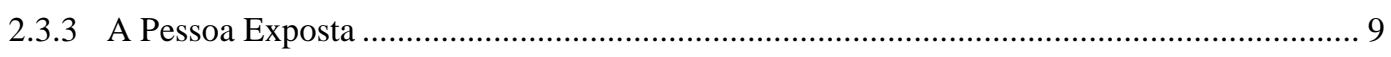

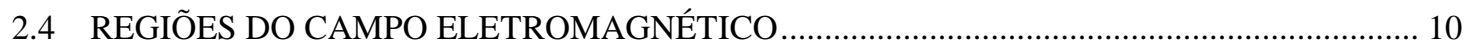

2.4.1 Redução do Ganho das Antenas Painéis na Região de Campo Próximo ............................... 11

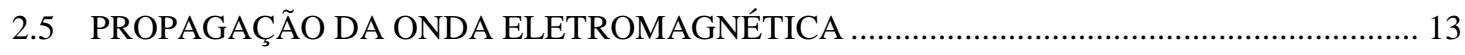

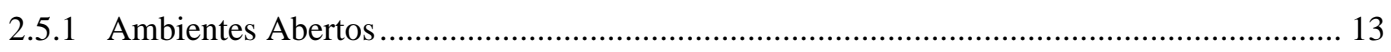

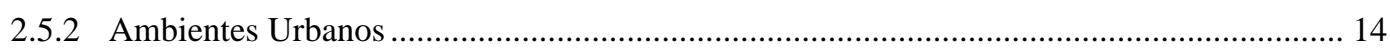

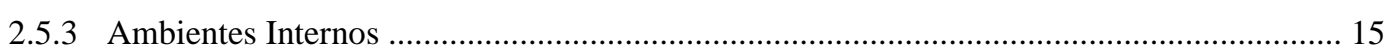

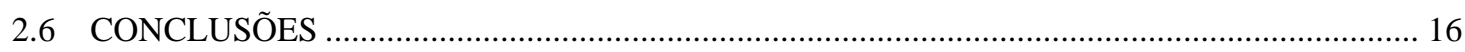

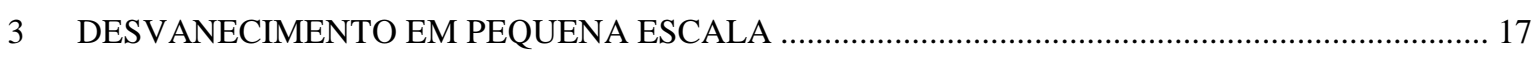

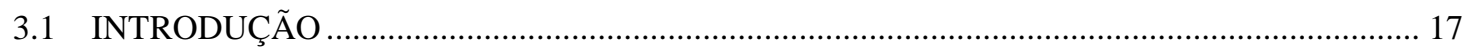

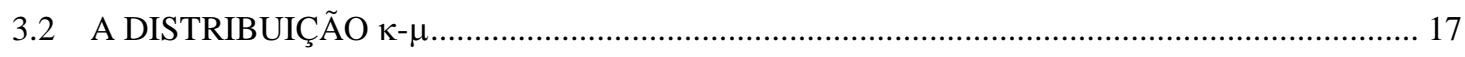

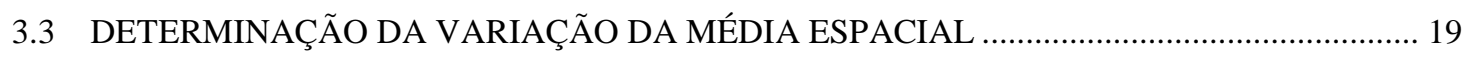

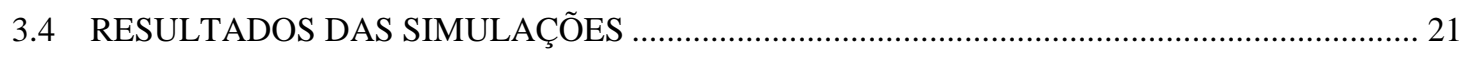

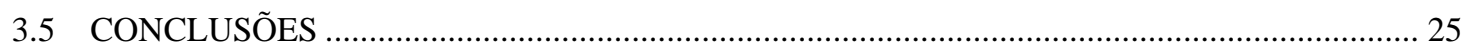

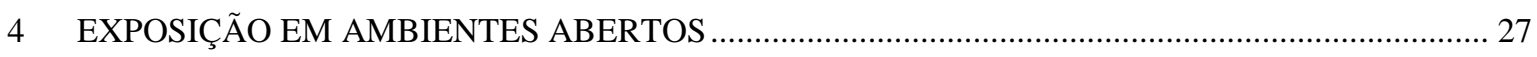

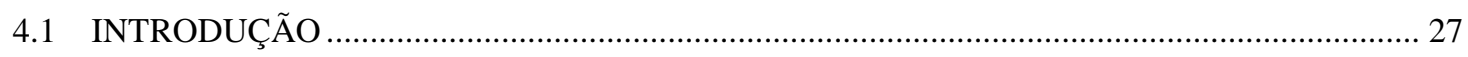

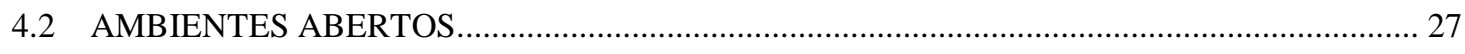

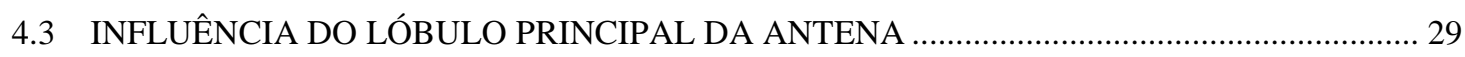

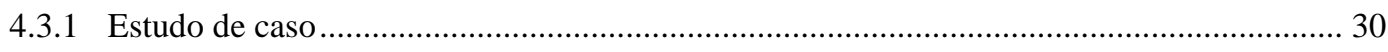

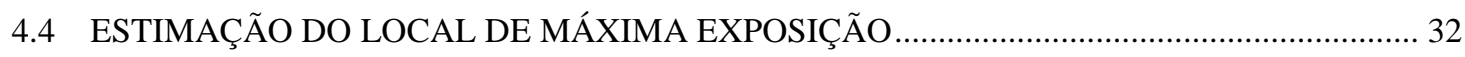

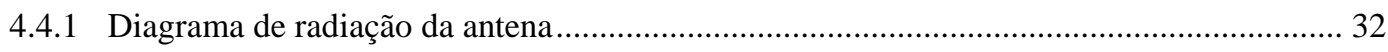

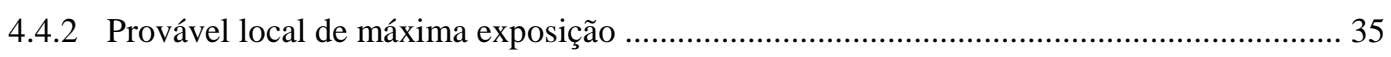

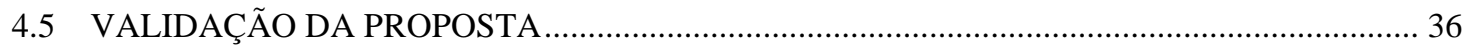

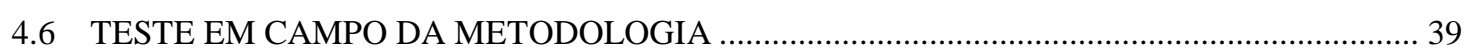

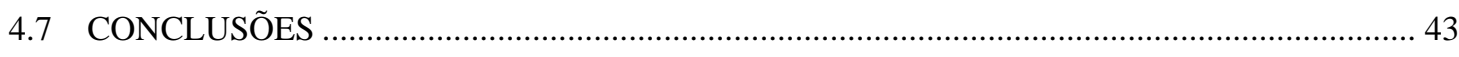

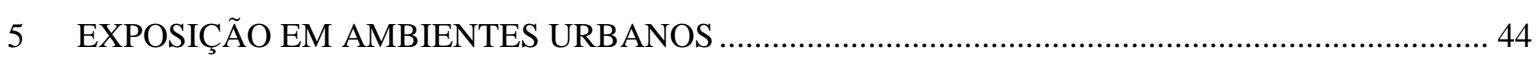

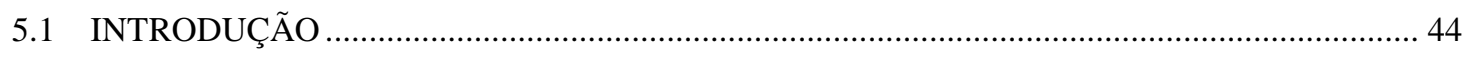

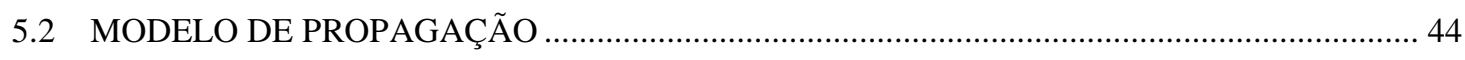

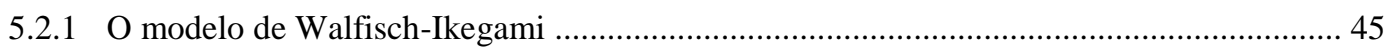

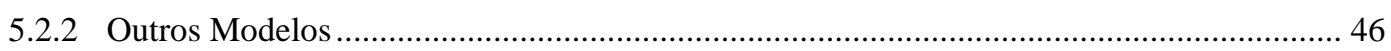

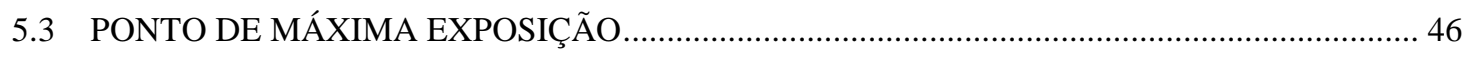

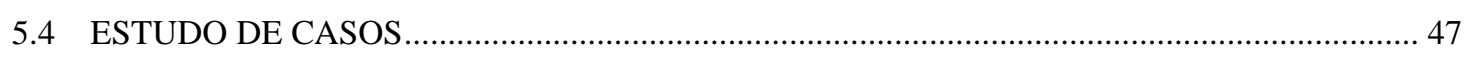

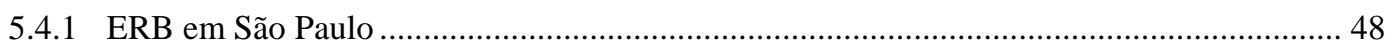




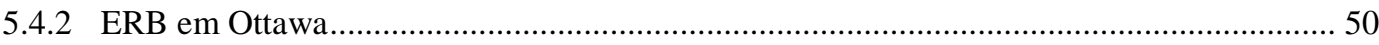

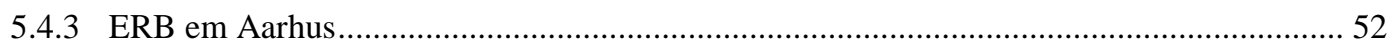

5.5 ANÁLISE DO DESVIO ENTRE OS PONTOS ESTIMADO E MEDIDO ............................... 54

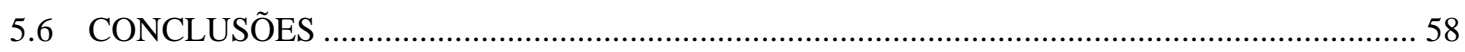

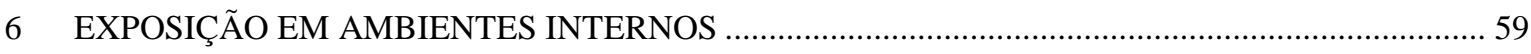

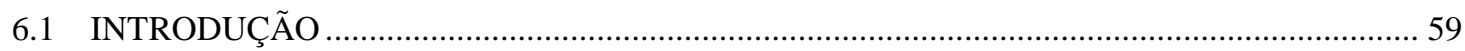

6.2 PROPAGAÇÃO EM ÁREAS ABERTAS DE AMBIENTES INTERNOS ................................ 59

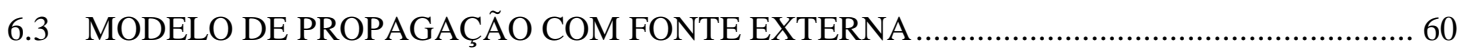

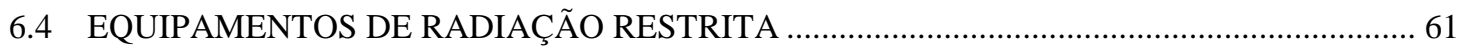

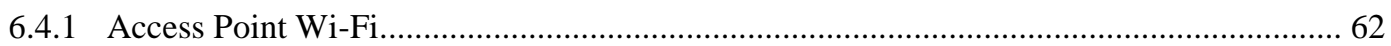

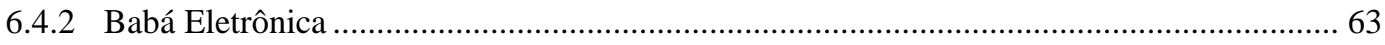

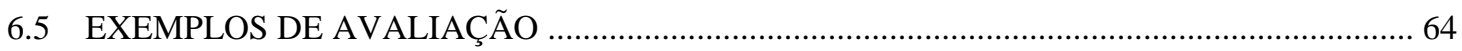

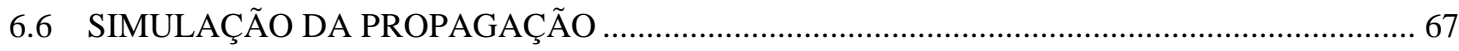

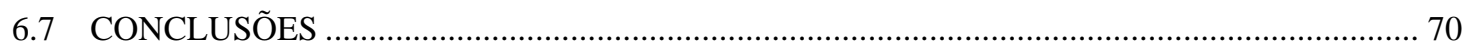

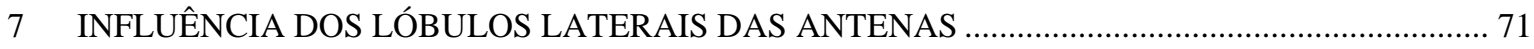

7.1 INTRODUÇÃ

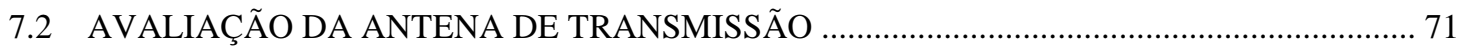

7.2.1 Procedimentos Práticos ................................................................................................ 73

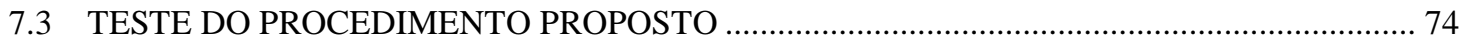

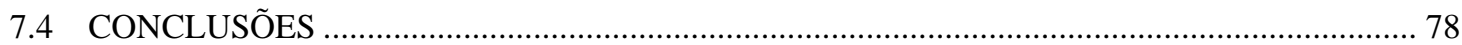

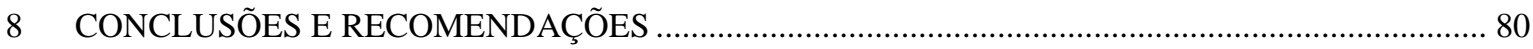

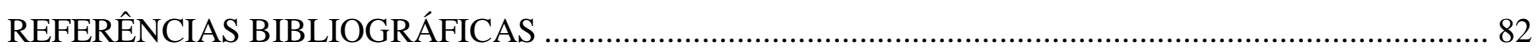




\section{LISTA DE TABELAS}

2.1: Principais características do CEMRF nas diferentes regiões (adaptado de [20]). D é a maior dimensão da antena e $\lambda$ é o comprimento de onda do sinal transmitido.

3.1: Relação da distribuição $\kappa-\mu$ com outras distribuições

3.2: Incerteza (95\%) para diferentes distribuições utilizando o Médodo de Monte Carlo

3.3: Incerteza (95\%) para diferentes distribuições de desvanecimento (Tabela I de [29])

3.4: Variação da média espacial, em $\mathrm{dB}$, para diferentes distribuições de desvanecimento $\left[\mathrm{F}_{\widehat{S}}\left(\gamma^{\prime} \mathrm{S}\right)-\mathrm{F}_{\widehat{S}}\left(\mathrm{~S} / \gamma^{\prime \prime}\right)=0,95\right]$

3.5: Estudos de casos

4.1: Exemplo de parâmetros de estação típica

4.2: Parâmetros para as ERBs.

4.3: Parâmetros de uma estação FM de baixa potência e de uma ERB.

4.4: Parâmetros das estações reais

5.1: ERB - São Paulo

5.2: ERB - Ottawa

5.3: ERB - Aarhus/ Dinamarca

5.4: Resultados para os locais estimados de máxima exposição $\left(X_{\max }^{\text {exp }}\right)$, região $R$ e locais medidos que apresentaram o maior valor de exposição a CEMRF.

6.1: Medição em uma grade 3 x 3 nas alturas de 1,1, 1,5 e 1,7 m, espaçadas 0,2 $\mathrm{m}$ na horizontal, paralelamente a janela.

6.2: Medições Wi-Fi com o AP na frente do usuário

6.3: Dispositivo localizado a 1,05 metros de altura 66

6.4: Medições com a sonda dentro do berço 66

7.1: Características e resultados das simulações 1, 2 e $3 \quad 74$

7.2: Características e resultados das simulações 4,5 e $6 \quad 76$

7.3: Características das fontes 1 e 2 e resultados. Coordenadas Lat. 15 ${ }^{\circ}$ 47 77 51.4" Long. 47 54' 26.4"; Azimute $220^{\circ}$ 


\section{LISTA DE FIGURAS}

2.1: Onda eletromagnética na região de campo distante. Figura adaptada de [18]

2.2: Distribuição considerando três pontos de medição $(1,1 \mathrm{~m}, 1,5 \mathrm{~m} \mathrm{e} 1,7 \mathrm{~m})$ para a determinação da média espacial.

2.3: Diagrama de radiação polar da antena CommScope HBX-6516DS-VTM

em $1.785 \mathrm{MHz}\left(+45^{\circ}\right)$. Plano horizontal em azul e plano vertical em vermelho.

2.4: Densidade de potência de uma antena painel a partir de $\mathrm{r}_{\mathrm{F}} / 100$. A máxima densidade de potência será de $200 \mathrm{~S}_{\mathrm{F}}$, mas em uma aproximação conservadora será de $400 \mathrm{~S}_{\mathrm{F}}$. Figura adaptada de [25].

2.5: Representação dos principais mecanismos de propagação em um ambiente complexo: visada direta, reflexão, difração, refração e espalhamento.

2.6: Perda de percurso, sombreamento e multipercurso versus distância. Figura adaptada de [27].

2.7: Propagação de um sinal externo para dentro de um apartamento, representado pelo ponto $\bullet$.

3.1: CDF para ambiente com canal com distribuição de desvanecimento $\kappa-\mu$, para $\kappa \rightarrow 0$ e $\mu=1$ (distribuição de Rayleigh) e médias espaciais com 1, 3, 6,9 e 20 pontos.

3.2: CDF da figura 3.1 em escala logarítmica.

4.1: Intensidade de campo elétrico ao longo da direção de azimute da antena setorial.

4.2: Modelo de dois raios para ambiente aberto em $1 \mathrm{GHz}$, mostrando a variação da intensidade de $E$ com a altura. O eixo vertical representa a altura, em metros, e o eixo horizontal representa a intensidade do campo elétrico com referência a $E$.

4.3: Região entre $X_{\text {inf }}$ (algumas dezenas de metros) até $X_{\text {sup }}$ (poucas centenas de metros) onde usualmente ocorre a máxima exposição.

4.4: Simulação utilizando o software EMF-Estimator

4.5: Diagrama de radiação da antena Kathrein 742 265, com tilt elétrico de $7^{\circ}$.

4.6: Diagrama de radiação da antena Andrews TBXLHA-6565C-VTM, com tilt elétrico de $8^{\circ}$.

4.7: Comparação de uma mesma antena com diferentes tilts elétrico para os dados da Tabela 4.2. Com um cenário com tilt de $0^{\circ}$, um dos lóbulos laterais foi o responsável pela máxima exposição.

4.8: Resultado para a estação FM da Tabela 4.3. Neste caso, o lóbulo lateral é responsável pela máxima exposição.

4.9: Resultado para a ERB da Tabela 4.3, que apresenta uma antena muito diretiva no plano vertical.

4.10: Sítio localizado no estacionamento do Estádio Mané Garrincha, compartilhado por três operadoras.

4.11: Resultados para o sistema GSM. $\diamond$ valores medidos, — valor estimado. 
4.12: Resultados para o sistema trunking (iDEN). ○ valores medidos, — valor estimado.

5.1: Aproximação de um percurso inclinado por um percurso plano. A figura (a) não é exatamente equivalente à (b), pois o eixo-y deveria também ser rotacionado em $\beta$ graus.

5.2: ERB hipotética localizada no centro urbano da cidade de de São Paulo. Prédios em ambos os lados da rua bloqueiam a propagação do sinal. As regiões mais livres apresentam maiores intensidade de CEM.

5.3: Visão em 3D da ERB no meio da região urbana.

5.4: Densidade de potência calculada com o software ICS Telecom. O ponto de máxima exposição está localizado em $75 \mathrm{~m}$, mesmo valor estimado para $\gamma$ $=2$ e maior do que para $\gamma=2,6$.

5.5: Perda de percurso no sentido oeste do sinal radiado pelo transmissor localizado na Rua Slater, 300 (Meas.). Neste caso, $P L=23,4+26,6 \log$ (d), com $\sigma=3,84 \mathrm{~dB}$. O ponto de interceptação entre ambos os modelos LS (regressão linear) e FS (espaço livre) ocorre na distância de $18 \mathrm{~m}$.

5.6: Densidade de potência em função da distância horizontal até a ERB, para o modelo de espaço livre e para o modelo com o PL específico. Neste gráfico foi considerado que abaixo do ponto de interceptação em $18 \mathrm{~m}$ o modelo específico converge para o modelo de espaço livre

5.7: Potência recebida do sinal de referência (RSRP) de um sistema LTE com largura de faixa de $20 \mathrm{MHz}$ com tilt de antena de $10^{\circ}$.

5.8: RSRP de um sistema LTE com largura de faixa de $20 \mathrm{MHz}$ com tilt da antena de $6^{\circ}$.

5.9: O ponto estimado de máxima exposição a CEMRF associado ao lóbulo principal é $\mathrm{X}_{\max }^{\exp }$. Devido a componente aleatória da perda de percurso, o local real de máxima exposição pode estar na região delimitada por $X_{0} \mathrm{e}$ $X_{1}$. Em destaque estão representadas a curva teórica de densidade de potência e valores de medição (círculos).

5.10: Valor de $p(X)$ para Brasília e Aahrus. $\mathrm{X}_{\max }^{\exp }$ é o local no qual $p(X)=50 \%$.

6.1: Representação esquemática de uma ERB com setor de interesse iluminando um prédio, com azimute apontando no sentido de $D$.

6.2: AP instalado sobre uma mesa de trabalho.

6.3: Babá eletrônica instalada perto de um berço.

6.4: ERB próxima a um prédio residencial.

6.5: Diagrama de radiação no plano horizontal real e aproximado da antena considerada na simulação.

6.6: Diagrama de radiação no plano vertical real e aproximado da antena considerada na simulação.

6.7: Intensidade de campo elétrico simulado dentro do apartamento, a $2 \mathrm{~m}$ da janela, com ERB a 25 m de distância.

6.8: Intensidade de campo elétrico simulado dentro do apartamento, a $2 \mathrm{~m}$ da janela, com ERB a 100 metros de distância.

7.1: Influência do tilt da antena no ponto de máxima exposição. 
7.2: Dependência da distância de máxima exposição a qualquer lóbulo em relação ao tilt e ao ângulo de meia-potência para uma antena instalada a uma altura de $30 \mathrm{~m}$ e altura de referência de $1,5 \mathrm{~m}$.

7.3: ERB de macrocélula com tilt de $3^{\circ}$ e ERB de microcélula com tilt de $1^{\circ}$ apresentaram máximo de exposição associado aos lóbulos laterais.

7.4: Sítio localizado no Parque da Cidade, DF, ao lado do Centro de Eventos.

7.5: Intensidade de campo elétrico para o sistema GSM.

7.6: Intensidade de campo elétrico para o sistema UMTS. 


\section{LISTA DE SÍMBOLOS, NOMENCLATURA E ABREVIAÇÕES}

AP - Ponto de acesso (do inglês Access Point)

$\mathrm{BCCH}$ - Canal de broadcasting (tecnologia GSM)

CEMRF - Campo eletromagnético na faixa de radiofrequências

$E$ - Intensidade de campo elétrico

EIRP - Potência efetiva isotropicamente radiada

ERB - Estação rádiobase

$\mathrm{F}(\theta, \phi)$ - diagrama de radiação normalizado

$\mathrm{G}_{\text {máx }}-$ Ganho máximo da antena

$H$ - Intensidade de campo magnético

ITU - União Internacional de Telecomunicações

LOS - Visada direta (do inglês line-of-sight)

NLOS - Sem visada direta (do inglês non-line-of-sight)

RNI - Radiação não-ionizante

$\mathrm{S}(\theta, \phi)$ - Densidade de potência no ângulo de elevação $\theta$ e azimute $\phi$

SAR - Taxa de absorção específica

SLL - Nível de lóbulo lateral

Z - Impedância intrínseca do meio

$\mathrm{Z}_{0}$ - Impedância intrínseca do vácuo

$X_{\text {inf }}$ - Ponto "iluminado" pelo primeiro nulo da antena abaixo da linha do horizonte

$X_{\text {sup }}$ - Ponto "iluminado" pela máxima radiação da antena

$\mathrm{X}_{\text {main }}^{\text {exp }}$ - Ponto provável de máxima exposição devido o lóbulo principal

$X_{\max }^{\exp }$ - Ponto provável de máxima exposição

$\mathrm{X}_{\mathrm{ssl}}^{\mathrm{exp}}$ - Ponto provável de máxima exposição devido o lóbulo lateral

$\gamma$ - Expoente da perda de percurso

$\Gamma$ - Coeficiente de reflexão

$\kappa$ - Razão entre potência total das componentes em visada e a potência total das ondas espalhadas

$\mu$ - Representação física do número de clusters de multipercurso 


\section{INTRODUÇÃO}

Atualmente, há aproximadamente 70.000 estações rádio base (ERBs) instaladas no Brasil, número que tende a aumentar devido a crescente demanda por maior cobertura e capacidade de tráfego, além da introdução de novas tecnologias que operam em faixas de frequências cada vez mais altas. A disseminação de estações de radiocomunicação implica em um cada vez maior nível de radiação eletromagética no ambiente, o que tem despertado uma preocupação mundial quanto aos efeitos associados aos campos eletromagnéticos na faixa de radiofrequêncas (CEMRF) radiados pelas antenas dessas estações.

No caso da exposição humana a CEMRF, existem duas abordagens: sob a óptica de possíveis efeitos adversos à saúde; e sob o prisma da caracterização do ambiente eletromagnético. Em relação à primeira abordagem, a Organização Mundial de Saúde (OMS), a Comissão Internacional de Proteção Contra Radiação Não-Ionizante (ICNIRP) e o Instituto de Engenheiros Eletrônicos e Eletricistas (IEEE) desenvolvem estudos para estabelecer limites de exposição e avaliação dos efeitos biológicos dessa exposição. Em relação à segunda abordagem, a Comissão Internacional de Eletrotécnica (IEC), o IEEE e a União Internacional de Telecomunicações (ITU) são os organismos internacionais que desenvolvem normas e recomendações para caracterizar o ambiente e avaliar a conformidade da exposição aos limites estabelecidos [1].

Basicamente, as normas e recomendações internacionais específicas possibilitam a avaliação da exposição de duas formas: a primeira, mais simples, considera apenas os cálculos teóricos, enquanto a segunda considera medições em campo. Em relação às medições em campo, para possibilitar a correta configuração dos equipamentos de medição, além dos parâmetros do sistema radiante, como altura, ganho, tilt da antena e potência efetiva isotropicamente radiada (EIRP), são considerados aspectos da tecnologia como, por exemplo, largura de faixa, tipo de modulação e técnica de acesso ao meio.

Um dos pontos fundamentais para garantir uma avaliação adequada da exposição humana a CEMRF é a seleção criteriosa dos pontos de medição. Nos referidos documentos técnicos, em [2-3] são feitos comentários gerais, e em [4-5] são indicadas distâncias mínimas acima das quais a estação específica sendo avaliada já atenderia o limite. 
A motivação deste estudo foi a percepção de que, para a elaboração de relatórios de conformidade quando são realizadas medições, os pontos de avaliação não estão sendo escolhidos de forma adequada. Em geral, eles são selecionados com base na maior facilidade de instalação de equipamentos de medição ou em locais considerados sensíveis, como frentes de escolas, hospitais ou em praças públicas, sem identificar tecnicamente os locais de máxima exposição associados à estação sendo avaliada.

Neste trabalho, será apresentada uma nova metodologia para estimar o local de máxima exposição a CEMRF associados a uma estação de radiocomunicação. A originalidade desta tese consiste em utilizar uma fórmula fechada com parâmetros básicos do sistema radiante, preenchendo uma lacuna até então não $\operatorname{coberta}^{1}$ por normas internacionais que abordam a escolha dos locais de avaliação da exposição, sem contudo orientar sobre como identificar os pontos de máxima exposição.

Adicionalmente, a relevância deste trabalho inclui a caracterização do ambiente eletromagnético, levando em conta os parâmetros do sistema radiante instalado, a propagação do campo eletromagnético e a exposição da pessoa, tanto para ambientes internos quanto para ambientes externos. Desta forma, a aplicação da presente metodologia auxilia a tarefa dos técnicos que realizam medições em campo para avaliar a conformidade de uma estação de radiocomunicação. O estudo sobre possíveis efeitos adversos à saúde está fora do escopo deste trabalho, mas informações atualizadas nesse tema podem ser obtidas em [7-10].

A tese está organizada da seguinte forma: no capítulo 2 são apresentados conceitos fundamentais para caracterizar o ambiente eletromagnético no qual pessoas estão expostas a campos gerados por sistemas de radiocomunicações. Em seguida, no capítulo 3, é abordado o efeito da variação do campo eletromagnético ao longo do corpo de uma pessoa na avaliação de sua exposição, para posteriormente explicar e apresentar exemplos de como proceder para mitigar esse fenômeno. Os capítulos 4 e 5 apresentam a metodologia para estimar o local de máxima exposição a CEMRF associados ao lóbulo principal da antena de uma estação de radiocomunicação, seja em ambientes abertos ou urbanos. Complementarmente a esses dois capítulos anteriores, o capítulo 6 trata da exposição em

\footnotetext{
${ }^{1}$ Após contribuição para a ITU-T, a proposta baseada neste trabalho foi inserida na Recomendação ITU-T K.100 [6], recentemente aprovada.
} 
ambientes internos, seja devido a fontes de RF externas ou internas ao ambiente. $\mathrm{O}$ capítulo 7 apresenta estudos sobre a influência dos lóbulos laterais das antenas na determinação da máxima exposição. Por fim, no capítulo 8, são apresentadas conclusões e recomendações deste trabalho, além de sugestões de trabalhos futuros. 


\section{O AMBIENTE ELETROMAGNÉTICO}

\subsection{INTRODUÇÃO}

Do ponto de vista eletromagnético, o ambiente possui contribuições de radiação natural e de fontes artificiais, fabricadas pelo homem. A radiação natural pode ser de origem terrestre, a exemplo da descarga atmosférica, ou extraterrestre, como a solar e a espacial [11]. As fontes artificias geram radiação intencional ou não intencional. Ela será considerada intencional quando for causada por equipamento utilizado para gerar campos eletromagnéticos (CEM) que se propagam em meios não conduzidos, como nos casos de radiocomunicação (ERB, radiodifusão, equipamento de radiação restrita etc.) ou em aplicações médicas (equipamentos de imagem por ressonância magnética, de hipertermia, entre outros). Por outro lado, a radiação será não intencional quando for causada por dispositivo cujo objetivo não é a transmissão de ondas eletromagnéticas no espaço, como computadores, linhas de transmissão de energia elétrica e equipamentos de PLC (powerline communications).

No contexto de exposição humana a CEM, uma separação importante é a da radiação ionizante da radiação não ionizante (RNI). A primeira, como os raios- $\gamma$ e os raios-X, pode quebrar as ligações que mantêm as moléculas ligadas em células e, portanto, produzir ionização da matéria [12]. Por outro lado, os CEM da RNI são demasiadamente fracos para quebrar essas ligações, não sendo capazes de produzir a emissão de elétrons de átomos ou moléculas. A RNI caracteriza-se por apresentar frequência inferior a $3 \times 10^{15} \mathrm{~Hz}$ e energia, por fóton, menor que $12 \mathrm{eV}$ [5].

A faixa de radiofrequência (RF) é a parte do espectro eletromagnético abaixo de 3.000 $\mathrm{GHz}$, que, do ponto de vista do conhecimento tecnológico atual, é passível de uso por sistemas de radiocomunicação [13-14]. Todavia, várias referências adotam a faixa entre 9 $\mathrm{kHz}$ e $300 \mathrm{GHz}$ (ou 8,3 kHz e $300 \mathrm{GHz}$ ) para se referir ao espectro de radiofrequência quando dos estudos relacionados à exposição humana a CEMRF [3-5, 11, 15].

\footnotetext{
${ }^{2}$ Na Conferência Mundial de Radiocomunicações (WRC) realizada em 2012, definiu-se que a atribuição para serviços de radiocomunicações começaria em $8,3 \mathrm{kHz}$ e não mais em $9 \mathrm{kHz}$. Dessa forma, algumas referências estão atualizando o limite inferior, como já ocorreu em [15].
} 
Neste trabalho, o interesse é a RNI, mais especificamente aquela emitida por equipamentos de radiocomunicações utilizados em serviços ou aplicações na faixa de RF, incluindo o Serviço Móvel Pessoal (SMP), serviços de radiodifusão, como TV e rádio FM, e equipamentos de radiação restrita, como access point Wi-Fi e babá eletrônica, nos quais os principais mecanismos de propagação são a visada direta, multipercurso, difração e refração.

\subsection{A TAXA DE ABSORÇÃO ESPECÍFICA}

Para a avaliação da exposição humana a CEMRF, é comum dividir o estudo em duas faixas de frequências: sinais que oscilam até $100 \mathrm{kHz}$ são considerados de baixa frequência; e sinais acima de $100 \mathrm{kHz}$ até $300 \mathrm{GHz}$ são considerados de alta frequência. Esta classificação decorre da interação do campo eletromagnético com o corpo humano e das unidades dosimétricas ${ }^{3}$ utilizadas para avaliar cada exposição. Enquanto em baixa frequência as unidades dosimétricas estão associadas à geração de corrente elétrica no corpo humano; em alta frequência, o principal parâmetro a ser avaliado é a taxa de absorção específica (SAR - Specific Absorption Rate).

A SAR representa a taxa de absorção de energia pelos tecidos do corpo, sendo a medida dosimétrica mais utilizada nos estudos sobre exposição humana a CEMRF entre $100 \mathrm{kHz}$ e $10 \mathrm{GHz}$.

A quantidade de energia eletromagnética absorvida pelos tecidos do corpo depende da intensidade de campo elétrico na região em que a pessoa está localizada. Da energia que incide no corpo de uma pessoa, somente uma parte é absorvida, o restante atravessa o corpo, é refletida ou sofre espalhamento sem ser absorvida [16]. A SAR pode ser matematicamente expressa como:

$$
\mathrm{SAR}=\frac{\sigma_{\text {tecido }} \times E_{i}^{2}}{\rho}\left\lceil\frac{\mathrm{W}}{\mathrm{kg}}\right]
$$

\footnotetext{
${ }^{3}$ As unidades dosimétricas consideradas pela ICNIRP são [10]:

- densidade de corrente elétrica (J), até $10 \mathrm{MHz}$;

- corrente elétrica (I), até $110 \mathrm{MHz}$;

- taxa de absorção específica (SAR), na faixa de $100 \mathrm{kHz}$ a $10 \mathrm{GHz}$;

- absorção específica (SA), para campos pulsados, na faixa de $300 \mathrm{MHz}$ a $300 \mathrm{GHz}$;

- densidade de potência (S), na faixa de $10 \mathrm{GHz}$ a $300 \mathrm{GHz}$
} 
em que $\sigma_{\text {tecido }}$ é a condutividade elétrica do tecido exposto, $E_{i}$ é a intensidade de campo elétrico no tecido (valor RMS) e $\rho$, a densidade volumétrica da massa de tecido exposta.

Observa-se que a SAR está associada à dissipação de energia, implicando em efeitos térmicos, que são os únicos efeitos adversos comprovados à saúde em relação à exposição humana a CEMRF [7, 9-12, 16, 17].

Se forem desconsiderados os mecanismos de condução de calor e outros de difusão térmica, a relação entre acréscimo de temperatura e SAR é dada por:

$$
\mathrm{SAR}=\left.c \frac{d T}{d t}\right|_{t \rightarrow 0}
$$

em que $c$ é o calor específico da matéria, $T$, a temperatura e $t$, o tempo de exposição.

Assim, os limites de proteção contra os CEMRF são baseados em restrições básicas cuja avaliação em termos de SAR depende de medições em laboratório e/ou modelamento matemático. Para avaliações práticas em campo, foram estabelecidos limites para os níveis de referência, os quais consideram condições de máximo acoplamento entre o campo eletromagnético e a pessoa de referência exposta. Atendendo os níveis de referência, se atenderá as restrições básicas. O não atendimento dos níveis de referência não implica necessariamente que as restrições básicas não são atendidas.

Portanto, os níveis de referência buscam avaliar quais os valores limites de unidades derivadas (intensidade de campo elétrico, intensidade de campo magnético ou densidade de potência) que geraria, em determinado ambiente, uma intensidade de campo elétrico interno a uma pessoa de referência, de tal forma a garantir o atendimento das restrições básicas.

\subsection{CARACTERIZAÇÃO DO AMBIENTE ELETROMAGNÉTICO}

Para o propósito de avaliar a exposição humana a CEMRF, devem ser considerados três componentes básicos: a fonte de RF, o canal sem fio e a pessoa exposta. No primeiro, são incluídas as características do sistema radiante, como potência radiada, ganho, tilt e ângulo de meia-potência da antena. O segundo está relacionado com a atenuação da amplitude da onda eletromagnética, que se propaga em um meio não controlado, sujeito a variações que dependem da distância (perda de percurso) e também dos efeitos de multipercurso e 
sombreamento. O terceiro componente está relacionado com as características da pessoa exposta, incluindo, mas não se limitando, a altura, o peso e a posição (em pé, deitado, sentado etc.).

\subsubsection{A Fonte de RF}

No contexto deste trabalho, a fonte de RF é o sistema de radiocomunicação responsável pela irradiação de uma pessoa, como, por exemplo, uma estação transmissora de TV digital ou uma ERB. O sistema de radiocomunicação é composto, basicamente, por transceptor, cabos (ou guias de onda), conectores e antena, podendo possuir elementos adicionais como filtros e duplexer.

A antena é o transdutor entre um meio guiado ou conduzido e o meio não confinado (ar, espaço). Apesar de ser um dispositivo recíproco, no presente caso, a antena será tratada como um elemento emissor que concentra a energia eletromagnética recebida do transmissor e radia a onda eletromagnética de acordo com suas características direcionais. Logo, dependendo do contexto, o termo antena pode ser utilizado intercambiável com fonte de RF, uma vez que a origem da onda eletromagnética será a localização da antena.

Pode-se caracterizar a fonte de RF por sua potência radiada, distribuição angular da radiação, frequência de operação, largura de faixa, polarização, entre outros parâmetros. Assim, as características construtivas, de operação e de instalação da antena são importantes para a avaliação da exposição humana a CEMRF, pois a distribuição espacial da energia eletromagnética será dependente desses parâmetros, do efeito do ambiente no sinal radiado, além da relação entre dimensões da antena e distância entre a fonte e o ponto de referência sendo avaliado.

\subsubsection{O Canal sem Fio}

A propagação da onda eletromagnética emitida por uma estação de radiocomunicação está sujeita a variações espaciais e temporais em diferentes escalas, proporcionais à complexidade do ambiente (urbano, suburbano, rural, densidade de prédios, árvores, ambientes abertos ou fechados etc.). Assim, o canal sem fio envolve a caracterização de como a onda eletromagnética irá se propagar no ambiente que contém a fonte de RF e a pessoa exposta. 
Considerando uma fonte pontual isotrópica ideal no espaço livre, a onda eletromagnética irá se dispersar uniformemente em todas as direções a partir de sua origem. A densidade de potência, que corresponde à razão entre a potência total radiada e a área da superfície esférica que envolve a fonte, é expressa por:

$$
\mathrm{S}=\frac{P_{R A D}}{4 \cdot \pi \cdot R^{2}}\left[\frac{\mathrm{W}}{\mathrm{m}^{2}}\right]
$$

em que $P_{R A D}$ é a potência total radiada e $R$, a distância da fonte ao ponto de observação.

As antenas práticas possuem ganho, que nada mais é do que a concentração de energia eletromagnética em determinadas direções em detrimento de outras. Normalmente, utilizase a potência equivalente isotropicamente radiada (EIRP), que representa o produto entre a potência entregue à antena e o ganho em determinada direção. Se a direção não for especificada, fica subentendido que se está referindo à EIRP máxima, isto é, na direção de máximo ganho da antena. Logo, a densidade de potência na direção de máximo ganho de uma antena, em um ambiente de espaço livre e em campo distante, pode ser escrita como:

$$
\mathrm{S}=\frac{\mathrm{EIRP}}{4 \cdot \pi \cdot R^{2}}
$$

Na maioria das vezes, a avaliação da exposição humana a CEM associada a uma estação de radiocomunicação ocorre distante da fonte de RF. Nessa região, conhecida como região de campo distante, os vetores intensidade de campo elétrico $(E)$, intensidade de campo magnético $(H)$ e direção de propagação $(k)$ são mutuamente ortogonais, conforme mostrado na figura 2.1 [18]. Nesse caso, tem-se que:

$$
\mathrm{S}=\frac{E^{2}}{120 . \pi}=120 . \pi \cdot H^{2}
$$

A partir de (2.5), a intensidade de campo elétrico pode ser obtida por:

$$
E=(377 \times S)^{0,5}
$$

Apesar de ser muito utilizado para estimar a exposição, caracterizar o canal sem fio como espaço livre é simplista, podendo superestimar a exposição. Nos próximos capítulos, o modelamento do canal sem fio será aprofundado. 


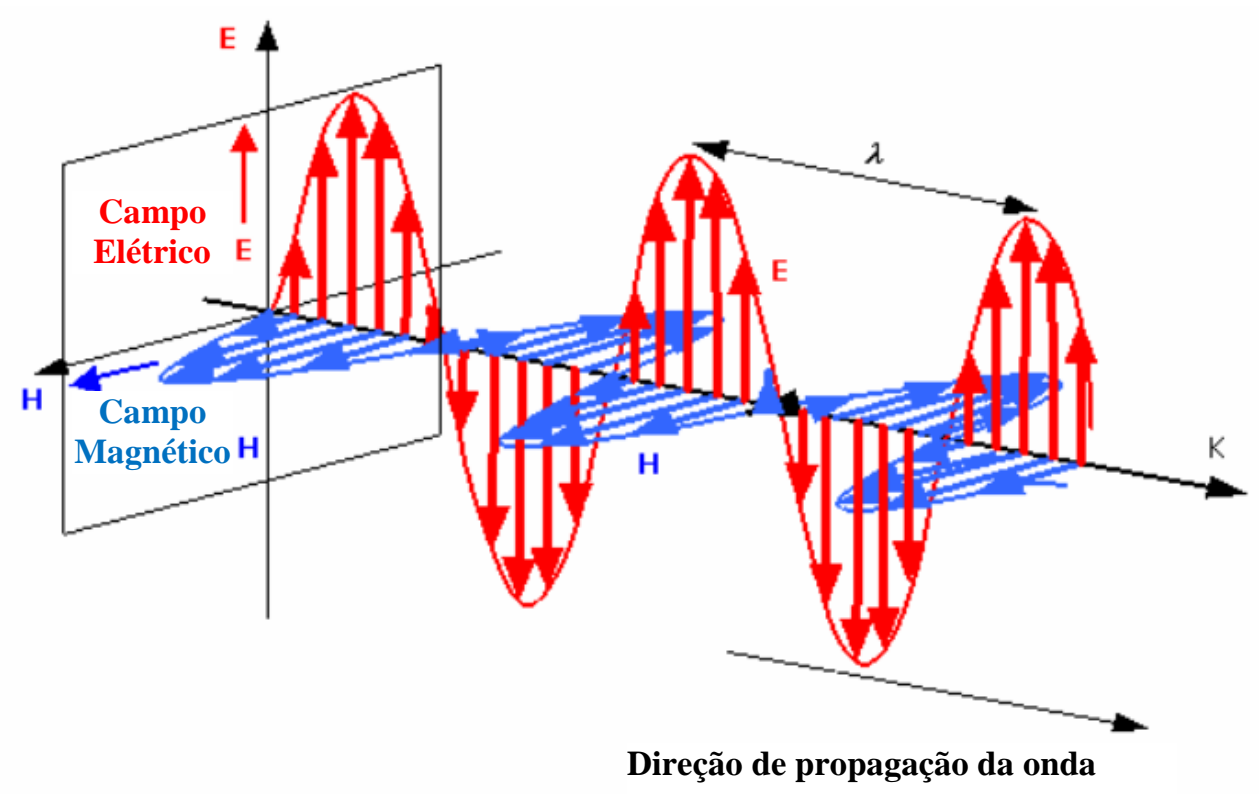

Figura 2.1: Onda eletromagnética na região de campo distante. Figura adaptada de [18]

\subsubsection{A Pessoa Exposta}

As normas relacionadas à exposição humana a CEMRF estabelecem limites de exposição localizada e para o corpo inteiro, considerando uma pessoa adulta de referência. Assim, uma pessoa comum, para a mesma intensidade de campo elétrico, pode absorver mais ou menos energia eletromagnética em relação à outra pessoa, dependendo de suas características físicas e posição, além das características do sinal que se propaga. Todavia, os limites estabelecidos consideram valores conservadores, no qual foi aplicado um fator de proteção a fim de proteger qualquer pessoa, seja criança, adulto, idoso ou enfermo.

Considerando que a incidência de campo elétrico ao longo do corpo de uma pessoa ocorre comumente com distribuição não uniforme, é necessária a determinação da média espacial, principalmente para frequências superiores a $300 \mathrm{MHz}$. Mesmo que a densidade de potência ou a intensidade de campo elétrico esteja muito abaixo do limite, recomenda-se a execução de tal procedimento, para possibilitar a repetibilidade do resultado [19]. A figura 2.2 apresenta a distribuição típica para uma média espacial com três pontos, considerando a representação do corpo humano. Se apenas um ponto fosse selecionado, o corpo inteiro seria representado por apenas aquele ponto, gerando um potencial de risco de grandes desvios entre o valor de exposição avaliado e o valor real de exposição de corpo inteiro. Se uma maior precisão for necessária, um número maior de pontos pode ser escolhido, como, 
por exemplo, 6, 9 ou 20 pontos. A seleção de pontos pode representar um plano ou um volume.

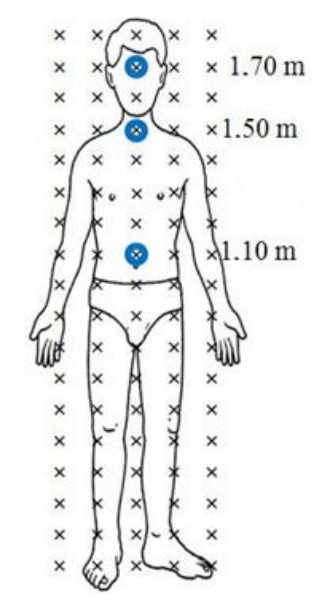

Figura 2.2: Distribuição considerando três pontos de medição $(1,1 \mathrm{~m}, 1,5 \mathrm{~m}$ e 1,7 m) para a determinação da média espacial.

\subsection{REGIÕES DO CAMPO ELETROMAGNÉTICO}

De maneira geral, para a avaliação do campo eletromagnético transmitido pela antena, o espaço pode ser dividido nas seguintes regiões: campo próximo reativo, campo próximo radiante e campo distante. A transição entre essas regiões é gradativa e ocorre de acordo com o afastamento da fonte, no entanto, há, na literatura, diferentes interpretações entre os pontos de separação dessas regiões [2, 20-24]. A Tabela 2.1 apresenta um resumo das principais características dessas regiões, levando em conta uma das opções de convenção para essa separação. O equacionamento e explicação dessas regiões podem ser encontrados em livros textos como [21, 22].

Os diagramas de radiação fornecidos pelos fabricantes de antenas são válidos para a região de campo distante. Na região de campo próximo, o ganho máximo será menor, mas, em outras direções, o ganho pode ser maior ou menor, uma vez que, nos locais onde ocorreriam nulos da antena em campo distante, a intensidade de radiação tende a ser maior no campo próximo [4]. Quanto mais a onda se aproxima do campo distante, mais a frente de onda se aproxima de uma geometria plana, além disso, os vetores intensidade de campo elétrico $(E)$ e intensidade de campo magnético $(H)$ e o vetor que indica a direção de propagação vão se tornando perpendiculares entre si. Nessa região, a impedância da onda converge para a impedância intrínseca do meio $\left(Z_{0}=120 \pi \Omega\right)$, a densidade de potência 
torna-se o produto entre os vetores $E$ e $H$, e, por fim, as características direcionais da antena se aproximam do seu diagrama de radiação comercial. A figura 2.3 apresenta o diagrama de radiação de uma antena setorial utilizada na prestação do SMP.

Tabela 2.1: Principais características do CEMRF nas diferentes regiões (adaptado de [20]). $D$ é a maior dimensão da antena e $\lambda$ é o comprimento de onda do sinal transmitido.

\begin{tabular}{|l|c|c|c|}
\hline & $\begin{array}{c}\text { Campo próximo } \\
\text { reativo }\end{array}$ & $\begin{array}{c}\text { Campo próximo } \\
\text { radiante }\end{array}$ & Campo distante \\
\hline Limite inferior & 0 & $\lambda$ & Máx $\left(3 \lambda ; 2 D^{2} / \lambda\right)$ \\
\hline Limite superior & $\lambda$ & $\operatorname{Máx}\left(3 \lambda ; 2 D^{2} / \lambda\right)$ & $\infty$ \\
\hline $\begin{array}{l}\text { Densidade de } \\
\text { Potência } S\left[\mathrm{~W} / \mathrm{m}^{2}\right]\end{array}$ & $S \leq|E \| H|$ & $S \leq|E| H \mid$ & $S=|E||H|$ \\
& $\approx \frac{|E|^{2}}{Z_{0}} \approx Z_{0}|H|^{2}$ & $=\frac{|E|^{2}}{Z_{0}}=Z_{0}|H|^{2}$ \\
\hline $\mathrm{E} \perp \mathrm{H}$ & $\mathrm{Não}$ & Localmente & Sim \\
\hline $\mathrm{Z}=\mathrm{E} / \mathrm{H}$ & $\neq \mathrm{Z}_{0}$ & $\approx \mathrm{Z}_{0}$ & $=\mathrm{Z}_{0}$ \\
\hline
\end{tabular}

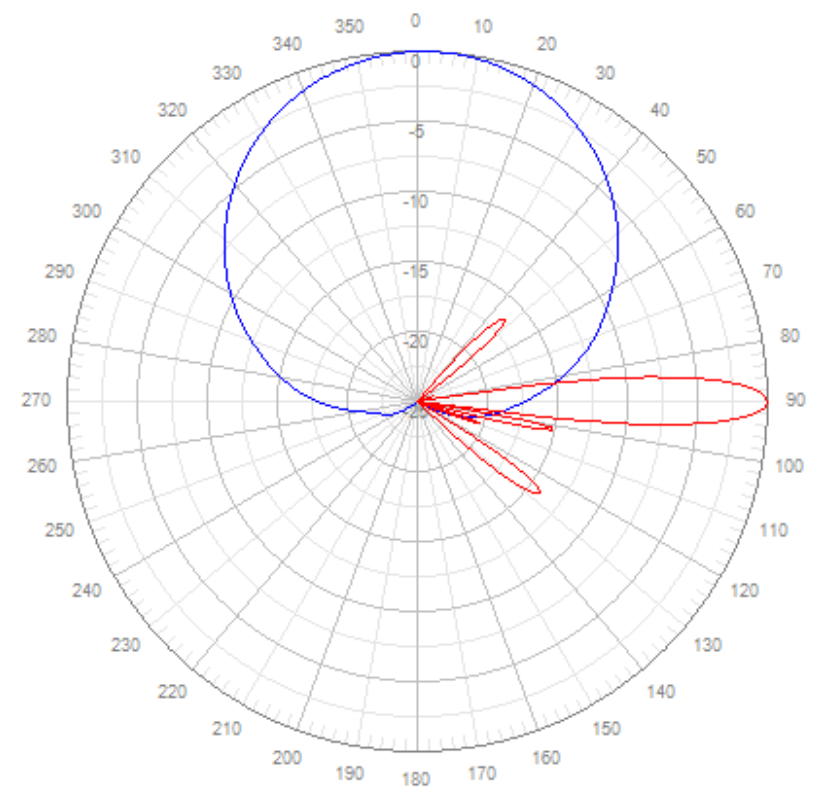

Figura 2.3: Diagrama de radiação polar da antena CommScope HBX-6516DS-VTM em $1.785 \mathrm{MHz}\left(+45^{\circ}\right)$. Plano horizontal em azul e plano vertical em vermelho.

\subsubsection{Redução do Ganho das Antenas Painéis na Região de Campo Próximo}

A figura 2.4 apresenta o modelo utilizado em $[25,26]$ para estimar a densidade de potência na direção de máximo ganho de uma antena painel, como as utilizadas em ERBs. Na 
figura, percebem-se os ajustes necessários para estimar a densidade de potência (S) na região de campo próximo, a partir de $\mathrm{r}_{\mathrm{F}} / 100$, em que $\mathrm{r}_{\mathrm{F}}=2 D^{2} / \lambda$ é a distância do campo distante. Em [25], se considera o decaimento proporcional a $\mathrm{r}^{-2}$ a partir de $\mathrm{r}_{\mathrm{F}} / 4$ e, para distâncias menores, um decaimento proporcional $\mathrm{a} \mathrm{r}^{-1}$. Com essa abordagem se estará sendo conservador, pois a curva real não estará em um nível superior à resposta real da

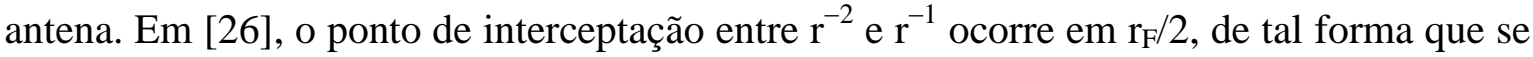
pode estimar um valor médio para a densidade de potência. A densidade de potência máxima a partir de um centésimo de $\mathrm{r}_{\mathrm{F}}$ não ultrapassará 200 vezes a densidade de potência em $r_{F}\left(S_{F}\right)$.

$\mathrm{Na}$ figura 2.4 se inseriu uma curva tracejada para enfatizar que aproximadamente em $0,62 D^{2} / \lambda$ ocorre o descolamento perceptível entre a curva real e o modelo de espaço livre (em [26], a diferença entre as curvas é de $1 \mathrm{~dB}$ nesse ponto). Essa característica é importante principalmente para avaliação da exposição ocupacional, isto é, aquela no qual o trabalhador está exposto devido sua atividade laboral, mas tendo conhecimento sobre as ondas eletromagnéticas e a capacidade para controlar seu tempo de permanência no local de trabalho.

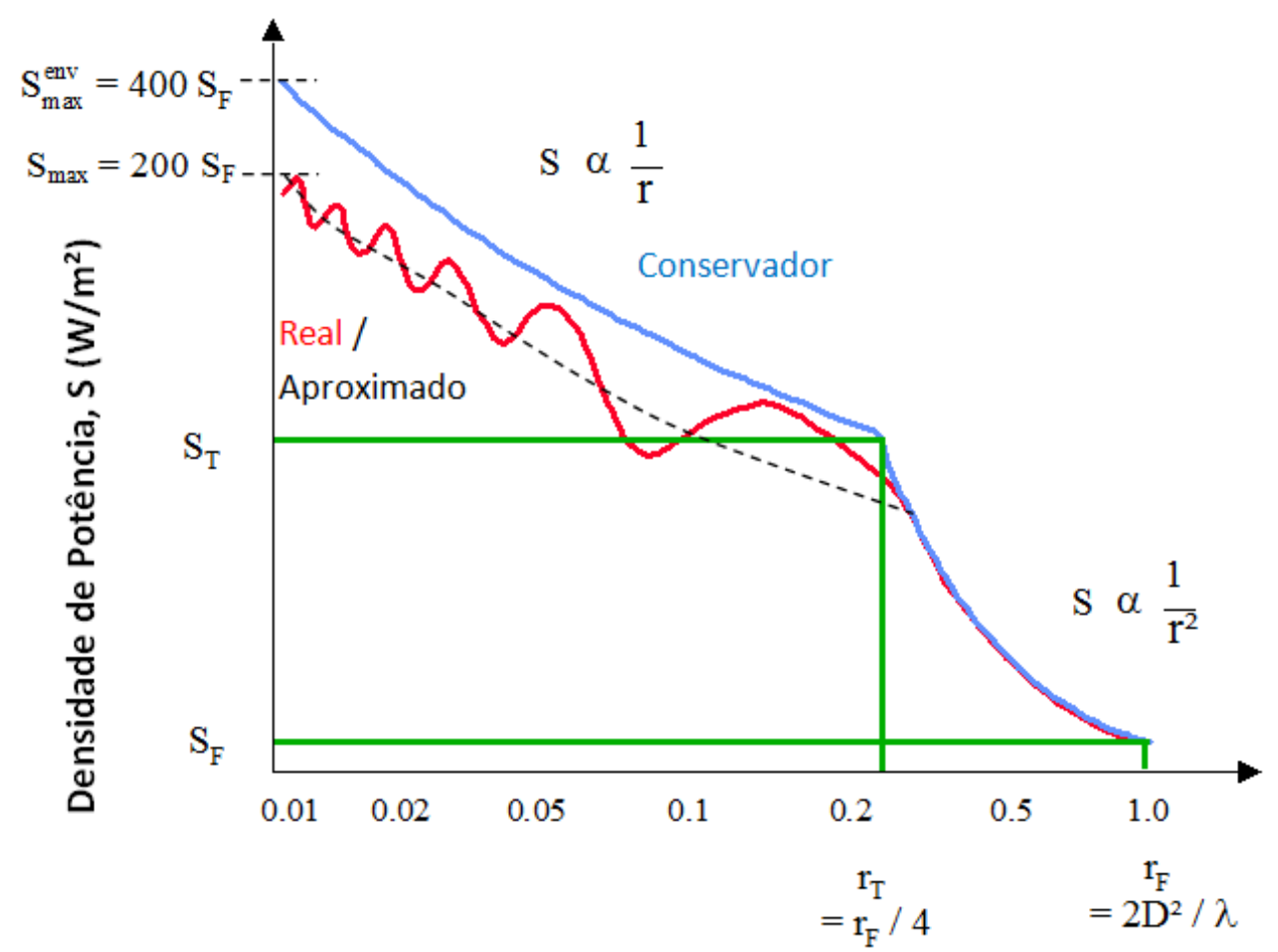

Figura 2.4: Densidade de potência de uma antena painel a partir de $\mathrm{r}_{\mathrm{F}} / 100$. A máxima densidade de potência será de $200 \mathrm{~S}_{\mathrm{F}}$, mas em uma aproximação conservadora será de $400 \mathrm{~S}_{\mathrm{F}}$. Figura adaptada de [25]. 


\subsection{PROPAGAÇÃO DA ONDA ELETROMAGNÉTICA}

A onda eletromagnética que se propaga em ambientes com alguma urbanização está sujeita a variações espaciais e temporais em diferentes escalas, proporcionais à complexidade do ambiente. $\mathrm{O}$ modelo de propagação no espaço livre, apresentado anteriormente, deve ser modificado para que se considere não apenas a perda de percurso isoladamente, mas também o sombreamento e multipercurso. Para a avaliação da exposição humana a CEMRF, inicialmente será introduzido o modelo de dois raios, que considera a perda no espaço livre, com uma reflexão no solo. Outros modelos serão apresentados conforme sejam tratados ambientes mais complexos.

\subsubsection{Ambientes Abertos}

O modelo de dois raios é uma simplificação do método de traçado de raios e pode ser utilizado quando uma única reflexão no solo domina o efeito de multipercurso, de tal forma que a propagação pode ser analisada aplicando óptica geométrica. A pessoa exposta receberá um campo elétrico composto de dois componentes: um em visada direta (LOS), que representa o sinal transmitido em espaço livre; e outro sem visada direta (NLOS), que é o sinal transmitido refletido no solo. A componente NLOS é proporcional à componente em visada por um fator complexo $\Gamma$ (coeficiente de reflexão). $O$ parâmetro $\Gamma$ depende da frequência e polarização da onda, da permissividade e condutividade da superfície refletora, além do ângulo do raio incidente.

Para distâncias menores que a distância crítica, o sinal composto apresenta uma sequência de interferências construtivas e destrutivas, resultando em um padrão de onda com máximos e mínimos locais (desvanecimento em pequena escala). A distância crítica pode ser aproximada pelo quádruplo do produto entre as alturas da antena transmissora e do ponto de recepção, dividido pelo comprimento de onda [27].

O comportamento do decaimento da densidade de potência do sinal propagante no modelo de dois raios pode ser aproximado realizando a média móvel, de tal forma que picos e vales locais serão mitigados, resultando em decaimento de $20 \mathrm{~dB} /$ década para distâncias superiores a altura da antena de transmissão e inferiores à distância crítica [27]. Resumidamente, por meio da média móvel na abordagem de dois raios, se identificará um resultado compatível com a condição de espaço livre. Para uma abordagem conservadora, 
uma vez que a exposição humana a CEMRF não é apenas uma questão de engenharia, mas também de proteção à saúde, é recomendável considerar o coeficiente de reflexão como um valor absoluto, de tal forma que as componentes em visada e sem visada estão em fase.

\subsubsection{Ambientes Urbanos}

Ambientes urbanos ou ambientes internos são mais complexos do que um ambiente aberto, pois apresentam múltiplos objetos que produzem réplicas do sinal original por meio dos diversos mecanismos de propagação, como reflexão, difração ou espalhamento. Nestes casos, o modelo de propagação de espaço livre pode superestimar o nível real de exposição. Adicionalmente, os ambientes complexos aumentam a distribuição nãouniforme ao longo do corpo de uma pessoa, uma vez que essas réplicas chegam ao corpo humano com diferentes amplitudes, fases e tempos de atraso.

A figura 2.5 apresenta um típico cenário urbano. $\mathrm{O}$ ponto $\mathrm{P}_{1}$ é iluminado pelo lóbulo principal do setor de interesse da ERB, no ângulo de máxima intensidade de radiação. Parte da energia é refletida, parte penetra e atravessa o prédio, ocorrendo tanto absorção quanto refração no prédio (como se fosse um obstáculo com multi-camadas). Parte do sinal que atravessa o prédio alcançará as pessoas identificadas por $\mathrm{M}_{1}$ e $\mathrm{M}_{2}$. A componente que sofreu absorção pode ser mais relevante em $\mathrm{M}_{1}$ do que as componentes que foram difratadas em $\mathrm{P}_{2}$ e $\mathrm{P}_{3}$. Porém, a certa distância a componente difratada pode ser dominante, como, por exemplo, em $\mathrm{M}_{2}$. A pessoa $\mathrm{M}_{3}$ está sendo irradiada por um raio direto combinado com outros refletidos $\left(\mathrm{P}_{3}\right.$ e $\left.\mathrm{P}_{4}\right)$ e espalhados $\left(\mathrm{P}_{5}\right)$. Basicamente, o sombreamento ocorre devido ao bloqueio e difração dos sinais, enquanto o multipercurso é devido ao efeito de reflexões e espalhamento.

A perda de percurso é calculada pela relação entre a potência recebida e a potência transmitida de um sinal. A figura 2.6 apresenta as três componentes básicas da perda percurso, que são: perda de percurso isoladamente, desvanecimento em grande escala (sombreamento) e desvanecimento em pequena escala (multipercurso). Quanto mais complexo for o ambiente, com mais obstáculos e obstruções, maior a relevância das componentes de multipercurso e sombreamento. 


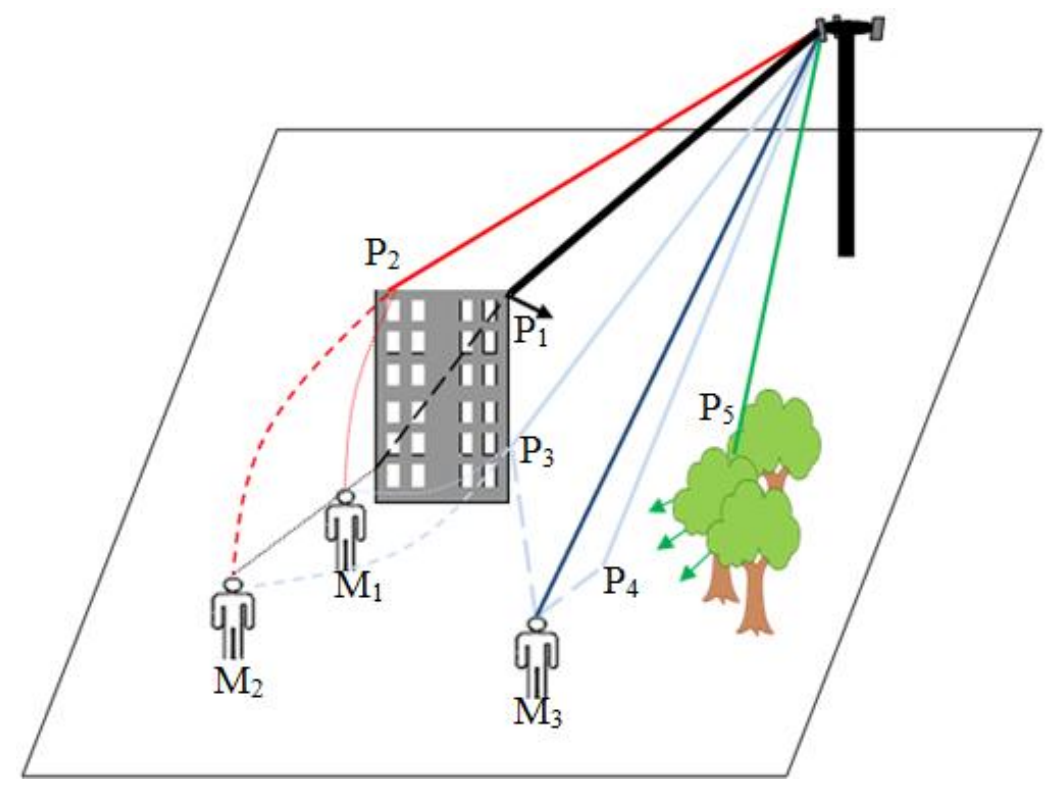

Figura 2.5: Representação dos principais mecanismos de propagação em um ambiente complexo: visada direta, reflexão, difração, refração e espalhamento.

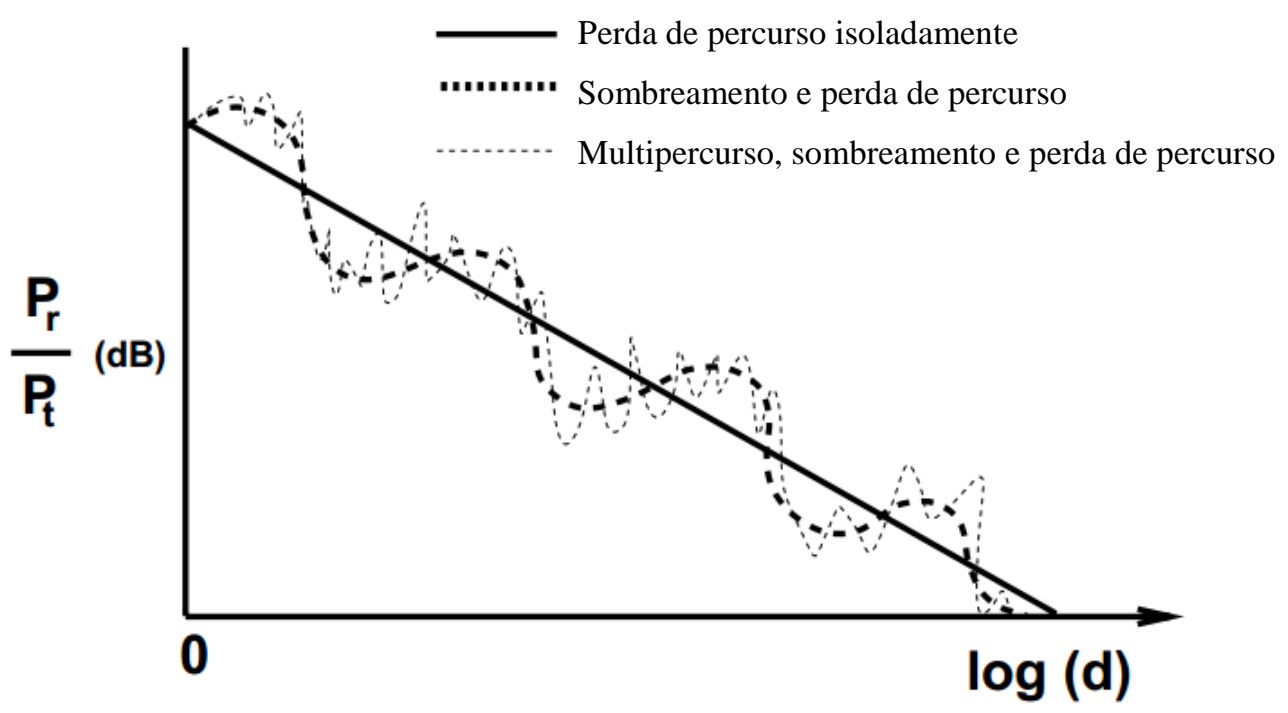

Figura 2.6: Perda de percurso, sombreamento e multipercurso versus distância. Figura adaptada de [27].

\subsubsection{Ambientes Internos}

A propagação de ondas eletromagnéticas em ambientes internos (indoor) apresenta um complexo comportamento de multipercurso influenciando a caracterização do canal de propagação, uma vez que as construções têm diferentes estruturas físicas, leiaute de ambientes (por exemplo, quartos, salas, cozinha), disposição de mobília, além do tráfego humano. No entanto, alguns modelos simples de perda de percurso podem ser utilizados 
para estimar a intensidade do sinal em diferentes partes do ambiente interno. Uma atenuação adicional, conhecida como perda de penetração, ocorre quando o sinal proveniente de uma fonte externa se propaga para dentro de ambientes internos. Assim, ambientes internos representam mais um caso de ambientes complexos, como exemplificado na figura 2.7 .

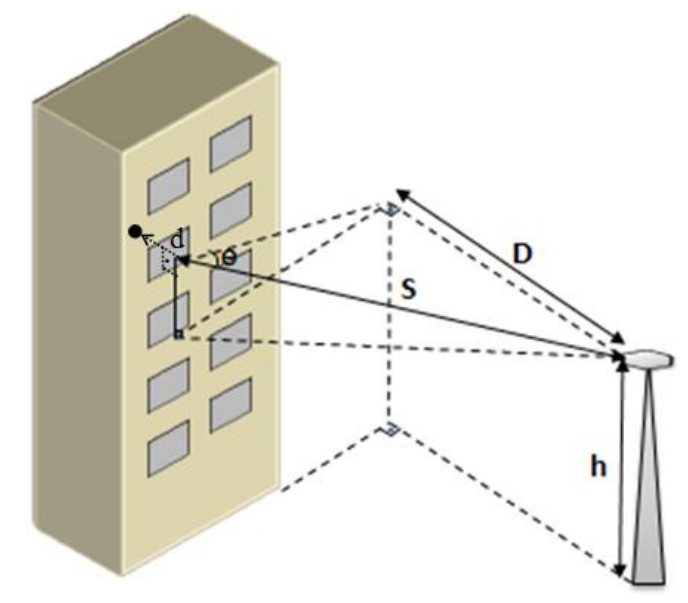

Figura 2.7: Propagação de um sinal externo para dentro de um apartamento, representado pelo ponto •

\subsection{CONCLUSÕES}

Para caracterizar adequadamente o ambiente eletromagnético, deve-se conhecer razoavelmente a fonte de RF, o canal por onde a onda se propaga, além de se definir os pontos relevantes nos quais pessoas podem estar expostas. Usualmente, a avaliação da exposição ocorre na região de campo distante, ou, pelo menos, na região de campo próximo radiante. Adicionalmente, vários mecanismos podem atuar sobre o sinal ao longo de sua propagação, de tal forma a aumentar a complexidade do sinal, o que também aumenta os requisitos técnicos para proceder a avaliação criteriosa da exposição. Assim, neste capítulo, foram apresentados conceitos fundamentais utilizados para caracterizar o ambiente eletromagnético, os quais serão revisitados nos capítulos seguintes. 


\section{DESVANECIMENTO EM PEQUENA ESCALA}

\subsection{INTRODUÇÃO}

Diretrizes e normas de exposição a CEMRF estabelecem limites de exposição localizada e para o corpo inteiro. No entanto, o desvanecimento em pequena escala gera uma distribuição não uniforme do campo eletromagnético ao longo do corpo de uma pessoa. Por isso, para minimizar o efeito da variação estatística do sinal ao longo do corpo, é recomendável a realização da média espacial na avaliação da exposição de corpo inteiro $[20,28]$. Mesmo que a densidade de potência ou a intensidade de campo esteja muito abaixo do limite, é desejável a realização da média espacial, envolvendo pelo menos três pontos, para possibilitar a repetibilidade do processo [20].

O desvanecimento em pequena escala pode causar flutuações dentro da faixa nos sinais de faixa larga, enquanto que, em sinais faixa estreita, toda a amplitude do sinal é afetada no domínio da frequência. Logo, o efeito de desvanecimento de pequena escala é mais grave para sinais de faixa estreita [29].

A referência [29] apresenta os resultados de uma campanha realizada a fim de se obter coeficientes típicos de variação de densidade de potência $(\eta)$, dada por $\sigma / S$, em que $\sigma$ é o desvio padrão e $S$ é o valor médio de exposição a CEMRF em um volume ou superfície representando o corpo humano, ambos relacionados à densidade de potência. Os valores típicos foram levantados para canais com diferentes características de desvanecimento em pequena escala, modelados como distribuições Rayleigh, Rice e Nakagami-m, para calcular o erro na estimativa de densidade de potência média local. Os resultados obtidos são referenciados em normas internacionais $[2,30]$.

\subsection{A DISTRIBUIÇÃO $\kappa-\mu$}

A distribuição $\kappa-\mu$ pode ser utilizada para representar um sinal de RF com desvanecimento em pequena escala em cenários LOS. Diferentemente das distribuições tradicionais que têm apenas um grau de liberdade, a distribuição $\kappa-\mu$ tem dois parâmetros ( $\kappa$ e $\mu$ ), o que permite um melhor ajuste em algumas distribuições reais, principalmente para sinais de 
baixa intensidade, para os quais as distribuições de desvanecimento tradicionais não se ajustam bem [31].

A função densidade de probabilidade para um sinal com desvanecimento $\kappa-\mu$, de envoltória $\mathrm{R}$ e raiz quadrática média $\widehat{\mathrm{r}}=\sqrt{\mathrm{E}\left(\mathrm{R}^{2}\right)}$, é dada por [31]

$$
f_{R}(r)=\frac{2 \mu(1+k)^{\frac{\mu+1}{2}}}{k^{\frac{\mu-1}{2}} \cdot \exp (\mu k)}\left(\frac{r}{\hat{r}}\right)^{\mu} \exp \left[-\mu(1+k)\left(\frac{r}{\hat{r}}\right)^{2}\right] I_{\mu-1}\left(2 \mu \sqrt{k(1+k)} \frac{r}{\hat{r}}\right)
$$

em que $\kappa>0$ é a razão entre a potência total das componentes em visada e a potência total das ondas espalhadas, $\mu>0$ é a representação física do número de clusters de multipercurso e $I_{\mu-1}(\cdot)$ é a função de Bessel modificada de primeiro tipo e ordem $\mu-1$.

Considerando que a média espacial é a raiz quadrada da soma dos quadrados da intensidade de campo elétrico medida em cada ponto, dividida pelo número de pontos, ou seja, é a média dos valores de densidade de potência, deve-se considerar a função densidade de probabilidade da potência, que no caso da distribuição $\kappa-\mu$, fazendo a transformação de variáveis, é dada por [31]

$$
f_{W}(w)=\frac{\mu(1+k)^{\frac{\mu+1}{2}}}{\overline{\mathrm{w}} \cdot k^{\frac{\mu-1}{2}} \cdot \exp (\mu k)}\left(\frac{w}{\overline{\mathrm{w}}}\right)^{\frac{\mu-1}{2}} \exp \left[-\frac{\mu(1+k) w}{\overline{\mathrm{w}}}\right] I_{\mu-1}\left(2 \mu \sqrt{k(1+k) \frac{w}{\overline{\mathrm{w}}}}\right)
$$

em que $\overline{\mathrm{W}}=\mathrm{E}[\mathrm{W}]$.

As equações (3.1) e (3.2) podem ser aplicadas para analisar o desvanecimento em pequena escala, respectivamente, da intensidade de campo elétrico e da densidade de potência. No entanto, uma vez que será avaliada a média espacial, (3.2) deve ser empregada. É importante notar que a intensidade de campo elétrico e a densidade de potência podem seguir diferentes distribuições. Por exemplo, para quaisquer duas variáveis aleatórias X e Y (componentes em fase e em quadratura), com média zero e desvio padrão $\sigma$, a envoltória $\left(\mathrm{R}=\sqrt{\mathrm{X}^{2}+\mathrm{Y}^{2}}\right)$ terá distribuição de Rayleigh, enquanto que a potência $\left(\mathrm{W}=\mathrm{R}^{2}\right)$ terá distribuição exponencial [28]. A média zero de ambas as variáveis gaussianas indicam um cenário NLOS. Se existir a componente em visada (LOS), então X e Y terão médias $\mu_{\mathrm{X}} \mathrm{e}$ $\mu_{\mathrm{Y}} \neq 0$ e desvio padrão $\sigma_{\mathrm{X}}=\sigma_{\mathrm{Y}}=\sigma$, e o sinal será composto por componentes LOS e NLOS. 
A distribuição $\kappa-\mu$ é geral, uma vez que inclui várias outras distribuições clássicas em sua formulação. Outras distribuições podem ser obtidas ajustando os parâmetros $\kappa$ e $\mu$ de (3.1) de acordo com a Tabela 3.1, em que ' $\mathrm{k}$ ' se refere ao parâmetro de desvanecimento de Rice e 'm', ao parâmetro de desvanecimento de Nakagami-m. Tanto a distribuição Rayleigh quanto a de Rice consideram somente um cluster de multipercurso. Apesar de poder ser interpretada como clusters de ondas de multipercurso sem um componente dominante (LOS), a distribuição de Nakagami-m pode ser derivada para as distribuições de Rayleigh, Rice e gaussiana unilateral [31]. Em [31], há uma descrição completa, incluindo estimadores e validação para a distribuição $\kappa-\mu$.

Tabela 3.1: Relação da distribuição $\kappa-\mu$ com outras distribuições.

\begin{tabular}{|c|c|l|}
\hline \multicolumn{1}{|c|}{$\boldsymbol{\kappa}$} & $\boldsymbol{\mu}$ & Obtenção das seguintes distribuições \\
\hline $\mathrm{k}$ & 1 & Rice \\
\hline$\rightarrow 0$ & 1 & Rayleigh \\
\hline$\rightarrow 0$ & $\mathrm{~m}$ & Nakagami-m \\
\hline$\rightarrow 0$ & 0,5 & Gaussiana Unilateral \\
\hline
\end{tabular}

\subsection{DETERMINAÇÃO DA VARIAÇÃO DA MÉDIA ESPACIAL}

O Método de Monte Carlo é uma ferramenta poderosa para representar experimentos físicos. Se por um lado apresenta soluções aproximadas, por outro, permite obter muitas informações do processo físico com muito menos manipulações algébricas. O método de Monte Carlo é utilizado para resolver problemas através da geração de uma enorme sequência de números aleatórios que seguem uma determinada distribuição estatística, que representa um processo estocástico real. Assim, é possível deduzir propriedades estatísticas recuperando informações a partir da sequência de números aleatórios gerados.

O valor médio da amostra $\hat{\mathrm{x}}$ é um estimador não viciado do valor médio real $\overline{\mathrm{x}}$ da variável aleatória $X$ [32]. O espalhamento de $\hat{\mathrm{x}}$ ao redor de $\overline{\mathrm{x}}$ é proporcional ao desvio padrão real $\sigma(\mathrm{x})$ e inversamente proporcional à raiz quadrada do número de amostras $\mathrm{N}$, conforme apresentado a seguir.

$$
\sigma(\hat{x})=\frac{\sigma(x)}{\sqrt{N}}
$$


Há vários métodos para gerar uma variável aleatória $X$ a partir de uma função distribuição de probabilidade acumulada $\mathrm{F}(\mathrm{x})$ [33]. Aqui será utilizado o método da transformação, que consiste em gerar um número pseudoaleatório U uniformemente distribuído no intervalo $[0,1]$, e então calcular $x$ que faz com que $F(x)=U$. Em outras palavras, $X=F^{-1}(U)$, em que $\mathrm{X}$ possui a distribuição desejada [32, 33].

Neste trabalho, foi gerada uma sequência de um milhão de números aleatórios, para cada escolha de parâmetros $\kappa$ e $\mu$. Uma interpretação física equivalente poderia ser de uma ampla campanha com 50.000 locais avaliados (para cada conjunto $\kappa$ e $\mu$ escolhido), com média espacial de 20 pontos em cada local, sendo que nesses locais os parâmetros de desvanecimento possuem as mesmas características. Em cada local, a avaliação é feita em um plano considerando o corpo humano. A média espacial desses 50.000 locais foi avaliada para medições simuladas de 1 ponto a 20 pontos, porém os valores foram tabulados assumindo-se médias espaciais para 1, 3, 6, 9 e 20 pontos.

Em ambientes reais, a distância entre pontos de um processo de média espacial deve ser, idealmente, suficiente para representar medições descorrelacionadas, empiricamente da

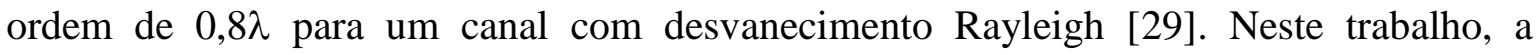
geração de um número pseudoaleatório é independente do número anterior gerado, apresentando, assim, um comportamento similar ao ruído, podendo ser considerado descorrelacionado.

Erro de estimação ocorre ao se assumir a média das densidades de potência ( $\widehat{S})$ como sendo a estimativa da densidade de potência média $(S)$ e $F_{\widehat{S}}$ a função distribuição de probabilidade acumulada $(\mathrm{CDF})$ de $\widehat{\mathrm{S}}$. A probabilidade de se ter um erro na estimação da densidade de potência média menor do que $10 \log (\gamma)$ dB é determinada por [29]:

$$
p(\gamma)=F_{\widehat{S}}(\gamma S)-F_{\widehat{S}}(S / \gamma), \quad \text { para } \gamma \geq 1
$$

e o erro $\varepsilon_{\mathrm{x}} \%$, em $\mathrm{dB}$, para $\mathrm{x} \%$ é dado por:

$$
\varepsilon_{\mathrm{x}} \%=10 \log \left[\mathrm{p}^{-1}(\mathrm{x} \%)\right]
$$

em que $\mathrm{p}^{-1}$ é a função inversa de $\mathrm{p}$. 
Uma equação útil que representa a variância normalizada de potência (ou densidade de potência) é dada por [31]:

$$
\frac{S^{2}}{\sigma^{2}}=\frac{\mu(1+\kappa)^{2}}{1+2 \kappa}=\frac{1}{\eta^{2}}
$$

\subsection{RESULTADOS DAS SIMULAÇÕES}

Em [29], apresenta-se o erro na estimação da média espacial da densidade de potência calculado de forma fechada para canais com desvanecimento de Rayleigh ou Rice (em termos de intensidade de campo elétrico), e por intermédio de simulação para o modelo de Nakagami-m, sem, no entanto, se especificar como as simulações foram realizadas.

Para validar o presente método, as simulações foram executadas com os mesmos parâmetros das distribuições apresentadas em [29], acrescentando-se a média espacial com 20 pontos. Adicionalmente, diferentes cenários foram simulados com a distribuição de desvanecimento $\kappa-\mu$, porém com o mesmo coeficiente de variação $\eta$, considerando, também, parâmetros $\kappa-\mu$ identificados em [31] para ambientes reais. Todas as simulações foram executadas para uma densidade de potência média (S) normalizada, isto é, 1 unidade de densidade de potência. A Tabela 3.2 apresenta os cálculos de incerteza aplicando as equações (3.4), (3.5) e (3.6) para os números aleatórios gerados.

A Tabela 3.3 apresenta os resultados obtidos em [29] para as distribuições tradicionais. Vale ressaltar que os valores da Tabela 3.3 representariam muito bem a incerteza se a função densidade de probabilidade $\mathrm{f}_{\widehat{\mathrm{S}}}(\widehat{\mathrm{S}})$ tivesse características de uma distribuição lognormal em escala linear (ou distribuição normal em escala logarítmica). Por exemplo, a média especial com apenas um ponto em um ambiente com desvanecimento Rayleigh possui $\varepsilon_{95 \%}=12,9 \mathrm{~dB}$, consequentemente $\gamma=19,5$, o que significa que com $95 \%$ de certeza a medição estaria entre $19,5^{-1}$ e 19,5 vezes o valor real da densidade de potência média (ou entre $4,42^{-1}$ e 4,42 vezes o valor real da média espacial da intensidade de campo elétrico).

Como pode ser visto nas tabelas 3.2 e 3.3, os valores são muito próximos, a maioria deles são iguais e somente um valor possui desvio superior a $0,1 \mathrm{~dB}$ (recordando que este valor computado em [29] para esta célula também foi baseado em simulação). 
Tabela 3.2: Incerteza (95\%) para diferentes distribuições utilizando o Método de Monte Carlo.

\begin{tabular}{|l|c|c|c|c|c|}
\hline \multicolumn{1}{|c|}{$\mathbf{N}$} & $\mathbf{1}$ & $\mathbf{3}$ & $\mathbf{6}$ & $\mathbf{9}$ & $\mathbf{2 0}$ \\
\hline$\varepsilon_{95 \%}(\mathrm{~dB})$ Gaussiana Unilateral $(\eta=1,4)$ & 23,8 & 9,3 & 5,7 & 4,4 & 2,8 \\
\hline$\varepsilon_{95 \%}(\mathrm{~dB})$ para Rayleigh $(\eta=1)$ & 12,8 & 5,7 & 3,7 & 3,0 & 2,0 \\
\hline$\varepsilon_{95 \%}(\mathrm{~dB})$ para Rice $1(\eta=0,6)$ & 6,8 & 3,2 & 2,2 & 1,8 & 1,2 \\
\hline$\varepsilon_{95 \%}(\mathrm{~dB})$ para Rice $2(\eta=0,3)$ & 2,7 & 1,5 & 1,1 & 0,9 & 0,6 \\
\hline
\end{tabular}

Tabela 3.3: Incerteza (95\%) para diferentes distribuições de desvanecimento (Tabela I de [29])

\begin{tabular}{|l|c|c|c|c|}
\hline \multicolumn{1}{|c|}{$\mathbf{N}$} & $\mathbf{1}$ & $\mathbf{3}$ & $\mathbf{6}$ & $\mathbf{9}$ \\
\hline$\varepsilon_{95 \%}(\mathrm{~dB})$ para Gaussiana Unilateral $(\eta=1,4)$ & 24,2 & 9,4 & 5,7 & 4,5 \\
\hline$\varepsilon_{95 \%}(\mathrm{~dB})$ para Rayleigh $(\eta=1)$ & 12,9 & 5,7 & 3,8 & 3,0 \\
\hline$\varepsilon_{95 \%}(\mathrm{~dB})$ para Rice $1(\eta=0,6)$ & 6,9 & 3,2 & 2,2 & 1,8 \\
\hline$\varepsilon_{95 \%}(\mathrm{~dB})$ para Rice $2(\eta=0,3)$ & 2,8 & 1,5 & 1,1 & 0,9 \\
\hline
\end{tabular}

A figura 3.1 mostra que $\mathrm{F}_{\widehat{S}}(\gamma S)$ pode ser aproximadamente 1 para valores muito abaixo do que $\gamma \mathrm{S}$, indicando uma superestimação para erros positivos. Por exemplo, a distribuição Rayleigh $(\eta=1)$ na Tabela 3.2 possui $\mathrm{F}_{\widehat{\mathrm{S}}}(\mathrm{w}=3,7)=0,975$ e $\mathrm{F}_{\widehat{\mathrm{S}}}(\mathrm{w}=6,72)=0,999$ para uma avaliação com apenas um ponto (média espacial com apenas um ponto). Isto significa que $\mathrm{F}_{\widehat{\mathrm{S}}}(\mathrm{w}=19,5)$ tende a 1 e $\mathrm{F}_{\widehat{\mathrm{S}}}\left(\mathrm{w}=19,5^{-1}\right)$ tende a 0,05 . Por isso, um parâmetro mais adequado para se avaliar a precisão da estimação seria computar $\mathrm{F}_{\widehat{\mathrm{S}}}\left(\gamma^{\prime} \mathrm{S}\right)=0,975 \mathrm{e}$ $\mathrm{F}_{\widehat{\mathrm{S}}}\left(\mathrm{S} / \gamma^{\prime \prime}\right)=0,025$, que garantirá a mesma incerteza de $95 \%, \mathrm{~F}_{\widehat{\mathrm{S}}}\left(\gamma^{\prime} \mathrm{S}\right)-\mathrm{F}_{\widehat{\mathrm{S}}}\left(\mathrm{S} / \gamma^{\prime \prime}\right)=0,95$, porém melhor representando a distribuição específica.

A Tabela 3.4 apresenta os resultados da Tabela 3.2, mas com $F_{\widehat{S}}\left(\gamma^{\prime} S\right)-F_{\widehat{S}}\left(S / \gamma^{\prime \prime}\right)$, aplicando vários valores para os parâmetros $\kappa \mathrm{e} \mu$, incluindo aqueles com o mesmo coeficiente de variação $\eta$. A figura 3.2 apresenta tais resultados em escala logarítmica. 


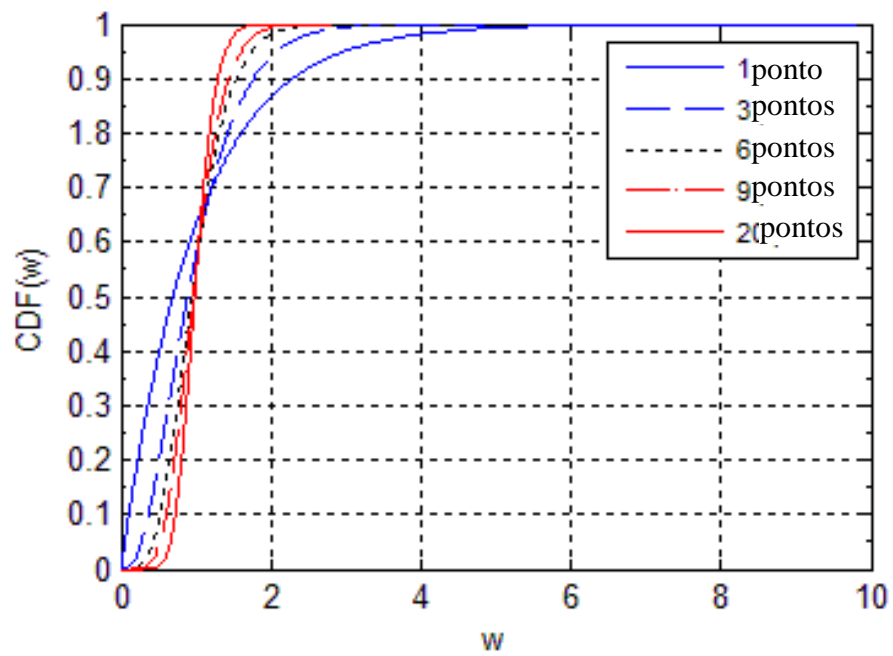

Figura 3.1: CDF para ambiente com canal com distribuição de desvanecimento $\kappa-\mu$, para $\kappa \rightarrow 0$ e $\mu=1$ (distribuição de Rayleigh) e médias espaciais com 1, 3, 6, 9 e 20 pontos.

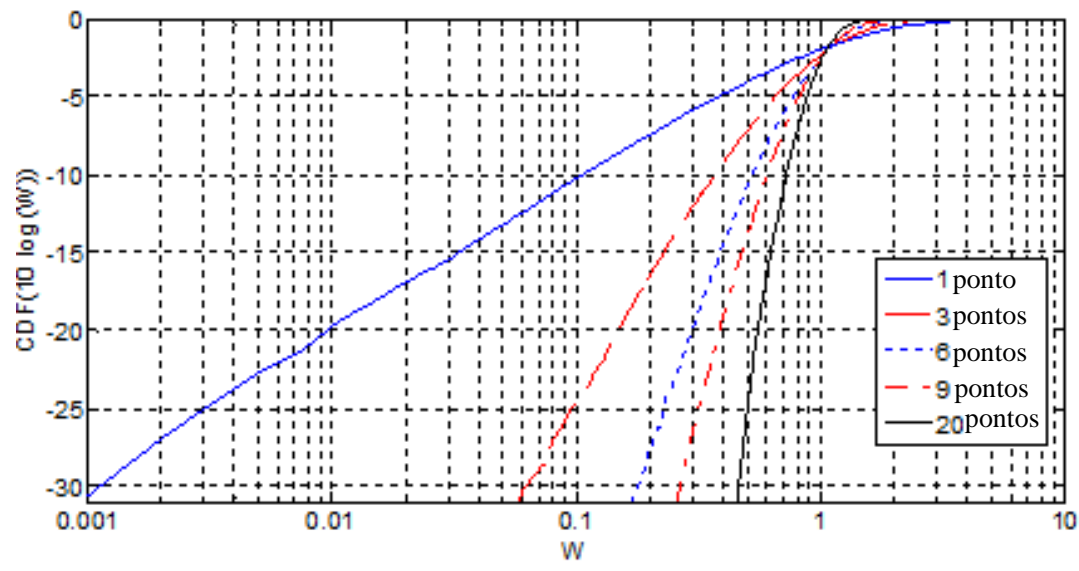

Figura 3.2: CDF da figura 3.1 em escala logarítmica.

Há vários exemplos de medições em campo mostrando a variação da média espacial [3, 6, 28, 29, 34]. Não é possível predizer a melhor distribuição de desvanecimento para um ambiente específico. Todavia, a existência ou não de visada direta e pós-processamento para avaliar $\eta$ pode indicar uma primeira aproximação em termos de distribuições tradicionais (por exemplo, $\eta<1$, Rice; $\eta=1$, Rayleigh; $\eta>1$ Nakagami-m). A metodologia para estimar $\eta$ pode ser encontrada em [29].

Uma avaliação completa sobre qual distribuição melhor se ajusta ao ambiente, incluindo a distribuição de desvanecimento $\kappa-\mu$ ou qualquer outra distribuição, merece uma análise mais profunda e está fora do escopo deste trabalho. Informações adicionais sobre a caracterização do ambiente podem ser encontradas em [31, 35-39]. Em [39] as faixas de valores típicos dos parâmetros $\kappa$ e $\mu$ são obtidos a partir de dados empíricos. 
Tabela 3.4: Variação da média espacial, em dB, para diferentes distribuições de desvanecimento

$$
\left[F_{\hat{S}}\left(\gamma^{\prime} S\right)-F_{S}\left(S / \gamma^{\prime \prime}\right)=0,95\right]
$$

\begin{tabular}{|c|c|c|c|c|c|}
\hline $\mathbf{N}$ & 1 & 3 & 6 & 9 & 20 \\
\hline Gaussiana Unilateral $(\eta=1,4)$ & $\begin{array}{c}-30 \\
+7\end{array}$ & $\begin{array}{c}-11,4 \\
+4,8\end{array}$ & $\begin{array}{l}-6,9 \\
+3,6\end{array}$ & $\begin{array}{l}-5,3 \\
+3,1\end{array}$ & $\begin{array}{l}-3,2 \\
+2,2\end{array}$ \\
\hline Rayleigh $(\eta=1) \leftrightarrow \kappa \rightarrow 0$ e $\mu=1$ & $\begin{array}{c}-15,9 \\
+5,7\end{array}$ & $\begin{array}{l}-6,8 \\
+3,8\end{array}$ & $\begin{array}{l}-4,3 \\
+2,9\end{array}$ & $\begin{array}{l}-3,4 \\
+2,5\end{array}$ & $\begin{array}{l}-2,2 \\
+1,7\end{array}$ \\
\hline Rice $1(\eta=0,6) \leftrightarrow \kappa=4$ e $\mu=1$ & $\begin{array}{l}-8,7 \\
+3,9\end{array}$ & $\begin{array}{l}-3,7 \\
+2,5\end{array}$ & $\begin{array}{l}-2,5 \\
+1,8\end{array}$ & $\begin{array}{l}-1,9 \\
+1,5\end{array}$ & $\begin{array}{l}-1,2 \\
+1,1\end{array}$ \\
\hline Rice $2(\eta=0,3) \leftrightarrow \kappa=20,71$ e $\mu=1$ & $\begin{array}{l}-3,2 \\
+2,2\end{array}$ & $\begin{array}{l}-1,6 \\
+1,3\end{array}$ & $\begin{array}{l}-1,1 \\
+1,0\end{array}$ & $\begin{array}{l}-0,9 \\
+0,8\end{array}$ & $\begin{array}{l}-0,6 \\
+0,6\end{array}$ \\
\hline$\kappa-\mu(\eta=0,6) \leftrightarrow \kappa=20$ e $\mu=0,258$ & $\begin{array}{r}-9,3 \\
+3,8\end{array}$ & $\begin{array}{l}-3,8 \\
+2,4\end{array}$ & $\begin{array}{l}-2,5 \\
+1,8\end{array}$ & $\begin{array}{l}-2,0 \\
+1,5\end{array}$ & $\begin{array}{l}-1,3 \\
+1,1\end{array}$ \\
\hline$\kappa-\mu(\eta=0,6) \leftrightarrow \kappa=2$ e $\mu=1,54$ & $\begin{array}{l}-8,3 \\
+3,9\end{array}$ & $\begin{array}{l}-3,7 \\
+2,5\end{array}$ & $\begin{array}{l}-2,4 \\
+1,8\end{array}$ & $\begin{array}{l}-1,9 \\
+1,5\end{array}$ & $\begin{array}{l}-1,2 \\
+1,1\end{array}$ \\
\hline$\kappa-\mu(\eta=0,485) \leftrightarrow \kappa=168,5$ e $\mu=0,05$ & $\begin{array}{l}-6,3 \\
+3,2\end{array}$ & $\begin{array}{l}-2,9 \\
+2,0\end{array}$ & $\begin{array}{l}-1,9 \\
+1,5\end{array}$ & $\begin{array}{l}-1,5 \\
+1,3\end{array}$ & $\begin{array}{l}-1,0 \\
+0,9\end{array}$ \\
\hline$\kappa-\mu(\eta=0,69) \leftrightarrow \kappa=2$ e $\mu=1,168$ & $\begin{array}{c}-10,6 \\
+4,3\end{array}$ & $\begin{array}{l}-4,4 \\
+2,8\end{array}$ & $\begin{array}{l}-2,9 \\
+2,1\end{array}$ & $\begin{array}{l}-2,3 \\
+1,7\end{array}$ & $\begin{array}{l}-1,4 \\
+1,2\end{array}$ \\
\hline
\end{tabular}

A média espacial real da intensidade de campo elétrico é dada por $\langle E\rangle$, porém, devido ao desvanecimento em pequena escala e um número pequeno de amostras, isto é, pontos de medição representando um corpo, há uma incerteza associada ao processo de média espacial. Assim, ao se realizar a avaliação, se terá $95 \%$ de certeza que a média espacial da intensidade de campo elétrico $E$ varia entre $\left\langle E>/ 10^{\frac{\gamma^{\prime \prime} \mathrm{dB}}{20}}\right.$ e $\left\langle E>\times 10^{\frac{\gamma^{\prime} \mathrm{dB}}{20}}\right.$, representando $\mathrm{F}_{\widehat{\mathrm{S}}}\left(\mathrm{S} / \gamma^{\prime \prime}\right)=0,025$ e $\mathrm{F}_{\widehat{\mathrm{S}}}\left(\gamma^{\prime} \mathrm{S}\right)=0,975$, respectivamente.

A Tabela 3.5 apresenta quatro estudos de casos indicando como o campo eletromagnético pode variar ao longo do corpo humano, levando em conta valores usuais de intensidade de campo elétrico encontrados em avaliações da exposição humana a CEM na faixa de RF. As distribuições de desvanecimento foram escolhidas considerando os parâmetros da Tabela 3.4 que foram derivados a partir de medições reais. Os valores de limites superior e inferior da incerteza em cada célula da tabela estão representados por $\gamma_{\mathrm{dB}}^{\prime}$ e $\gamma_{\mathrm{dB}}^{\prime \prime}$, respectivamente. Para a avaliação de um único ponto, a altura de referência usual no qual a sonda é instalada é de 1,5 m, enquanto que para a média espacial com 3 pontos, a sonda é instalada normalmente nas alturas de $1,10 \mathrm{~m}, 1,50 \mathrm{~m} \mathrm{e} \mathrm{1,70} \mathrm{m.}$ 
Tabela 3.5: Estudos de casos.

\begin{tabular}{|c|c|c|c|c|}
\hline caso & $\langle E\rangle$ & Desvanecimento & Pontos & Valor, V/m \\
\hline \multirow{4}{*}{ I } & \multirow{4}{*}{$0,3 \mathrm{~V} / \mathrm{m}$} & \multirow{4}{*}{ Rayleigh } & $\begin{array}{l}\text { Único Ponto } \\
\text { (Tab. 3.4, Linha 2) }\end{array}$ & $0,048 \ldots 0,578$ \\
\hline & & & $\begin{array}{l}\text { Único Ponto } \\
\text { (Tab. 3.3, Linha 2) }\end{array}$ & $0,069 \ldots 1,31$ \\
\hline & & & $\begin{array}{l}\text { Três Pontos } \\
\text { (Tab. 3.4, Linha 2) }\end{array}$ & $0,137 \ldots 0,465$ \\
\hline & & & $\begin{array}{l}\text { Três Pontos } \\
\text { (Tab. 3.3, Linha 2) }\end{array}$ & $0,156 \ldots 0,578$ \\
\hline \multirow{4}{*}{ II } & \multirow{4}{*}{$2 \mathrm{~V} / \mathrm{m}$} & \multirow{4}{*}{ Rice 2} & $\begin{array}{l}\text { Único Ponto } \\
\text { (Tab. 3.4, Linha 4) }\end{array}$ & $1,384 \ldots 2,576$ \\
\hline & & & $\begin{array}{l}\text { Único Ponto } \\
\text { (Tab. 3.3, Linha 4) }\end{array}$ & $1,466 \ldots 2,729$ \\
\hline & & & $\begin{array}{l}\text { Três Pontos } \\
\text { (Tab. 3.4, Linha 4) }\end{array}$ & $1,664 \ldots 2,323$ \\
\hline & & & $\begin{array}{l}\text { Três Pontos } \\
\text { (Tab. 3.3, Linha 4) }\end{array}$ & $1,683 \ldots 2,377$ \\
\hline \multirow{2}{*}{ III } & \multirow{2}{*}{$1 \mathrm{~V} / \mathrm{m}$} & \multirow{2}{*}{$\begin{array}{c}\kappa-\mu \\
(\eta=0,485)\end{array}$} & $\begin{array}{l}\text { Único Ponto } \\
\text { (Tab. 3.4, Linha 7) }\end{array}$ & $0,484 \ldots 1,445$ \\
\hline & & & $\begin{array}{l}\text { Três Pontos } \\
\text { (Tab. 3.4, Linha 7) }\end{array}$ & $0,716 \ldots 1,259$ \\
\hline \multirow{2}{*}{ IV } & \multirow{2}{*}{$0,6 \mathrm{~V} / \mathrm{m}$} & \multirow{2}{*}{$\begin{array}{c}\kappa-\mu \\
(\eta=0,69)\end{array}$} & $\begin{array}{l}\text { Único Ponto } \\
\text { (Tab. 3.4, Linha 8) }\end{array}$ & $0,177 \ldots 0,984$ \\
\hline & & & $\begin{array}{l}\text { Três Pontos } \\
\text { (Tab. 3.4, Linha 8) }\end{array}$ & $0,362 \ldots 0,828$ \\
\hline
\end{tabular}

\subsection{CONCLUSÕES}

Este capítulo apresentou a variação da média espacial para diferentes modelos de distribuição de desvanecimento simulando uma campanha com 50.000 locais avaliados, com média espacial de 1 a 20 pontos em cada local de medição, para cada conjunto de parâmetros de desvanecimento. O método de Monte Carlo foi a base de simulação e, para cada cenário, foi calculada a incerteza associada à estimação da média espacial da densidade de potência ou da intensidade de campo elétrico.

Foi mostrado que a execução da média espacial na avaliação da exposição humana a CEMRF é essencial para melhorar a precisão da análise. Por isso, para estimar a incerteza 
da média espacial, foi proposta uma tabela de referência (Tabela 3.4), que foi aplicada a ambientes típicos.

Os estudos de caso mostraram que a aplicação da Tabela 3.2 pode superestimar erros positivos, como no estudo de caso I, por isso, a Tabela 3.4 é mais adequada para refletir o comportamento assimétrico das distribuições de desvanecimento em pequena escala para um número pequeno de amostras e $\eta$ relativamente alto.

Nos ambientes simulados, que não foram exaustivos, mantendo o mesmo $\eta$, resultou em uma variação inferior a $0,2 \mathrm{~dB}$ para média espacial com pelo menos 3 pontos. Isto sugere que a estimação adequada do $\eta$, consequentemente a execução da média espacial, junto com distribuições de desvanecimento em pequena escala tradicionais parecem ser suficientes para avaliar a incerteza do desvanecimento em pequena escala na avaliação da exposição humana a CEMRF. 


\section{EXPOSIÇÃO EM AMBIENTES ABERTOS}

\subsection{INTRODUÇÃO}

A estimação do local de máxima exposição a CEM associado a uma estação de radiocomunicação depende, principalmente, das características do sistema radiante e do canal sem-fio.

Neste capítulo, será proposta uma metodologia para a determinação do local de máxima exposição a CEM, associado ao lóbulo principal da antena de uma estação de radiocomunicação em áreas abertas. A expressão analítica proposta considera informações de altura, ângulo de meia-potência e tilt da antena. Resultados de simulações e medições mostram a consistência da metodologia.

\subsection{AMBIENTES ABERTOS}

As antenas em ERBs, usualmente, são instaladas com um tilt para baixo, que pode ser tanto elétrico quanto mecânico ou ambos. Sem o tilt, a maior parte da potência radiada pela antena se espalharia sem alcançar os usuários da comunicação móvel. Comumente, o ponto de máxima exposição a CEM associado a uma ERB é devido ao lóbulo principal da antena, estando localizado entre algumas dezenas de metros e poucas centenas de metros do mastro. No nível do solo, a exposição em uma distância mais curta à ERB está associada aos lóbulos laterais da antena, que transportam menos energia do que o lóbulo principal [4, 40-42].

A figura 4.1 apresenta graficamente o comportamento do sinal radiado por uma ERB típica. Observa-se que há picos locais devido aos lóbulos laterais da antena em distâncias próximas da torre, porém o ponto de máxima exposição tende a ocorrer em local mais distante. A partir desse ponto, a densidade de potência decresce monotonicamente com a distância. 


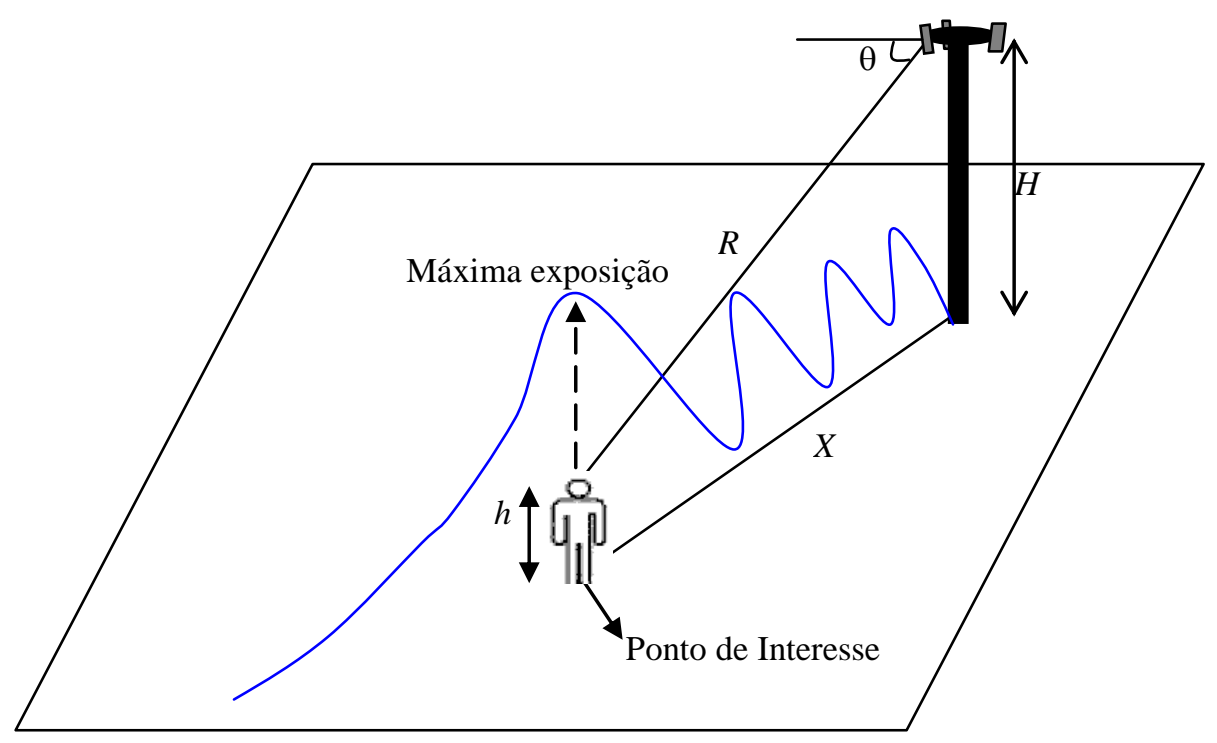

Figura 4.1: Intensidade de campo elétrico ao longo da direção de azimute da antena setorial.

A figura 4.2 apresenta o cenário do modelo de dois raios para um sinal de $1 \mathrm{GHz}$ e distâncias menores do que a distância crítica. A variação da intensidade de campo elétrico (E) ao longo do corpo inteiro apresentará picos e vales locais, porém, para uma pessoa de tamanho médio, a média da intensidade do campo elétrico tende a convergir ao nível da componente em visada. Para $|\Gamma|=0,6$, ocorrerá picos e vales locais com valores $1,6 \times E$ e $0,4 \times E$, respectivamente.

Adicionalmente, deve-se ressaltar que o corpo inteiro está passivo de exposição a CEM, assim, para minimizar o impacto do desvanecimento em pequena escala, a média espacial deve ser realizada $[2,20]$.

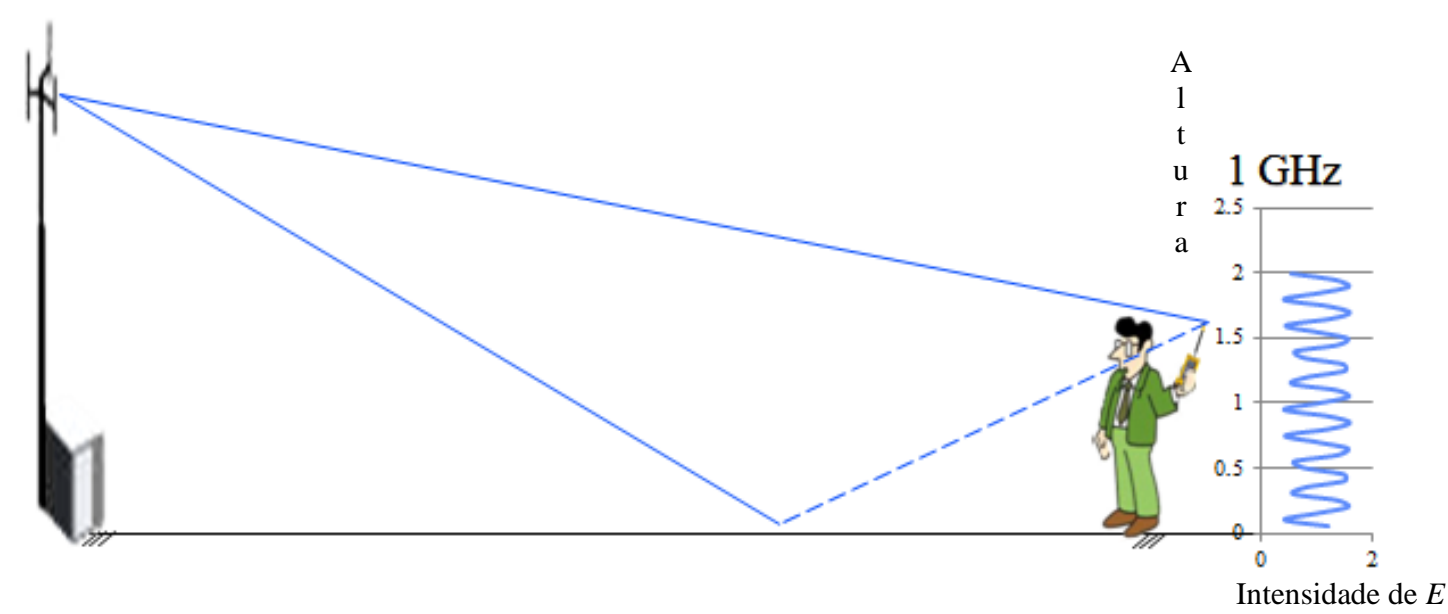

Figura 4.2: Modelo de dois raios para ambiente aberto em $1 \mathrm{GHz}$, mostrando a variação da intensidade de $E$ com a altura. $\mathrm{O}$ eixo vertical representa a altura, em metros, e o eixo horizontal representa a intensidade do campo elétrico com referência a $E$. 


\subsection{INFLUÊNCIA DO LÓBULO PRINCIPAL DA ANTENA}

O ponto de máxima exposição $\left(X_{\max }^{\text {exp }}\right.$ ) é o ponto no qual a pessoa estaria exposta a uma máxima densidade de potência associado com a emissão de uma fonte sob avaliação, considerando apenas o lóbulo principal da antena. Comumente, esse ponto ocorrerá na direção de azimute entre um ponto inferior $\left(X_{\text {inf }}\right)$, "iluminado" pelo primeiro nulo da antena abaixo da linha do horizonte, e um ponto superior $\left(X_{\text {sup }}\right)$, "iluminado" pela máxima radiação da antena. A partir de $X_{i n f}$, o nível de exposição cresce até alcançar um valor máximo. Esses pontos são determinados por

$$
\begin{aligned}
& X_{\text {inf }}=\frac{H-h}{\operatorname{tg}\left(\alpha+\theta_{\mathrm{n} 1}\right)} \\
& X_{\text {sup }}=\frac{H-h}{\operatorname{tg}(\alpha)}
\end{aligned}
$$

Nas equações (4.1) e (4.2), $H$ é a altura da antena; $h$ é a altura de referência em que as medições são realizadas; $\alpha$ é o tilt da antena, ou seja, o ângulo entre a direção de máxima radiação e o horizonte; e $\theta_{\mathrm{n} 1}$ é o ângulo do primeiro nulo abaixo da linha do horizonte.

O domínio da região de máxima exposição, equações (4.1) e (4.2), é a região aonde o lóbulo principal da antena alcança a altura $h$. Essa região é limitada considerando o primeiro nulo da antena, $\theta_{\mathrm{n} 1}$, mais o tilt $(\alpha)$ e o ângulo de máxima radiação, que, neste caso, também é $\alpha$.

Conforme ilustra a figura 4.3, dependendo do tilt da antena, o ponto de máxima exposição pode ocorrer mais próximo da estrutura de suporte da antena devido aos lóbulos laterais. Nessa figura, $\delta \mathrm{X}$ representa a distância entre a projeção ortogonal do elemento radiante sobre o solo e o mastro da ERB e X' é a separação entre o ponto de medição e o mastro da ERB. Usualmente, $\delta \mathrm{X}<<\mathrm{X}^{\prime}$, de tal forma que, nas medições, considera-se $\mathrm{X}^{\prime} \approx \mathrm{X}$.

O primeiro nulo do diagrama de radiação pode ser estimado usando a relação [15]

$$
\theta_{\mathrm{n} 1}=2,257 \times \frac{\theta_{\mathrm{bw}}}{2}
$$

em que $\theta_{\text {bw }}$ é o ângulo de meia-potência no plano vertical. 


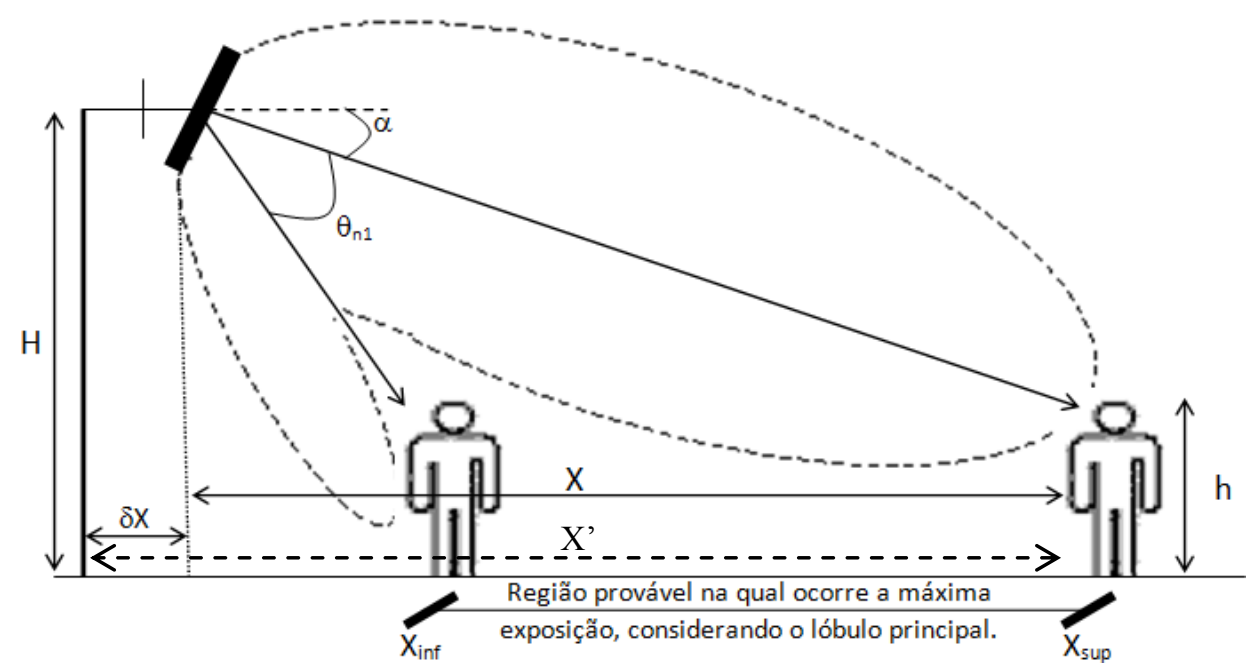

Figura 4.3: Região entre $X_{\text {inf }}$ (algumas dezenas de metros) até $X_{\text {sup }}$ (poucas centenas de metros) onde usualmente ocorre a máxima exposição.

\subsubsection{Estudo de caso}

Como exemplo, considere os dados da Tabela 4.1, que apresenta alguns parâmetros de uma ERB típica, bem com os resultados obtidos utilizando as equações (4.1), (4.2) e (4.3). Desconsiderando o espalhamento do sinal devido ao ambiente físico (solo, prédios, árvores etc.), a máxima exposição ocorrerá entre 82 m e 238 m da ERB.

Tabela 4.1: Exemplo de parâmetros de estação típica.

\begin{tabular}{|l|}
\hline ERB \\
\hline Altura $(H)=35 \mathrm{~m}$ \\
\hline Altura de referência $(h)=1,5 \mathrm{~m}$ \\
\hline Ângulo de meia-potência $=13^{\circ}$ \\
\hline Tilt $(\alpha)=8^{\circ}($ elétrico $)$ \\
\hline EIRP $=58 \mathrm{dBm}$ \\
\hline Resultados \\
\hline$\theta_{\mathrm{n} 1}=2,257 \times \frac{13}{2} \approx 14,67^{\circ}$ \\
\hline$X_{\text {inf }}=\frac{H-h}{t g\left(\alpha+\theta_{\mathrm{n} 1}\right)}=\frac{35-1,5}{t g(8+14,67)} \approx 82 \mathrm{~m}$ \\
\hline$X_{\text {sup }}=\frac{H-h}{t g(\alpha)}=\frac{35-1,5}{t g(8)} \approx 238 \mathrm{~m}$ \\
\hline
\end{tabular}

Para validar o cálculo de $X_{\text {inf }}$ e de $X_{\text {sup }}$, apresentado na Tabela 4.1, foi utilizado o software EMF-Estimator, que é parte da Recomendação ITU-T K.70 [4]. Esse aplicativo 
implementa o modelo ponto-fonte e contém uma biblioteca de diagramas de radiação de antenas para vários serviços de radiocomunicação. Além disso, as reflexões são consideradas de forma construtiva, isto é, em fase com o sinal em visada, portanto, os resultados são conservadores. O modelo ponto-fonte é totalmente aplicável na região de campo distante e apresenta resultados aceitáveis para o campo próximo radiante em distâncias superiores a $0,62 D^{2} / \lambda[4]$, em que $D$ é a maior dimensão da antena e $\lambda$, o comprimento de onda do sinal transmitido. A precisão do software foi demonstrada em [43], que compara os resultados com medições reais, e em [4], que apresenta simulações cujos valores obtidos são comparados com resultados do software comercial FEKO, que implementa o Método dos Momentos.

A figura 4.4 mostra a densidade de potência em função da distância para a ERB com os dados da Tabela 4.1 obtida utilizando-se o software EMF-Estimator. Percebe-se, na figura, que a máxima exposição ocorre aproximadamente em $172 \mathrm{~m}$. No gráfico, é possível identificar facilmente o ponto do primeiro nulo $\left(X_{i n f}\right)$ da antena, assim como visualizar que a máxima exposição não ocorre no ponto associado com a máxima emissão $\left(X_{\text {sup }}\right)$.

As equações (4.1) e (4.2) apresentam uma estimação grosseira da região em que ocorre a máxima exposição, considerando apenas o lóbulo principal do diagrama de radiação. Fazse necessário melhorar a precisão da estimação, a fim de que a ferramenta seja útil na avaliação da exposição humana a CEMRF.

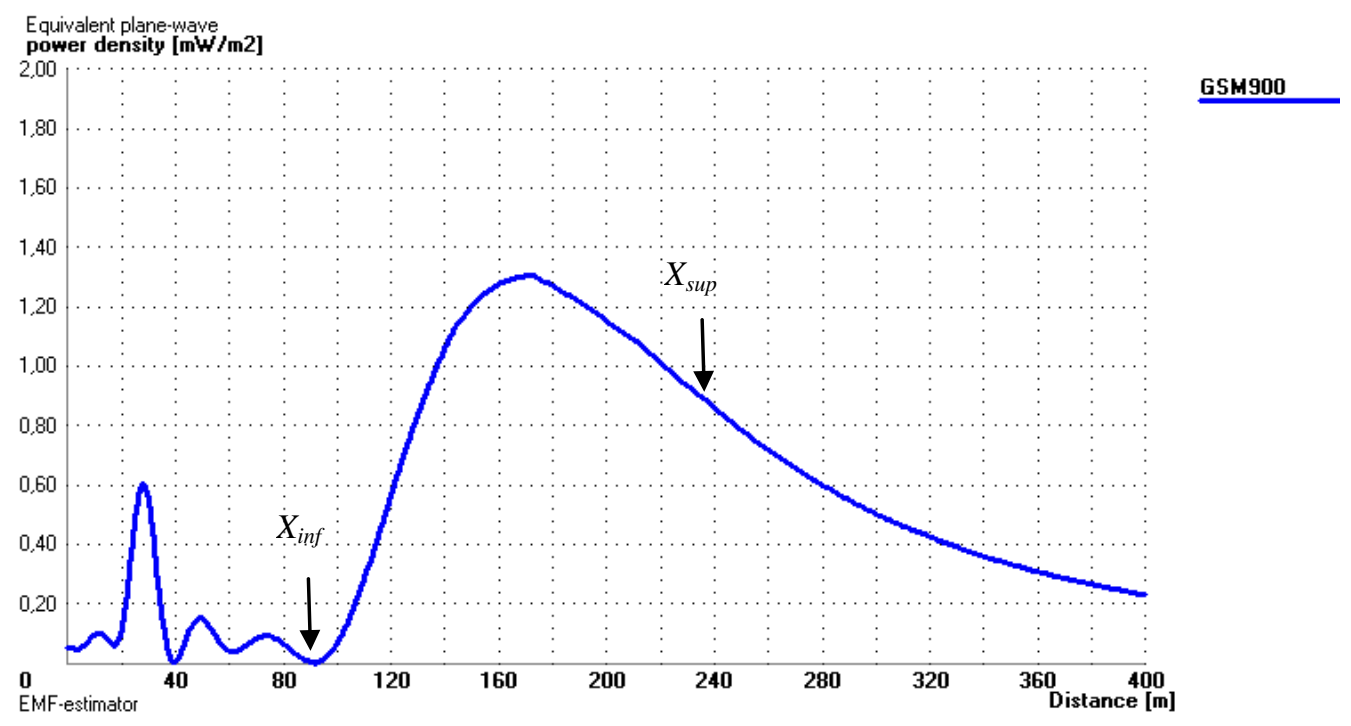

Figura 4.4: Simulação utilizando o software EMF-Estimator. 


\subsection{ESTIMAÇÃO DO LOCAL DE MÁXIMA EXPOSIÇÃO}

Conforme ilustra a figura 4.4, para distância maiores que $X_{\text {inf }}$ existe uma região em que a taxa com que a densidade de potência varia com o acréscimo da distância $x$ é positiva, isto

é, $\frac{d S}{d x}>0$, até alcançar um valor de máximo. No ponto $X_{\text {sup }}, \frac{d S}{d x}<0$. Logo, o objetivo é encontrar o ponto $X$, tal que $\frac{d S}{d x}=0$, sujeito a $X_{i n f}<X<X_{\text {sup }}$. Considerando uma abordagem conservadora do modelo de dois raios, com os sinais direto e refletido alcançando o ponto de referência em fase, a densidade de potência recebida $S(R, \theta, \varnothing)$ é dada por [15]:

$$
\mathrm{S}(\mathrm{R}, \theta, \emptyset)=\frac{P . G_{\max }}{4 . \pi}\left[f(\theta, \emptyset) \frac{1}{R}+|\Gamma| f\left(\theta^{\prime}, \emptyset^{\prime}\right) \frac{1}{R \prime}\right]^{2}
$$

em que $P$ é a potência fornecida à antena; $G_{\max }$ é o máximo ganho da antena; $f(\theta, \varnothing)$ é o padrão de radiação de intensidade campo elétrico da antena; $f\left(\theta^{\prime}, \emptyset^{\prime}\right)$ é o padrão de radiação de intensidade de campo elétrico da antena para o sinal refletido; $|\Gamma|$ é o módulo do coeficiente de reflexão; $R$ é a distância entre a antena e o ponto de referência; e $R$ ' é a distância entre a imagem da antena e o ponto de referência.

Na prática, os pontos de referência são próximos ao nível do solo, então os valores dos parâmetros do sinal refletido (imagem) podem ser aproximados aos valores dos parâmetros de visada, de tal forma que a densidade de potência pode ser calculada conforme [15]:

$$
\mathrm{S}(R, \theta, \varnothing)=\frac{(1+|\Gamma|)^{2} \cdot P \cdot G_{\max } \cdot F(\theta, \varnothing)}{4 \cdot \pi \cdot R^{2}}
$$

em que $F(\theta, \varnothing)$ é o ganho relativo e é numericamente igual a $[f(\theta, \varnothing)]^{2}$.

\subsubsection{Diagrama de radiação da antena}

Considerando que a máxima exposição ocorrerá na direção do azimute da antena, pode-se assumir $F(\theta, \emptyset)=F(\theta)$, na direção de máxima intensidade de radiação. Nesse caso, $F(\theta)$ pode ser aproximada por $\cos ^{q}(\theta)$, ou por $\cos ^{q}(\theta-\alpha)$, de forma geral a incluir o tilt da antena. Esta aproximação é essencial para ter solução analítica para derivada $\frac{d S}{d x}$ e é utilizada como modelo de referência em [21, 44, 45].

A ideia de utilizar este modelo surgiu a partir do diagrama de radiação simétrico produzido pelas cornetas cônicas corrugadas, que seguem essa equação e possibilitam a estimativa de 
seu ganho a partir de parâmetros da própria antena. Outros modelos foram estudados, mas a obtenção de uma equação para estimar analiticamente os pontos de máxima exposição de forma fechada foi obtido somente $\operatorname{com} \cos ^{q}(\theta-\alpha)$. No caso deste trabalho, o ganho máximo $\left(G_{\text {máx }}\right)$ das antenas de interesse pode ser obtido a partir dos dados do datasheet da antena ou do licenciamento da estação. Na prática, os diagramas de radiação das antenas setoriais não são perfeitamente simétricos, o que não é refletido com o modelo $\cos ^{q}(\theta-\alpha)$.

Seguindo a Recomendação ITU-T K.52 [15], a envoltória dos lóbulos laterais pode ser aproximada por uma constante $A_{s l}$, dada pelo nível de lóbulo lateral (SLL - side lobe level), modulado pelo fator de dipolo curto $\left(\cos ^{2} \theta\right)$. Dessa forma,

$$
F(\theta)=\left\{\begin{array}{cc}
\cos ^{q}(\theta-\alpha) & \text { lóbulo principal } \\
A_{s l} \cdot \cos ^{2}(\theta-\alpha) & \text { envoltória dos lóbulos }
\end{array}\right.
$$

Para o lóbulo principal e $\alpha=0$, tem-se

$$
F\left(\frac{\theta_{\mathrm{bw}}}{2}\right)=0,5=\cos ^{q}\left(\frac{\theta_{\mathrm{bw}}}{2}\right)
$$

O parâmetro $q$ em (4.7) é calculado considerando o ângulo de meia-potência, $\theta_{\mathrm{bw}}$, como

$$
q=\frac{\log \left(\frac{1}{2}\right)}{\log \left[\cos \left(\frac{\theta_{\mathrm{bw}}}{2}\right)\right]}
$$

As figuras 4.5 e 4.6 apresentam os diagramas de radiação obtidos por meio do modelo considerado, comparados com os diagramas reais, fornecidos por fabricantes de antenas e operadoras. A antena da figura 4.5 possui ângulo de meia-potência de $10^{\circ}$, o que resulta em $q=181,8062$, e tilt elétrico de $7^{\circ}$. A antena da figura 4.6 tem ângulo de meia-potência de $7^{\circ}$, resultando em $q=371,2738$, e tilt elétrico de $8^{\circ}$.

Considerando os resultados para o lóbulo principal apresentado na figura 4.5, o desvio do modelo proposto em relação à antena real até o ângulo de meia-potência é inferior a $2 \%$, e até o ganho relativo de $-6 \mathrm{~dB}(0,25$ em escala linear) é menor do que $7 \%$. No ponto de -9 $\mathrm{dB}(0,125$ em escala linear) existe um desvio de $24 \%$ ou aproximadamente $1 \mathrm{~dB}$, tal que, enquanto o diagrama real indica ganho de $9 \mathrm{~dB}$ abaixo do ganho máximo, o modelo aproximado apresenta um valor $8 \mathrm{~dB}$ abaixo. 
Em relação à antena modelo TBXLHA-6565C-VTM apresentada na figura 4.6, segundo o datasheet do fabricante, o ângulo de meia-potência é $7^{\circ}(q=371,2738)$. Todavia, o fabricante também disponibiliza informação do ganho de grau em grau. Assim, utilizando interpolação linear para uma aproximação mais fidedigna, o ângulo de meia-potência pode ser calculado como sendo $6,6836^{\circ}(q=407,2803)$. Neste caso, observa-se um desvio de $6 \%$ para o ganho relativo de $-6 \mathrm{~dB}$ e menos de $1 \mathrm{~dB}$ para o ganho relativo de $-9 \mathrm{~dB}$.

Avaliação similar foi feita para uma terceira antena, marca Decibel Products, Modelo DB844H65T6EXY, cujos resultados apresentaram menos de $10 \%$ de desvio para o ganho relativo de $-6 \mathrm{~dB}$ e menos de $1 \mathrm{~dB}$ de desvio para o ganho relativo de $-9 \mathrm{~dB}$.

Para as antenas testadas, o modelo $\cos ^{q}(\theta)$ apresentou um excelente resultado dentro do ângulo de meia-potência, um valor levemente superestimado dentro do ângulo de ganho relativo $-6 \mathrm{~dB}$ e um resultado aceitável dentro do ângulo de ganho relativo de $-9 \mathrm{~dB}$ (desvio inferior a $1 \mathrm{~dB}$ ).

A maior parte da envoltória dos lóbulos laterais está acima do diagrama de radiação real das antenas testadas. Assim, de maneira geral, o modelo proposto superestima a exposição a CEM, exceto em alguns picos dos lóbulos laterais. Para uma abordagem mais conservadora, uma envoltória constante igual ao maior nível de lóbulo lateral pode ser utilizada.

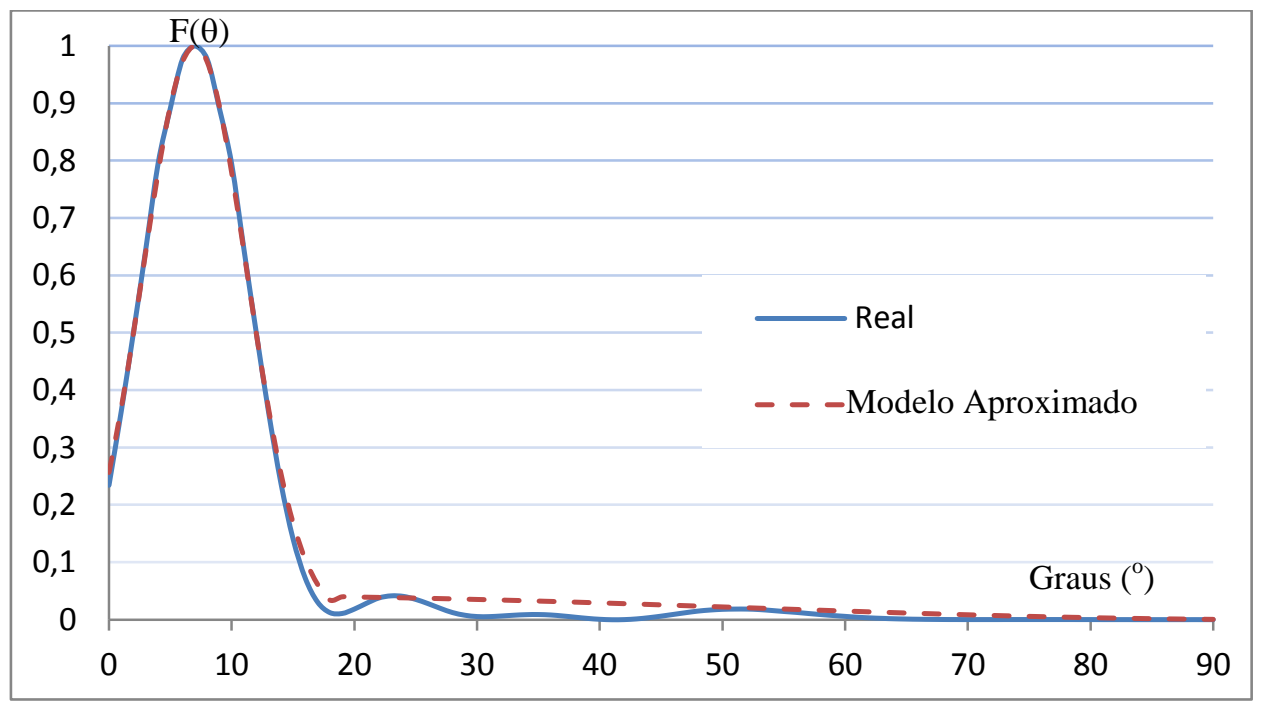

Figura 4.5: Diagrama de radiação da antena Kathrein 742 265, com tilt elétrico de $7^{\circ}$. 


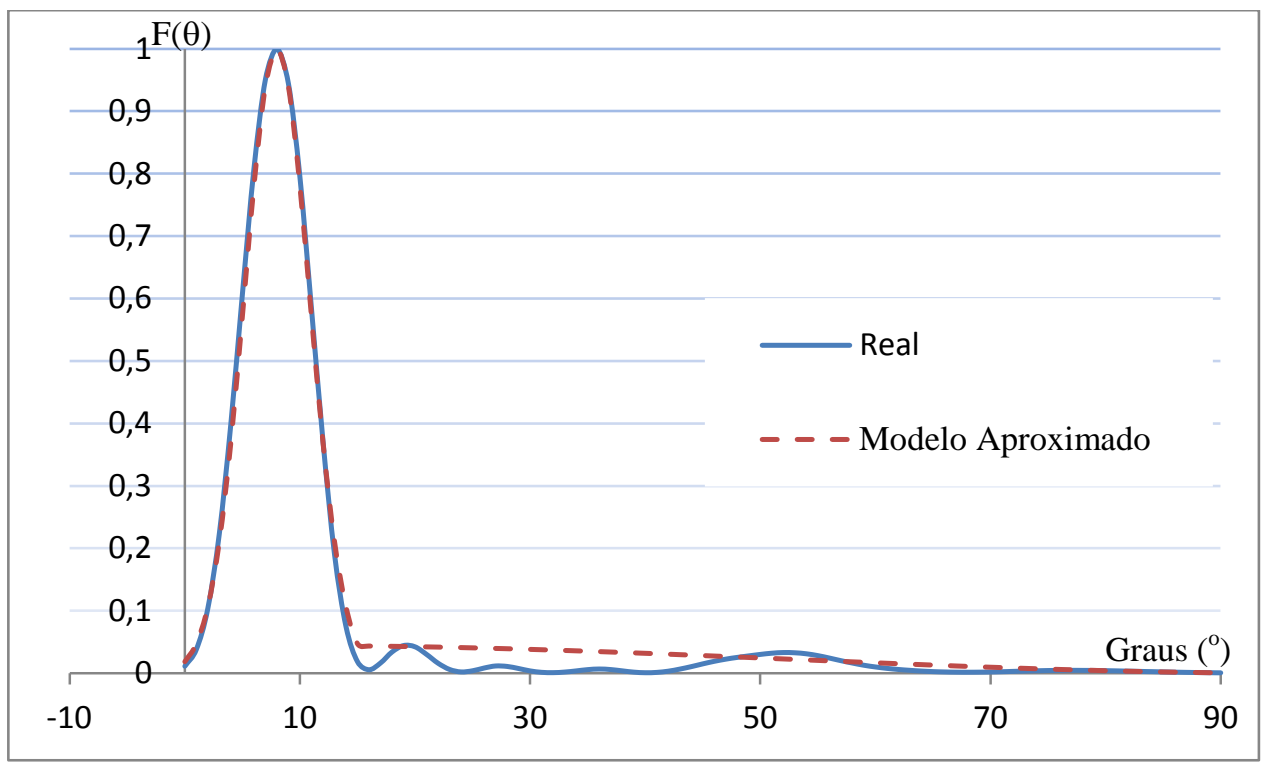

Figure 4.6: Diagrama de radiação da antena Andrews TBXLHA-6565C-VTM, com tilt elétrico de $8^{\circ}$.

\subsubsection{Provável local de máxima exposição}

Retornando à solução do problema proposto, substituindo (4.6) em (4.5) e utilizando o teorema de Pitágoras para determinar $R$ tem-se:

$$
\mathrm{S}(R, \theta, \varnothing)=\frac{(1+|\Gamma|)^{2} \cdot P \cdot G_{\max } \cdot \cos ^{q}(\theta-\alpha)}{4 \cdot \pi \cdot\left[x^{2}+(H-h)^{2}\right]}
$$

Utilizando-se da relação da trigonometria e a partir da figura 4.1, tem-se:

$$
\begin{aligned}
& \cos ^{q}(\theta-\alpha)=(\cos \theta \cdot \cos \alpha+\operatorname{sen} \theta \cdot \operatorname{sen} \alpha)^{q} \\
& \cos \theta=\frac{x}{\sqrt{x^{2}+(H-h)^{2}}} \\
& \operatorname{sen} \theta=\frac{H-h}{\sqrt{x^{2}+(H-h)^{2}}}
\end{aligned}
$$

Substituindo-se (4.10), (4.11) e (4.12) em (4.9), derivando e igualando a zero, obtém-se:

$$
\begin{aligned}
& \frac{d S}{d x}=\left[\frac{(1+|\Gamma|)^{2} \cdot P \cdot G_{\max } \cdot\left(\frac{x}{\sqrt{x^{2}+(H-h)^{2}}} \cdot \cos \alpha+\frac{H-h}{\sqrt{x^{2}+(H-h)^{2}}} \cdot \operatorname{sen} \alpha\right)^{q}}{4 \cdot \pi \cdot\left[x^{2}+(H-h)^{2}\right]}\right]^{\prime}=0 \\
& x=X_{\text {max }}^{\text {exp }}=\frac{\sqrt{\left[(H-h) \cdot \operatorname{tg} \alpha \cdot\left(1+\frac{q}{2}\right)\right]^{2}+2 \cdot q \cdot(H-h)^{2}}-(H-h) \cdot \operatorname{tg} \alpha \cdot\left(1+\frac{q}{2}\right)}{2}
\end{aligned}
$$


A equação (4.14), combinada com a equação (4.8), é muito importante para estimar o local provável de máxima exposição a CEM associado a uma estação de radiocomunicação. Essas equações provam que $X_{\max }^{\text {exp }}$ coincide com $X_{\text {sup }}$ somente se a antena estiver apontada diretamente para o solo. Em outras palavras, o ângulo de máxima radiação não é responsável pelo ponto de máxima exposição, exceto se $\alpha=90^{\circ}$.

Na realidade, o valor estimado $X_{\max }^{\text {exp }}$ indica que existe um local de máxima exposição em uma região que contém esse ponto. Porém, as componentes NLOS podem deslocar o ponto real de máxima exposição para uma posição mais próxima ou mais distante da estação de radiocomunicação. No entanto, é possível encontrar casos reais nos quais os lóbulos laterais causem uma maior exposição em pontos mais próximo da antena do que a exposição associada ao lóbulo principal em distâncias mais longes. O estudo dos lóbulos laterais será aprofundado no Capítulo 7.

\subsection{VALIDAÇÃO DA PROPOSTA}

O software EMF-Estimator foi utilizado para testar a metodologia proposta em cenários abertos, considerando-se as estações de radiocomunicação cujos parâmetros são apresentados nas Tabelas 4.2 e 4.3. Os resultados são mostrados nas figuras 4.7, 4.8 e 4.9, enquanto os locais estimados de máxima exposição estão incluídos nas respectivas tabelas. Nessas simulações, o parâmetro de reflexão $|\Gamma|$ foi configurado em zero.

É importante notar que a simulação com o software EMF-Estimator está limitada somente à distância mínima de $0,62 D^{2} / \lambda$, não possuindo limite superior definido, mesmo em distâncias superiores ao que seria a distância crítica. Assim, no caso da estação FM, o resultado do cálculo estimado foi coerente com a simulação, mas em um ambiente real o expoente da perda de percurso esperado para um caso similar ${ }^{4}$ é superior a 2 para distâncias maiores do que a distância crítica, que neste caso é de 75,5 m $(f=98 \mathrm{MHz})$.

\footnotetext{
${ }^{4} \mathrm{O}$ modelo de referência utilizado para predição de cobertura na radiodifusão é a Rec.ITU-R P.1546, que está na revisão 5. As distâncias de referências neste modelo vão de $1 \mathrm{~km}$ a $1.000 \mathrm{~km}$. Para distâncias inferiores $1 \mathrm{~km}$ se realiza uma interpolação que converge para o modelo de espaço livre a $40 \mathrm{~m}$ de distância da antena. Todavia, é possível convergir para o modelo de espaço livre em distâncias superiores a 0,04 km, dependendo das alturas das antenas e do ambiente de propagação (ex. mar, clutters).
} 
Tabela 4.2: Parâmetros para as ERBs.

\begin{tabular}{|c|c|}
\hline ERB & ERB \\
\hline Altura da antena $(H)=30 \mathrm{~m}$ & Altura da antena $(H)=30 \mathrm{~m}$ \\
\hline Altura de referência $(h)=1,5 \mathrm{~m}$ & Altura de referência $(h)=1,5 \mathrm{~m}$ \\
\hline Ângulo de meia-potência $=13^{\circ}$ & Ângulo de meia-potência $=13^{\circ}$ \\
\hline $\operatorname{Tilt}(\alpha)=0^{\circ}($ electrical $)$ & Tilt $(\alpha)=10^{\circ}($ electrical $)$ \\
\hline Nota: BSant_downtilt_0 ${ }^{\circ}$ & Nota: BSant_downtilt_10 $0^{\circ}$ \\
\hline Resultados & Resultados \\
\hline $\begin{array}{l}\text { Distância até o ponto de máxima exposição* } \\
\text { (simulação) }=208 \mathrm{~m}\end{array}$ & $\begin{array}{l}\text { Distância até o ponto de máxima exposição } \\
\text { (simulação) }=114 \mathrm{~m}\end{array}$ \\
\hline $\begin{array}{l}\text { Distância até o ponto de máxima exposição } \\
\text { (calculado eq. 4.14) }=209 \mathrm{~m}\end{array}$ & $\begin{array}{l}\text { Distância até o ponto de máxima exposição } \\
\text { (calculado eq. } 4.14 \text { ) }=113 \mathrm{~m}\end{array}$ \\
\hline $\begin{array}{l}\text { * Valor devido ao lóbulo principal, porém um } \\
\text { lóbulo lateral é responsável pelo pico de } \\
\text { exposição, em um ponto próximo ao mastro } \\
\text { da ERB. }\end{array}$ & \\
\hline
\end{tabular}

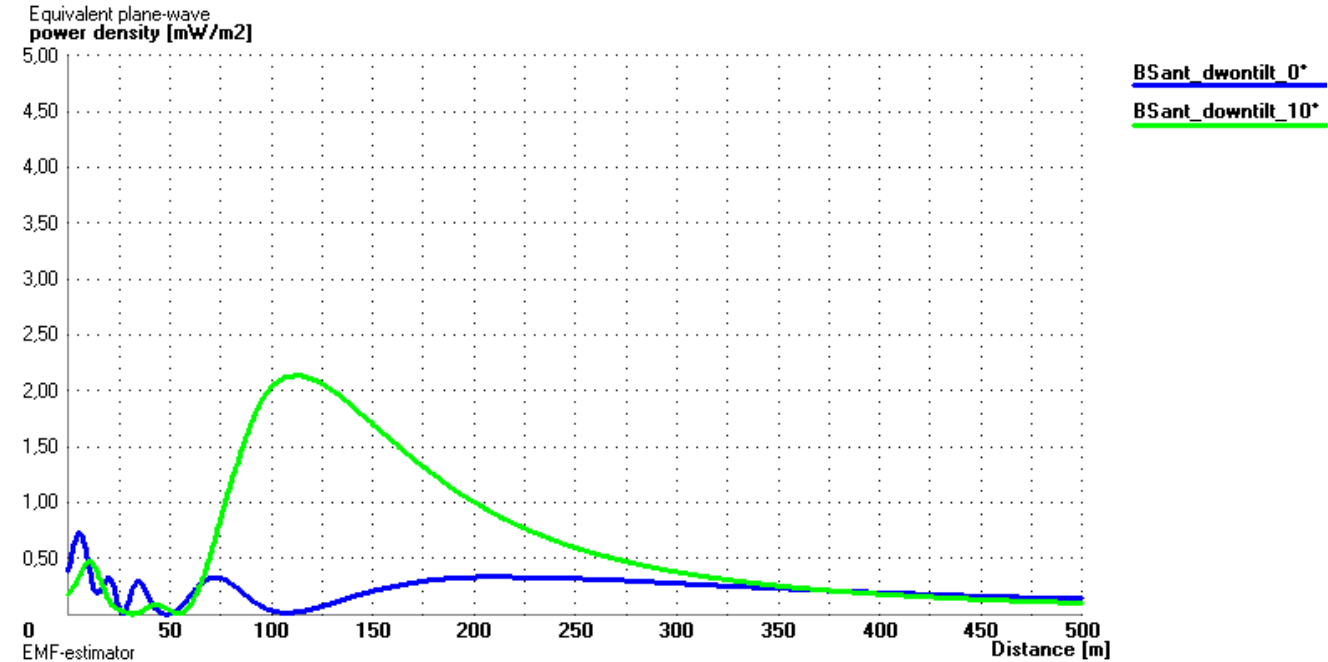

Figura 4.7: Comparação de uma mesma antena com diferentes tilts elétrico para os dados da Tabela 4.2. Com um cenário com tilt de $0^{\circ}$, um dos lóbulos laterais foi o responsável pela máxima exposição. 
Tabela 4.3: Parâmetros de uma estação FM de baixa potência e de uma ERB.

\begin{tabular}{|l|l|}
\hline \multicolumn{1}{|c|}{ Estação FM } & \multicolumn{1}{c|}{ ERB } \\
\hline Altura da antena $(H)=37 \mathrm{~m}$ & Altura da antena $(H)=25 \mathrm{~m}$ \\
\hline Altura de referência $(h)=1,5 \mathrm{~m}$ & Altura de referência $(h)=1,5 \mathrm{~m}$ \\
\hline Ângulo de meia-potência $=16,46^{\circ}$ & Ângulo de meia-potência $=7,5^{\circ}(\mathrm{G}=18 \mathrm{dBi})$ \\
\hline Tilt $(\alpha)=2,05^{\circ}$ (elétrico) & Tilt $(\alpha)=1^{\circ}$ (mecânico) \\
\hline \multicolumn{1}{|c|}{ Resultados } & Resultados \\
\hline $\begin{array}{l}\text { Distância até o ponto de máxima } \\
\text { exposição* (simulação) }=189 \mathrm{~m}\end{array}$ & $\begin{array}{l}\text { Distância até o ponto de máxima exposição } \\
\text { (simulação) }=277 \text { m }\end{array}$ \\
\hline $\begin{array}{l}\text { Distância até o ponto de máxima exposição } \\
\text { (calculado eq. 4.14) }=185 \mathrm{~m}\end{array}$ & $\begin{array}{l}\text { Distância até o ponto de máxima exposição } \\
\text { (calculado eq. 4.14) }=267 \mathrm{~m}\end{array}$ \\
\hline $\begin{array}{l}\text { * Devido ao lóbulo principal, porém o valor } \\
\text { de pico ocorre em } 59 \text { m devido a um lóbulo } \\
\text { lateral. }\end{array}$ & \\
\hline
\end{tabular}

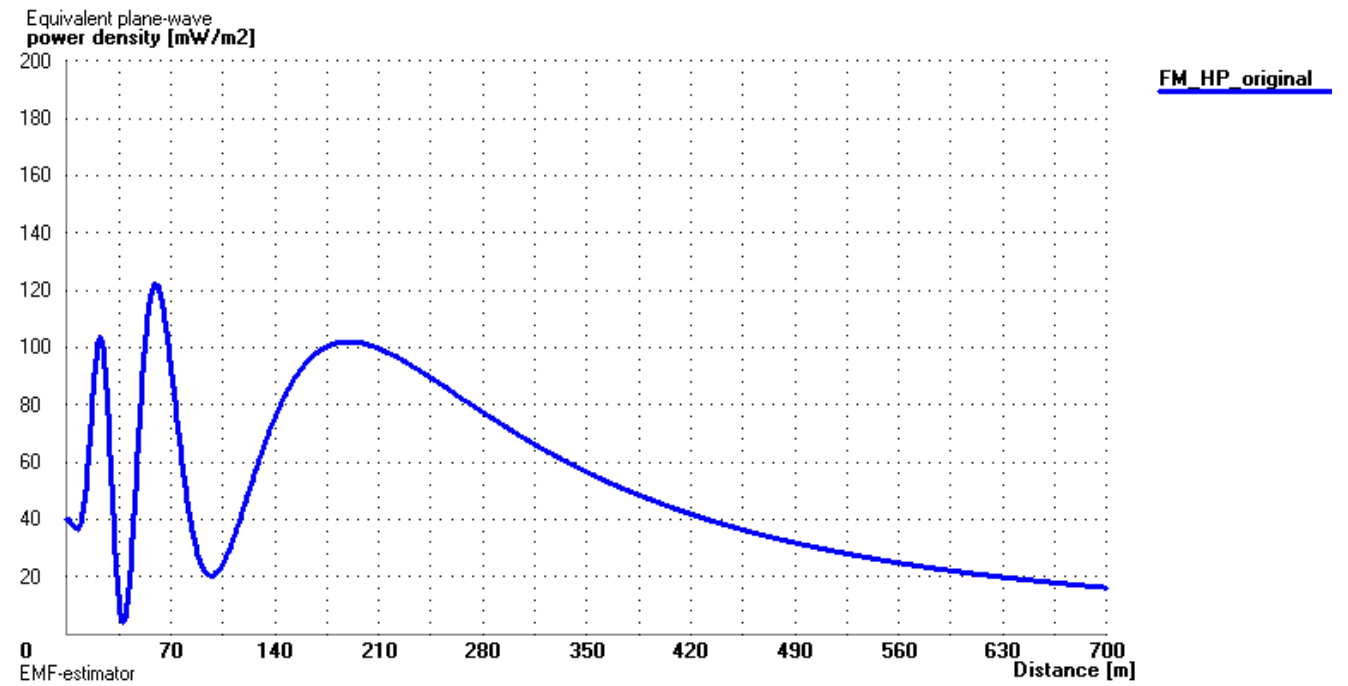

Figura 4.8: Resultado para a estação FM da Tabela 4.3. Neste caso, o lóbulo lateral é responsável pela máxima exposição. 


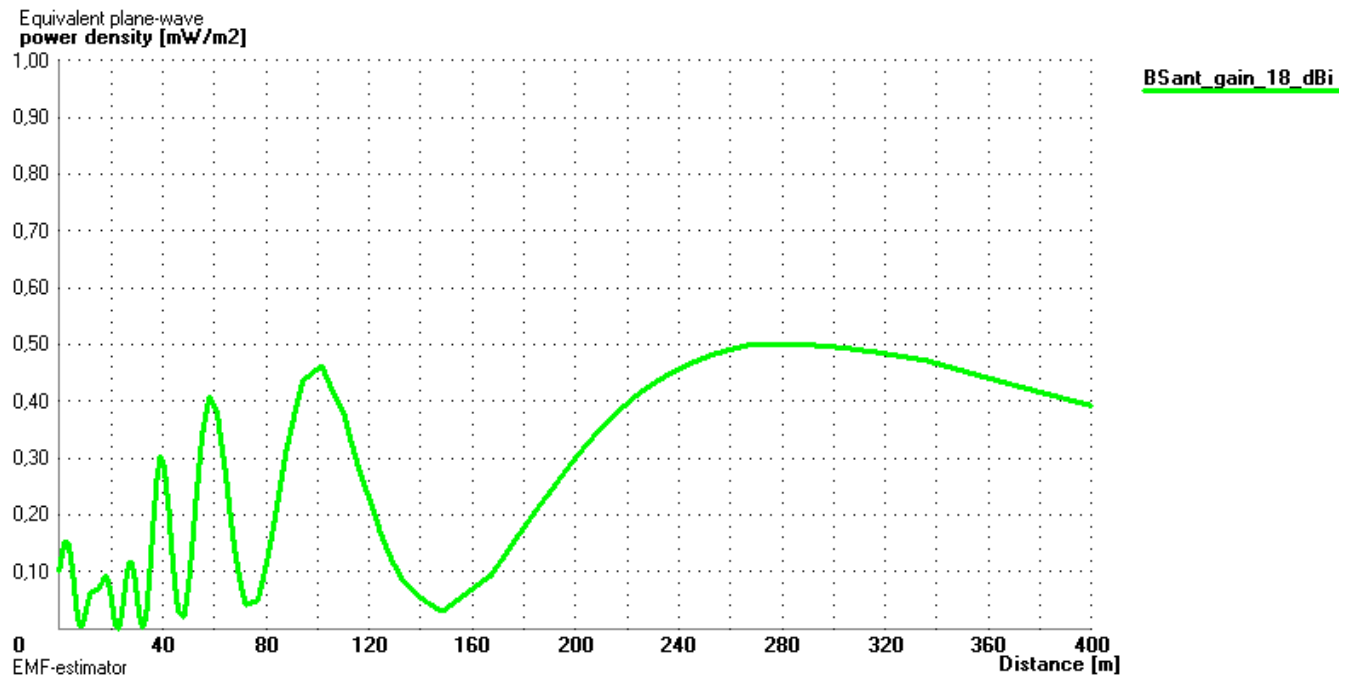

Figura 4.9: Resultado para a ERB da Tabela 4.3, que apresenta uma antena muito diretiva no plano vertical.

\subsection{TESTE EM CAMPO DA METODOLOGIA}

Adicionalmente às simulações, foi realizada a avaliação da exposição a CEM em um sítio real para testar a metodologia em campo, como mostrado na figura 4.10. O sítio avaliado está localizado no estacionamento do Estádio Mané Garrincha, em Brasília-DF. Este local foi escolhido por apresentar um amplo espaço aberto para realizar as medições. A torre do sítio era compartilhada por três operadoras. Duas das três ERBs possuíam o mesmo apontamento de antenas no setor de interesse, o que possibilitava a maior radial para medições. Nessa radial foi possível realizar medições em 15 pontos, de $10 \mathrm{~m}$ a $145 \mathrm{~m}$, neste azimute. A Tabela 4.4 apresenta informações relevantes sobre o sítio avaliado.

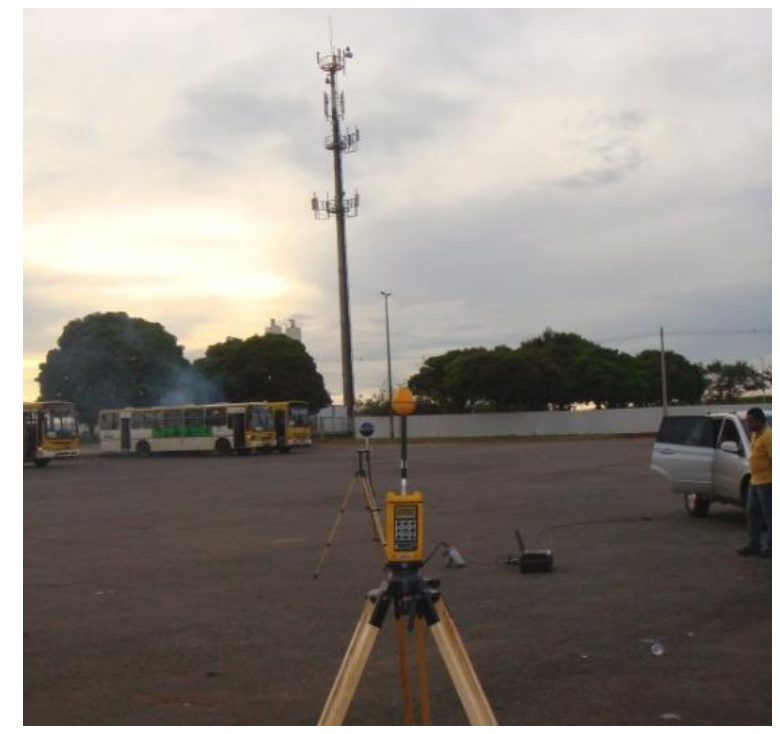

Figura 4.10: Sítio localizado no estacionamento do Estádio Mané Garrincha, compartilhado por três operadoras. 
Tabela 4.4: Parâmetros das estações reais.

\begin{tabular}{|c|c|}
\hline Operadora 1 (ERB) & Operadora 2 (ERB) \\
\hline Altura da antena $(H)=37,4 \mathrm{~m}$ & Altura da antena $(H)=25 \mathrm{~m}$ \\
\hline $\begin{array}{l}\text { Modelo de antena: Andrew - TBXLHA-6565C- } \\
\text { VTM }\end{array}$ & $\begin{array}{l}\text { Modelo de antena: Decibel Products - } \\
\text { DB844H65T6EXY }\end{array}$ \\
\hline Diagrama teórico ajustado para $1.920 \mathrm{MHz}$ & Diagrama teórico na ajustado para $880 \mathrm{MHz}$ \\
\hline Ganho $=17,14 \mathrm{dBi}$ & Ganho $=15,15 \mathrm{dBi}$ \\
\hline Tilt mecânico $(\alpha)=0^{\circ}$ & Tilt mecânico $(\alpha)=7^{\circ}$ \\
\hline Tilt elétrico $(\alpha)=8^{\circ}$ & Tilt elétrico $(\alpha)=6^{\circ}$ \\
\hline Ângulo de $3 \mathrm{~dB}$ no plano vertical $=7^{\circ}$ & Ângulo de $3 \mathrm{~dB}$ no plano vertical $=15^{\circ} \pm 1^{\circ}$ \\
\hline Polarização da antena: Cruzada $\left(+45^{\circ}\right)$ & Polarização da antena: Vertical \\
\hline Canal de controle $(\mathrm{BCCH})$ em $1.875,8 \mathrm{MHz}$ & Canal de controle (iDEN) em 857,2625 MHz \\
\hline Altura da sonda de medição $(h)=1,7 \mathrm{~m}$ & Altura da sonda de medição $(h)=1,7 \mathrm{~m}$ \\
\hline \multicolumn{2}{|c|}{ Nota: Coordenada Lat. $15^{\circ} 46^{\prime} 56.9^{\prime \prime}$ Long. $47^{\circ} 53^{\prime} 44.4^{\prime \prime}$ / Azimute da medição: $120^{\circ}$} \\
\hline Resultados & Resultados \\
\hline $\begin{array}{l}\text { Distância até o ponto de máxima exposição } \\
\text { (simulação) }=203 \mathrm{~m}\end{array}$ & $\begin{array}{l}\text { Distância até o ponto de máxima exposição } \\
\text { (simulação) }=72 \mathrm{~m}\end{array}$ \\
\hline $\begin{array}{l}\text { Distância até o ponto de máxima exposição } \\
\text { (calculado eq. } 4.14)=207 \mathrm{~m}\end{array}$ & $\begin{array}{l}\text { Distância até o ponto de máxima exposição } \\
\text { (calculado eq. } 4.14)=74 \mathrm{~m}\end{array}$ \\
\hline $\begin{array}{l}\text { Comentário: Ponto avaliado com maior valor a } \\
30 \text { m. Todavia, associado a um lóbulo lateral, } \\
\text { porém a tendência indica que o ponto de } \\
\text { máxima exposição está além de } 150 \mathrm{~m} \text {, como } \\
\text { esperado. }\end{array}$ & $\begin{array}{l}\text { Comentário: Ponto avaliado com maior valor a } \\
100 \text { m associado ao lóbulo principal, } \\
\text { provavelmente influencido por reflexões } \\
\text { construtivas. Porém, o segundo maior valor } \\
\text { medido estava a } 70 \mathrm{~m} \text {, como esperado. }\end{array}$ \\
\hline
\end{tabular}

A seguir, é apresentada a configuração básica dos equipamentos utilizados nos testes.

- R\&S TS-EMF (Analisador de Espectro FSH, sonda isotrópica de três eixos e laptop);

- Resolução de Faixa (RBW) de $200 \mathrm{kHz}$ para canais GSM e de $30 \mathrm{kHz}$ para canais iDEN;

- Detector RMS;

- Tripé com a sonda instalada a $1,70 \mathrm{~m}$;

- Fita métrica de $50 \mathrm{~m}$;

- GPS;

- Uma medição por ponto, aplicando média temporal; 
- O corpo do avaliador não estava na linha de visada entre sonda e antena, que ficava a pelo menos $2 \mathrm{~m}$ de distância para mitigar a influência das reflexões no corpo.

As principais características do equipamento R\&S TS-EMF são:

- Faixa de frequência de operação: $30 \mathrm{MHz}-3 \mathrm{GHz}$;

- Faixa dinâmica de medição: $1 \mathrm{mV} / \mathrm{m}$ - $100 \mathrm{~V} / \mathrm{m}$;

- Incerteza de medição (intervalo de confiança de 95\%):

$$
\begin{aligned}
& \circ \quad \pm 2,5 \mathrm{~dB} @ 0,9 \mathrm{GHz} \\
& \circ \quad \pm 2,97 \mathrm{~dB} @ 1,8 \mathrm{GHz} \\
& \circ \quad \pm 3,29 \mathrm{~dB}>2,4 \mathrm{GHz} .
\end{aligned}
$$

$\mathrm{O}$ equipamento utilizado mede a intensidade de campo elétrico nos três eixos ortogonais. $\mathrm{O}$ analisador de espectro comuta sequencialmente qual eixo da sonda irá medir, para posteriormente calcular o campo elétrico equivalente.

As figuras 4.11 e 4.12 apresentam os resultados de avaliação das ERBs do Operador 1 (sistema GSM) e do Operador 2 (sistema iDEN), respectivamente. Os valores medidos seguem os valores estimados, principalmente para o Operador 2, que instalou uma antena com menos lóbulos laterais.

A figura 4.11 apresenta as medições e valores teóricos para o sistema GSM, no qual é possível ver o comportamento oscilatório dos lóbulos laterais e a tendência de crescimento devido ao lóbulo principal. Porém, não foi possível realizar medições adicionais devido a questões de segurança, uma vez que depois de $145 \mathrm{~m}$ acabava o estacionamento, começava a calçada e depois, a rua. Desta forma, estima-se que o ponto de máxima exposição neste caso ocorra na rua, local no qual as pessoas não ficam estáticas. Utilizando (4.14) o ponto de máxima exposição deve ocorrer por volta de $207 \mathrm{~m}$.

A figura 4.12 apresenta as medições e valores teóricos para o sistema trunking de tecnologia iDEN. As medições estão bem próximas dos valores simulados. A medição a $100 \mathrm{~m}$ de distância da base da torre apresentou o maior valor de intensidade de campo elétrico, estando associado ao lóbulo principal, porém este é um ponto fora da curva, que ocorreu provavelmente devido à interferência construtiva entre o sinal direto e o sinal refletido no solo. $\mathrm{O}$ segundo maior valor medido ocorreu a $70 \mathrm{~m}$, muito próximo ao local de máxima exposição estimada, que foi $74 \mathrm{~m}$. 
Ambas as simulações apresentadas nas figuras 4.11 e 4.12 foram executadas considerando as informações técnicas disponíveis nas licenças para funcionamento da estação emitidas pela Agência Nacional de Telecomunicações, complementadas por técnicos das operadoras responsáveis pelas ERBs.

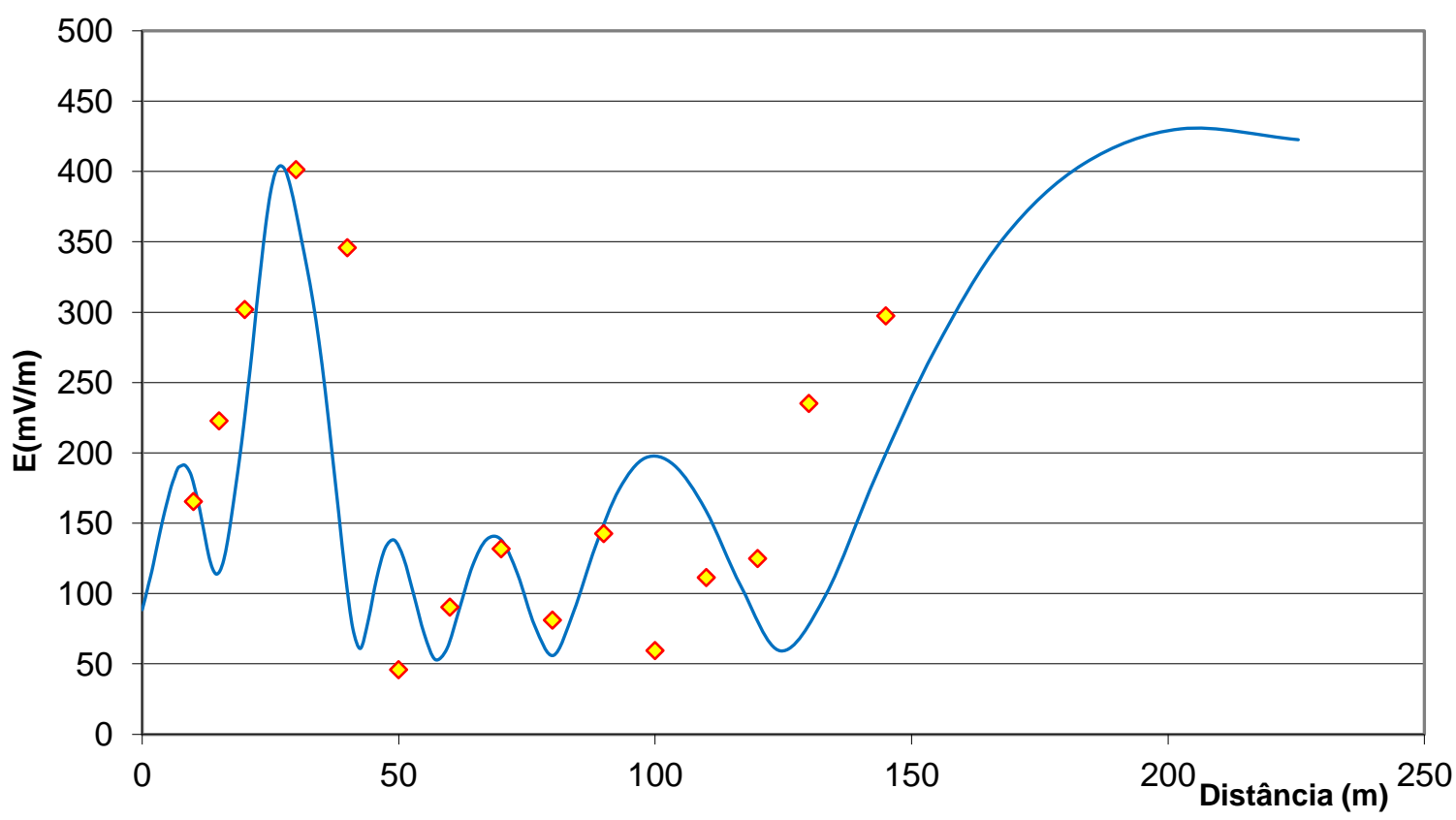

Figura 4.11: Resultados para o sistema GSM. $\diamond$ valores medidos, $\_$valor estimado.

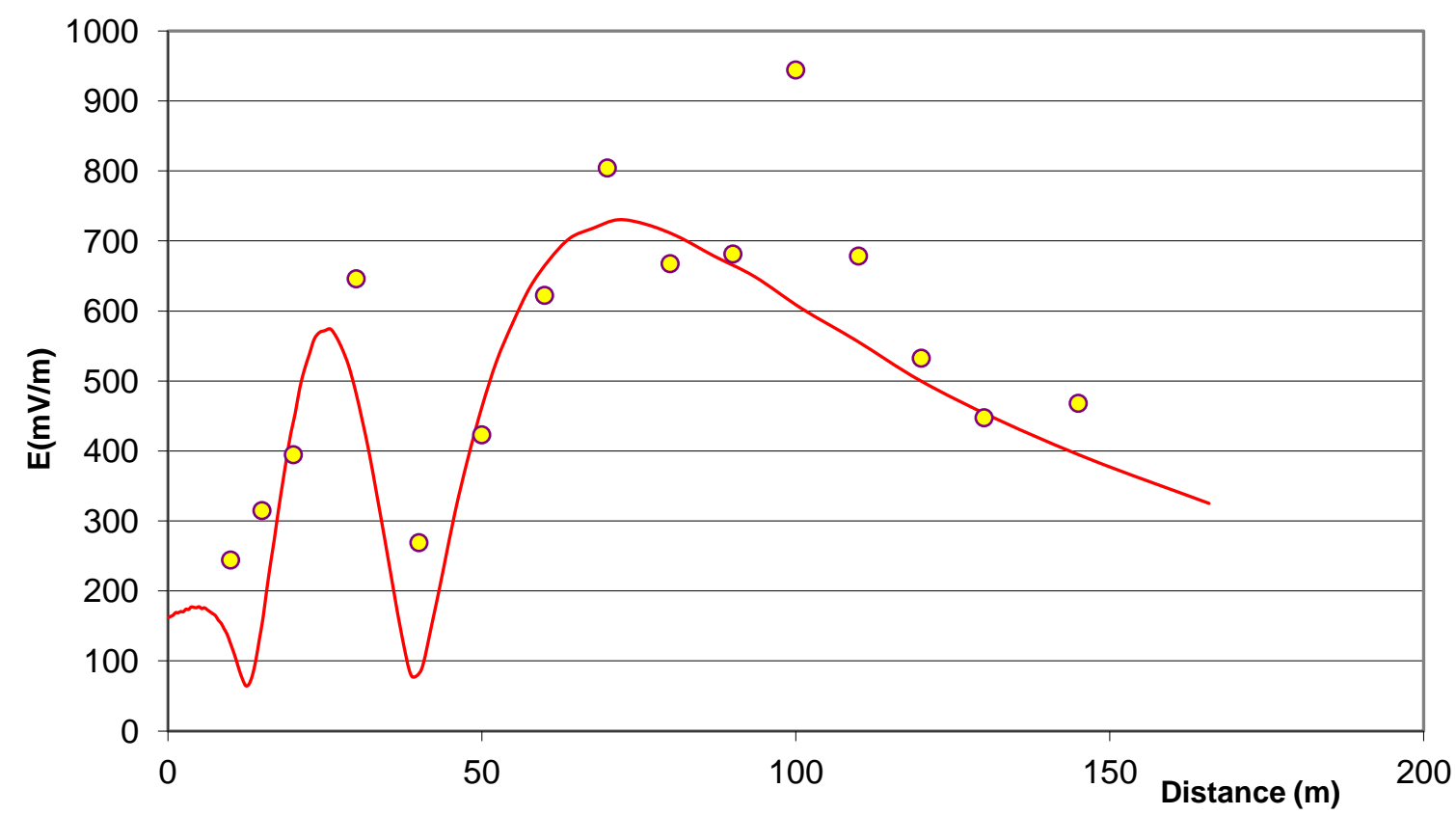

Figura 4.12: Resultados para o sistema trunking (iDEN). ○ valores medidos, — valor estimado. 


\subsection{CONCLUSÕES}

O equacionamento proposto é uma ferramenta importante para a avaliação da exposição humana a CEMRF, pois usualmente a seleção de pontos de medição é visual e subjetiva. Isso mostra que, na prática, se estaria avaliando a conformidade daquele ponto em relação aos limites estabelecidos, mas não do ambiente eletromagnético na vizinhança da estação de radiocomunicação.

Assim, os resultados identificados neste capítulo são importantes para se avaliar a conformidade de uma estação de radiocomunicação em relação aos limites de exposição, pois apresenta uma formulação original e prática, onde os únicos parâmetros necessários para realizar a estimação de máxima exposição fazem parte dos dados de licenciamento da estação e do datasheet da antena.

Vale ressaltar que, quando da realização da medição e do uso desta metodologia, é necessário procurar por gradientes na intensidade de campo elétrico para identificar o local de máxima de exposição. Esse local deverá ocorrer nas redondezas do ponto estimado, pois há algumas fontes de erro que não foram equacionadas. Entre essas fontes, incluem-se reflexão do sinal, perturbação do diagrama de radiação devido ao local de instalação, precisão do diagrama de radiação (fornecido de grau em grau), além dos dados de instalação que possuem precisão limitada, por exemplo, quanto à altura de instalação antena. 


\section{EXPOSIÇÃO EM AMBIENTES URBANOS}

\subsection{INTRODUÇÃO}

A estimação do local de máxima exposição a CEM associado a uma estação de radiocomunicação em um ambiente urbano é mais complexa do que em um ambiente totalmente aberto. Neste capítulo, será proposta uma generalização para estimar o local de máxima exposição em ambientes urbanos, com visada direta, a partir do uso de modelos de propagação mais adequados ao ambiente considerado.

Uma justificativa para os desvios entre o valor estimado e o valor real será apresentada, por meio de um modelamento matemático embasado em uma aproximação gaussiana para modelar o desvanecimento.

\subsection{MODELO DE PROPAGAÇÃO}

A combinação da perda de percurso $(P L)$ e sombreamento pode ser escrita na forma:

$$
P L(\mathrm{~dB})=A+10 \gamma \log \left(d / d_{0}\right)+s
$$

em que $A$ e $\gamma$ são funções de um ou mais dos seguintes parâmetros: frequência, altura da antena e ambiente; $d$ é a distância da antena ao ponto de observação; $d_{0}$ é uma distância de referência; e o parâmetro de desvanecimento de grande escala (sombreamento) $s$ é uma variável aleatória gaussiana, de média zero e desvio-padrão $\sigma$ [46]. Assume-se que as variações espaciais em escala local ocorrem somente devido ao desvanecimento em pequena escala [29]. Por exemplo, para o modelo de espaço livre $A=32,4+20 \cdot \log (f)$, em que $f$ é a frequência em $\mathrm{GHz} ; d_{0}=1 \mathrm{~m} ;$ e $\gamma=2$.

Se a perda de percurso segue (5.1), então a densidade de potência média, em $\mathrm{W} / \mathrm{m}^{2}$, pode ser estimada de acordo com a seguinte fórmula generalizada [47]:

$$
\mathrm{S}(\mathrm{d}, \theta, \varnothing)=\frac{P \cdot G_{\max } \cdot F(\theta, \varnothing)}{K \cdot d^{\gamma}}
$$

em que $P$ é a potência fornecida para a antena, em $\mathrm{W} ; G_{\max }$ é o ganho máximo da antena; $F(\theta, \phi)$ é o ganho numérico relativo, variando com os ângulos de elevação e de azimute; $K$ 
é um valor fixo para o modelo específico sendo considerado; e $\gamma$ é o expoente da perda de percurso.

O parâmetro $K$ em (5.2) pode ser calculado a partir do modelo de perda de percurso, como descrito a seguir. A potência recebida por uma antena isotrópica ideal $(0 \mathrm{dBi})$ é dada por:

$$
P_{R}=\frac{\text { EIRP }}{L}=\frac{P \cdot G_{\max } \cdot F(\theta, \varnothing)}{L}
$$

em que $L=10^{\frac{L_{\mathrm{dB}}}{10}}$ e $L_{\mathrm{dB}}=P L$ a uma distância $d$. A densidade de potência recebida é:

$$
\mathrm{S}=\frac{P_{R}}{\mathrm{~A}_{\mathrm{eff}}}=\frac{\mathrm{EIRP}}{K \cdot d \gamma}
$$

em que $A_{\text {eff }}=\frac{\lambda^{2}}{4 \pi}$ é a área efetiva da antena isotrópica. Substituindo (5.3) em (5.4), é possível calcular $K$ como:

$$
K=\frac{\mathrm{A}_{\mathrm{eff}} L}{d^{\gamma}}
$$

O parâmetro $K$ não tem influência na determinação do ponto de máxima exposição, somente na densidade de potência e, consequentemente, na intensidade do campo elétrico.

\subsubsection{O modelo de Walfisch-Ikegami}

O modelo de Walfisch-Ikegami (modelo COST-WI) considera várias informações para descrever o ambiente urbano, como altura e separação entre prédios, largura das ruas e orientação das ruas em relação à propagação do sinal direto. Este modelo separa os casos de visada direta e sem visada direta. No caso de LOS, tanto a fonte de CEMRF, quanto o receptor estão em uma canyon street. A formulação deste modelo é baseada em medições realizadas em Estocolmo, Suécia [48].

Para o modelo COST-WI em visada direta, $A=42,6+20 \cdot \log (f)$ e $\gamma=2,6$. Ele é adequado para ser utilizado para a faixa de frequências entre $800-2.000 \mathrm{MHz}$, altura da estação base $(H)$ entre 4-50 m, altura da antena da estação móvel entre $1-3 \mathrm{~m}$ e $20 \mathrm{~m} \leq d \leq 5.000 \mathrm{~m}$.

Considerando o equacionamento apresentado anteriormente, é possível estimar a densidade de potência no ponto de recepção em cenários que seguem o modelo COST-WI em visada direta como sendo: 


$$
\mathrm{S}(d, \theta, \emptyset)=\frac{P \cdot G_{\max } \cdot F(\theta, \varnothing)}{2,08 d^{2,6}}
$$

Percebe-se que o expoente em (5.7) é o mesmo expoente da perda de percurso do modelo considerado, enquanto o valor 2,08 está associado ao parâmetro $A$, e consequentemente ao parâmetro $K$.

\subsubsection{Outros Modelos}

Segundo a referência [49], para as medições em visada direta em 1,9 GHz e 3,5 GHz os resultados são próximos ao modelo de espaço livre, com perda de percurso decaindo proporcionalmente a $d^{-2}$, de forma similar a outros trabalhos encontrados na literatura para diferentes faixas de frequências; nestes casos, $\gamma=2$ e $K \neq 4 \pi$. A referência [50] também identificou $\gamma \approx 2$ em áreas suburbanas para 3,5 GHz $(\gamma=2,13$ para antenas de recepção a 6 m e $10 \mathrm{~m}$, mas com diferentes valores do parâmetro $A$ ).

Outros modelos de propagação, como Hata, ECC-33 e SUI, também podem ser escritos, com alguns ajustes, na forma $P L=A+10 \cdot \gamma \cdot \log (d)$.

Esses modelos complexos apresentam resultados melhores para situações sem visada direta e comumente superestimam a perda de percurso em ambientes com LOS. De uma forma geral, cenário com visada direta possui $\gamma \approx 2$ (2,6 para COST-WI com LOS), enquanto para os casos sem visada direta apresenta $\gamma$ entre 3 e 5 .

\subsection{PONTO DE MÁXIMA EXPOSIÇÃO}

A influência de $F(\theta, \phi)$ para os casos sem visada direta foi relatada em [51]. Em ambientes abertos, o ponto de máxima exposição ocorre na direção de azimute da antena. Porém, em ambientes urbanizados aumentam as chances de existir construções nessa direção, de tal forma que outras direções com visada direta à antena passam a ser relevantes.

O produto $F(\theta) \times F(\phi)$ é uma boa aproximação para a radiação frontal da antena e uma aproximação razoável para a radiação no sentido das costas da antena [4]. Fixando-se o valor de $\phi$, o diagrama de radiação no plano vertical da antena também pode ser aproximado por $\cos ^{q}(\theta-\alpha)$. Desta forma, calculando $d S / d x=0$ em (5.2) e isolando $x$, obtém-se: 


$$
x=X_{\max }^{\exp }=\frac{\sqrt{\left[(H-h) \cdot \operatorname{tg} \alpha \cdot\left(1+\frac{q}{\gamma}\right]^{2}+\frac{4 \cdot q \cdot(H-h)^{2}}{\gamma}\right.}-(H-h) \cdot \operatorname{tg} \alpha \cdot\left(1+\frac{q}{\gamma}\right)}{2}
$$

A presente metodologia prevê também os casos nos quais há uma inclinação na região em que ocorre a avaliação, como, por exemplo, em uma rua que apresenta uma subida ou descida. O impacto da inclinação $(\beta)$ de uma rua em $X_{\max }^{\text {exp }}$ pode ser mitigado se for adequadamente adicionado/subtraído o valor de $\beta$ no tilt $(\alpha)$ da antena, tornando o plano inclinado um caminho sem inclinação, por meio de rotação de eixos, como mostrado na figura 5.1. O erro introduzido no eixo- $x$ por esta aproximação é $h$.sen $\beta$, que representa um valor muito menor do que $X_{\max }^{\exp }$. Desta forma, (5.8) pode ser utilizada, nestes casos, com a devida correção em $\alpha$, gerando um $\alpha$ '.

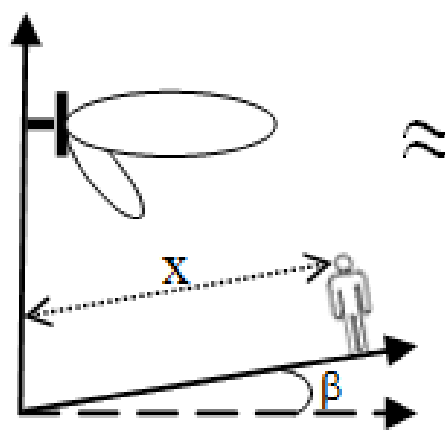

(a)

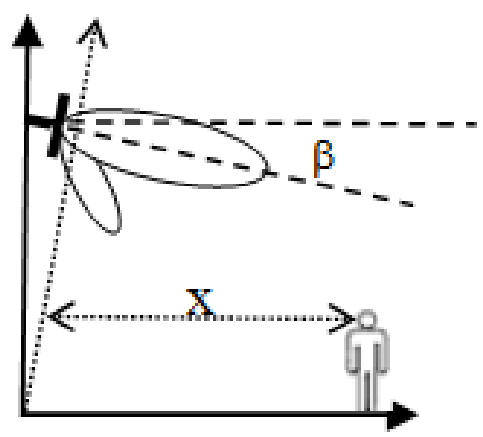

(b)

Figura 5.1: Aproximação de um percurso inclinado por um percurso plano. A figura (a) não é exatamente equivalente à (b), pois o eixo-y deveria também ser rotacionado em $\beta$ graus.

\subsection{ESTUDO DE CASOS}

A metodologia proposta foi testada em simulações, medições e dados coletados em outros trabalhos para ambientes urbanizados com visada direta.

O software de simulação utilizado foi o Radio Planning and Technical Spectrum Management, da ICS Telecom [52], configurado para executar o modelo baseado nas recomendação ITU-R Calculation of free-space attenuation (Rec. 525) e Propagation by diffraction (Rec. P.526). 


\subsubsection{ERB em São Paulo}

O primeiro caso considerado foi o sítio hipotético, ilustrado nas figuras 5.2 e 5.3, instalado no centro da cidade de São Paulo, no qual apenas um setor da ERB foi simulado para avaliar a influência desta única fonte. $\mathrm{O}$ azimute da antena é $0^{\circ}$ Norte, enquanto a orientação da rua na qual a torre está instalada é aproximadamente $35^{\circ}$ Norte, tendo grandes prédios em 3 das 4 esquinas, como mostrado na figura 5.3. Neste caso, o ponto de máxima exposição ao nível da rua não ocorrerá na direção de máxima intensidade de radiação da antena, mas de acordo com a orientação da rua, que possui visada direta com a antena.

As características técnicas da ERB são apresentadas na Tabela 5.1, assim como os resultados calculados para diferentes valores de $\gamma$ e também o resultado da simulação. A figura 5.4 mostra que os locais de máxima exposição simulados e calculados são compatíveis. Os resultados do cálculo e simulação foram iguais para $\gamma=2$ devido ao modelo de propagação escolhido para a simulação, que foi o modelo de espaço livre combinado com difração.

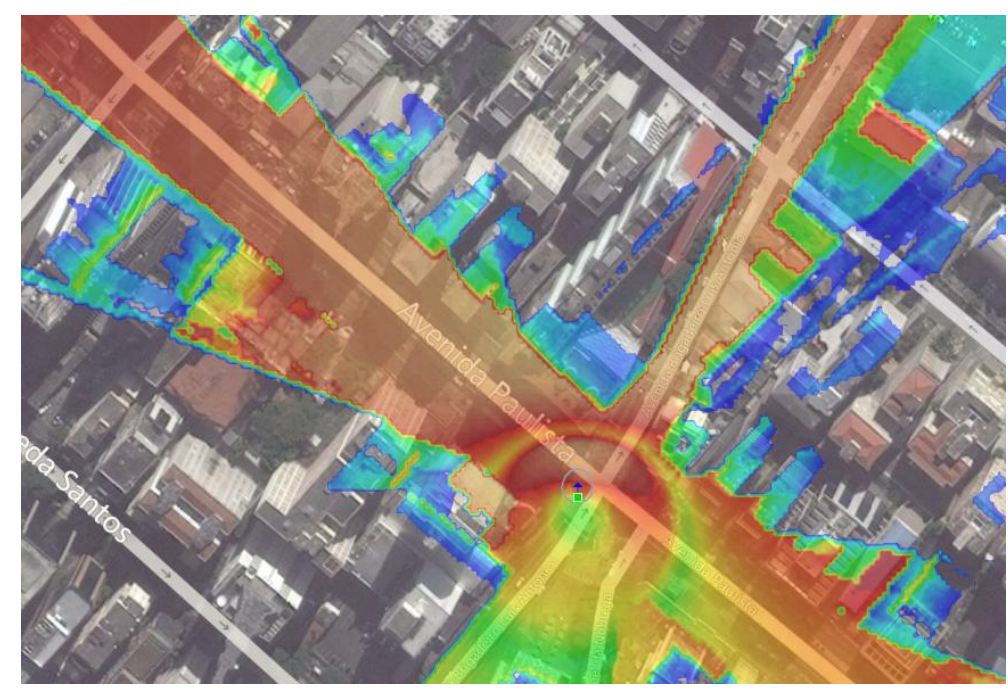

Figura 5.2: ERB hipotética localizada no centro urbano da cidade de São Paulo. Prédios em ambos os lados da rua bloqueiam a propagação do sinal. As regiões mais livres apresentam maiores intensidade de CEM. 


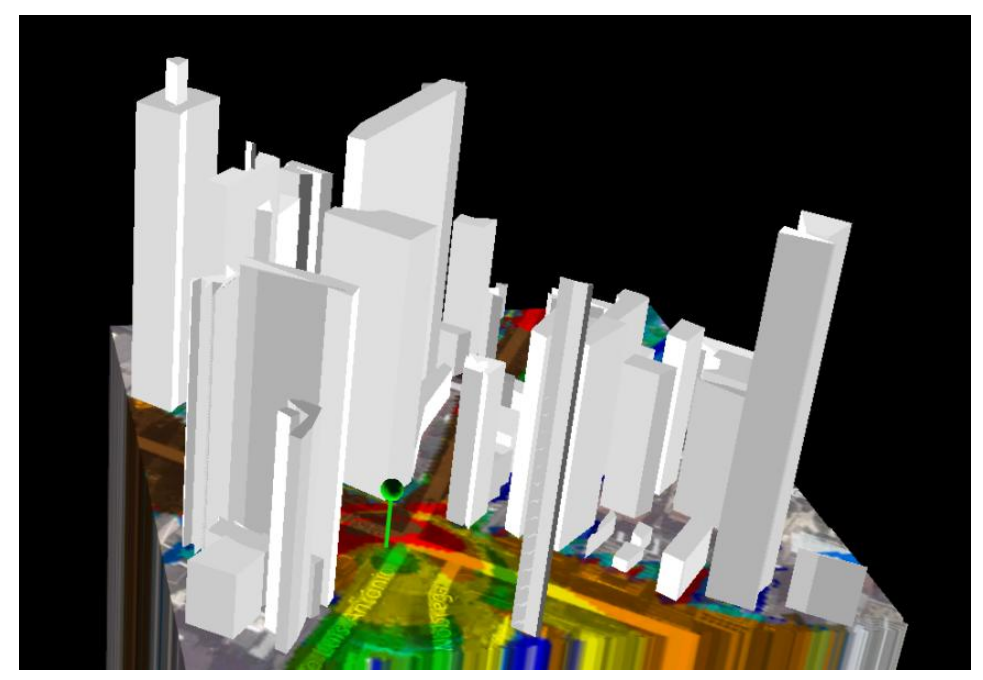

Figura 5.3: Visão em 3D da ERB no meio da região urbana.

Tabela 5.1: ERB - São Paulo

\begin{tabular}{l|c}
\hline \multicolumn{2}{c}{ Características Técnicas } \\
\hline Altura da antena $(H)$ & $30 \mathrm{~m}$ \\
\hline Altura de referência $(h)$ & $1,5 \mathrm{~m}$ \\
\hline Ângulo de $3 \mathrm{~dB}$ no Plano Vertical & $25,6^{\circ}$ \\
\hline Ângulo de $3 \mathrm{~dB}$ no Plano Horizontal & $88^{\circ}$ \\
\hline Tilt $(\alpha)$ & $10^{\circ}($ mecânico $)$ \\
\hline EIRP & $1.000 \mathrm{~W}(60 \mathrm{dBm})$ \\
\hline Frequência & $900 \mathrm{MHz}$ \\
\hline \multicolumn{1}{c}{ Resultados } \\
\hline$X_{\max }^{\text {exp calculado }}$ & $75 \mathrm{~m} \mathrm{@} \gamma=2$ \\
\hline$X_{\max }^{\text {exp }}$ calculado & $68 \mathrm{~m} \mathrm{@} \gamma=2,6$ \\
\hline$X_{\max }^{\text {exp }}$ simulado & $75 \mathrm{~m}$ \\
\hline
\end{tabular}

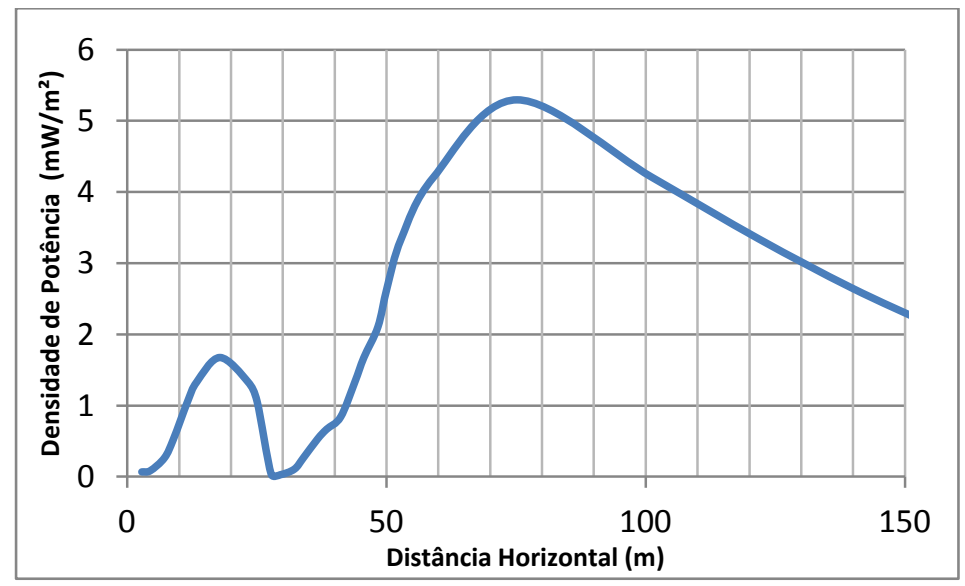

Figura 5.4: Densidade de potência calculada com o software ICS Telecom. O ponto de máxima exposição está localizado em $75 \mathrm{~m}$, mesmo valor estimado para $\gamma=2$ e maior do que para $\gamma=2,6$. 


\subsubsection{ERB em Ottawa}

O segundo caso considera medições de perda de percurso em $910 \mathrm{MHz}$ realizadas no centro da cidade de Ottawa, no Canadá [53]. Nessa campanha, a antena do transmissor possuía altura de $8,5 \mathrm{~m}$, enquanto a antena do receptor estava instalada em uma unidade móvel, com altura de 3,65 m. As medições foram realizadas em rotas com visada direta e sem visada direta, em áreas com prédios mais altos do que as antenas em ambos os lados da rua. Para testar a metodologia proposta, somente as medições com visada direta na direção oeste da Rua Slater foram utilizadas.

As antenas de transmissão e de recepção são omnidirecionais e a discriminação do plano de elevação foi considerada na avaliação da perda de percurso. Esses valores foram obtidos a partir dos gráficos apresentados em [53]. A potência recebida foi amostrada aproximadamente uma vez a cada metro, com um receptor calibrado.

O gráfico da perda de percurso é mostrado na figura 5.5. Utilizando-se da análise de regressão linear foi obtido um modelo de perda de percurso, conforme a equação a seguir.

$$
P L=23,4+26,6 \log (d)
$$

O modelo em (5.9) é muito próximo ao modelo COST-WI com visada direta, que é dado por $P L=23,8+26 \log (d)$, em $910 \mathrm{MHz}$.

Utilizando a formulação apresentada nas equações (5.2) e (5.3), a densidade de potência média pode ser estimada para esse estudo de caso como sendo:

$$
\mathrm{S}(d, \theta, \varnothing)=\frac{P \cdot G_{\max } \cdot F(\theta, \varnothing)}{1,89 \cdot d^{2,66}}
$$

A partir do modelo apresentado nas equações (5.9) e (5.10), foram executadas simulações seguindo o procedimento descrito em [41], com os resultados apresentados na Tabela $5.2 \mathrm{e}$ na figura 5.6. As características técnicas da ERB são apresentadas na Tabela 5.2. Como esperado, os locais de máxima exposição calculados e simulados são muito próximos. 


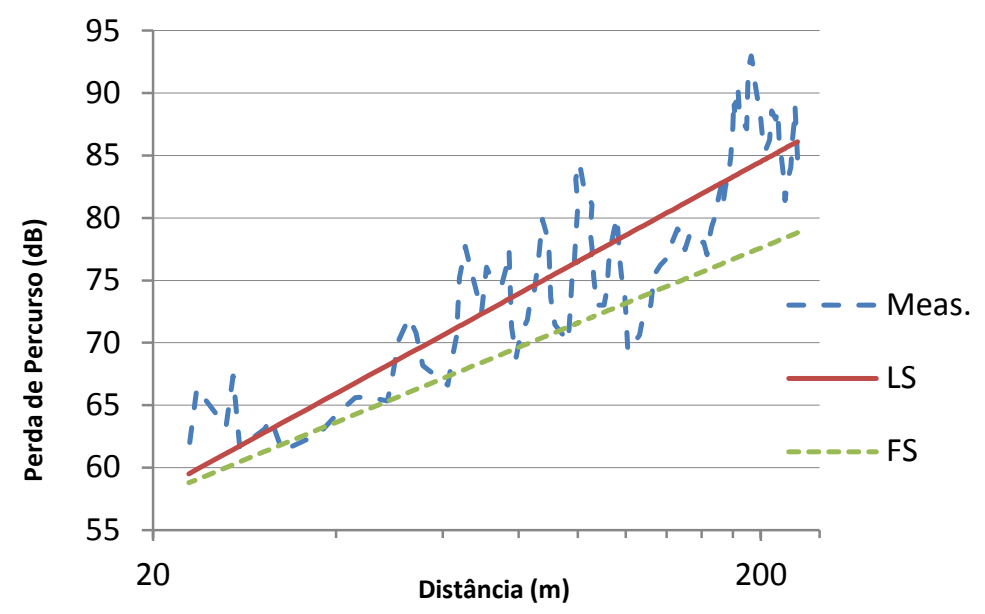

Figura 5.5: Perda de percurso no sentido oeste do sinal radiado pelo transmissor localizado na Rua Slater, 300 (Meas.). Neste caso, $P L=23,4+26,6 \log (d)$, com $\sigma=3,84 \mathrm{~dB}$. O ponto de interceptação entre os modelos LS (regressão linear) e FS (espaço livre) ocorre na distância de $18 \mathrm{~m}$.

Tabela 5.2: ERB - Ottawa.

\begin{tabular}{l|c}
\hline \multicolumn{2}{c}{ Características Técnicas } \\
\hline Altura da antena $(H)$ & $11,5 \mathrm{~m}$ \\
\hline Altura de referência $(h)$ & $1,5 \mathrm{~m}$ \\
\hline Modelo da Antena & CommScope CV3PX308R1 \\
\hline Ângulo de 3 dB no Plano Vertical & $10,5^{\circ}$ \\
\hline Ângulo de 3 dB no Plano Horizontal & $64^{\circ}$ \\
\hline Tilt $(\alpha)$ & $5^{\circ}($ elétrico $)$ \\
\hline EIRP & $10 \mathrm{~W}(40 \mathrm{dBm})$ \\
\hline & Resultados \\
\hline$X_{\text {max }}^{\text {exp }}$ calculado & $55,9 \mathrm{~m} @ \gamma=2,66$ \\
\hline$X_{\text {max }}^{\text {exp }}$ calculado & $56,3 \mathrm{~m} @ \gamma=2,6$ \\
\hline$X_{\text {max }}^{\text {exp }}$ calculado & $61 \mathrm{~m} @ \gamma=2$ \\
\hline$X_{\text {max }}^{\text {exp }}$ simulado & $56 \mathrm{~m}$ para o PL estimado \\
\hline$X_{\text {max }}^{\text {exp }}$ simulado & $62 \mathrm{~m}$ para modelo de espaço livre \\
\hline
\end{tabular}




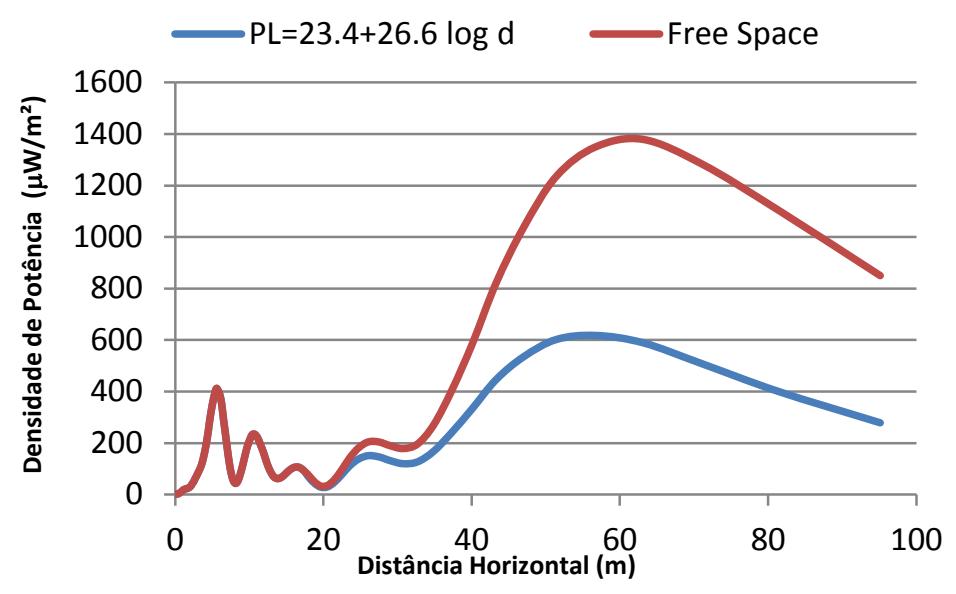

Figura 5.6: Densidade de potência em função da distância horizontal até a ERB, para o modelo de espaço livre e para o modelo com o PL específico. Neste gráfico foi considerado que abaixo do ponto de interceptação em 18 m o modelo específico converge para o modelo de espaço livre.

\subsubsection{ERB em Aarhus}

O terceiro caso utiliza dados coletados em campanha executada no centro de Aarhus, uma cidade média e urbana na Dinamarca, com prédios de altura média entre 15-18 m e larguras de rua de aproximadamente $20 \mathrm{~m}$ [51]. As características técnicas da ERB, que opera em 2,6 GHz, são apresentadas na Tabela 5.3, assim como os resultados para os diferentes valores de $\gamma$ e simulação.

Baseado nos dados coletados do GPS e no perfil do terreno disponível no Google Earth, a inclinação da rua é de aproximadamente $3,8^{\circ}$ em um raio de $100 \mathrm{~m}$ a partir da ERB (Setor 1 de [51]). O receptor foi instalado em uma unidade móvel com uma antena omnidirecional com ganho de $5 \mathrm{dBi}$ com plano terra e $2,5 \mathrm{~m}$ de altura, equipado com network scanner. A taxa de amostragem era de 50 amostras/s para uma velocidade média do veículo de $15 \mathrm{~km} / \mathrm{h}$. Evidentemente, o ponto de máxima recepção de potência é o mesmo ponto de máxima densidade de potência. Neste cenário, não foi realizada a correção da potência recebida devido ao ângulo de chegada na antena de recepção. Por isso, somente medições mais distantes do que $20 \mathrm{~m}$ foram consideras a fim de minimizar a influência do plano de elevação da antena. As figuras 5.7 e 5.8 mostram que os pontos de máxima exposição são coerentes com os resultados da metodologia proposta. 
Tabela 5.3: ERB - Aarhus, Dinamarca.

\begin{tabular}{l|c}
\hline \multicolumn{2}{c}{ Características Técnicas } \\
\hline Altura da antena $(H)$ & $23 \mathrm{~m}$ \\
\hline Altura de referência $(h)$ & $2,5 \mathrm{~m}$ \\
\hline Ganho da antena $(\mathrm{dBi})$ & 16 \\
\hline Ângulo de 3dB no plano vertical & \multicolumn{2}{|c}{$5,4^{\circ}$} \\
\hline Ângulo de 3dB no plano vertical & \multicolumn{2}{|c}{$60^{\circ}$} \\
\hline Tilt $(\alpha)$ & $6^{\circ}$ \\
\hline Inclinação da rua $(\beta)$ & \multicolumn{2}{|c}{$\approx 3,8^{\circ}$} \\
\hline Potência máxima do transmissor & \multicolumn{2}{|c}{$2 \times 46 \mathrm{dBm}$} \\
\hline
\end{tabular}

\section{Resultados}

\begin{tabular}{l|c|c}
\hline \multirow{2}{*}{$X_{\max }^{\exp }$ calculado, $\gamma=2$} & $\alpha^{\prime}=9,8^{\circ}$ & $\alpha^{\prime}=13,8^{\circ}$ \\
\cline { 2 - 3 }$X_{\text {max }}^{\text {exp }}$ calculado, $\gamma=2,6$ & $108 \mathrm{~m}$ & $79 \mathrm{~m}$ \\
\hline$X_{\text {max }}^{\text {exp }}$ medido para $\alpha^{\prime}=9,8^{\circ}$ & $\alpha^{\prime}=9,8^{\circ}$ & $\alpha^{\prime}=13,8^{\circ}$ \\
\hline$X_{\text {max }}^{\text {exp }}$ medido para $\alpha^{\prime}=13,8^{\circ}$ & $105 \mathrm{~m}$ & $78 \mathrm{~m}$ \\
\hline
\end{tabular}

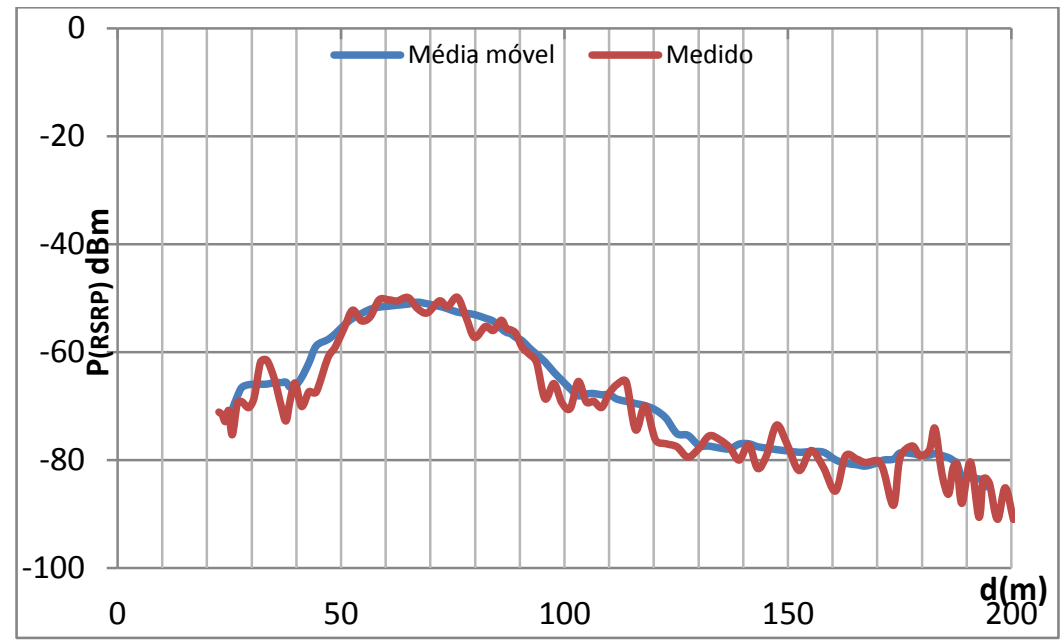

Figura 5.7: Potência recebida do sinal de referência (RSRP) de um sistema LTE com largura de faixa de 20 $\mathrm{MHz}$ com tilt de antena de $10^{\circ}$. 


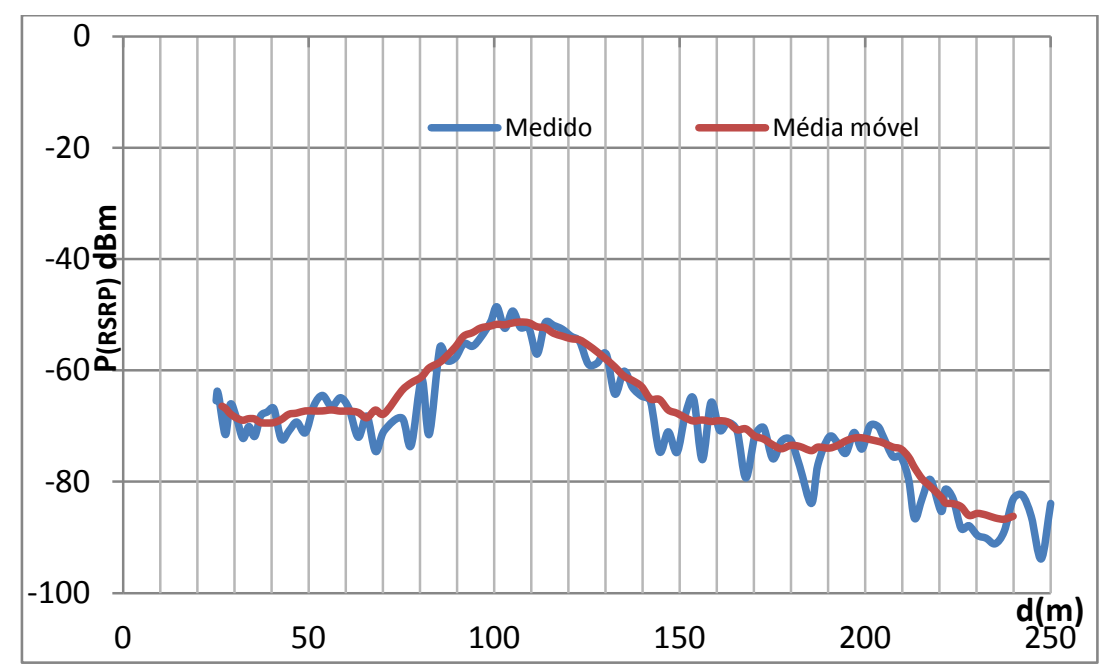

Figura 5.8: RSRP de um sistema LTE com largura de faixa de $20 \mathrm{MHz}$ com tilt da antena de $6^{\circ}$.

\subsection{ANÁLISE DO DESVIO ENTRE OS PONTOS ESTIMADO E MEDIDO}

O valor de $X_{\text {max }}^{e x p}$ indica a região provável onde ocorre a exposição máxima a CEMRF associado a uma estação de radiocomunicação. Vale ressaltar que as mesmas fontes de erro que contribuem no desvio entre as posições de máxima exposição estimada e real para ambientes abertos, valem para os ambientes urbanizados com visada direta, com uma maior contribuição do sinal espalhado e difratado nesses ambientes mais complexos. Adicionalmente, ainda existe mais uma fonte de erro que é a estimação da inclinação de uma rua com base nos resultados de GPS. Por isso, o procedimento de andar ao redor do local estimado de máxima exposição buscando encontrar o gradiente que leve ao ponto real de máxima exposição deve ser executado.

Como mostrado nos resultados das medições, o valor medido oscila ao redor de um valor esperado. Essa variação ocorre devido ao desvanecimento, tanto em pequena escala quanto em grande escala, porém, para assegurar estatísticas realistas do desvanecimento em pequena escala, seriam necessárias medições com espaçamento menores a $0,1 \lambda$ [54]. Como não se tem informações suficientes para caracterizar adequadamente o desvanecimento em pequena escala, se apresentará um modelo que explica o desvio do valor médio.

Considerando que a perda de percurso pode ser escrita conforme a eq. (5.1); considerando também a aproximação gaussiana (em $\mathrm{dB}$ ) para as componentes de desvanecimento em pequena e grande escala; fica claro que o ponto de máxima exposição, calculado a partir da 
eq. (5.3), pode ocorrer em um local diferente de $X_{\max }^{\exp }$ devido a componente aleatória $s$. Vale ressaltar que o valor de pico não coincide necessariamente com o local de máxima média espacial, mas, nesse ponto da avaliação, a sensibilidade do técnico avaliador é muito importante para identificar o local de medição mais relevante e fixar a sonda para proceder a avaliação conforme protocolo.

Assim, se pode estimar a região $R$, ao redor de $X_{\max }^{\exp }$, na qual a intensidade de campo elétrico medido em qualquer ponto dentro desta região pode ser superior à intensidade de campo elétrico medido em $X_{\max }^{\text {exp }}$, com uma probabilidade $\mathrm{p}_{\min }$ [55]. Esta região está representada na figura 5.9, onde $R$ está limitado por $X_{0}$ e $X_{1}$. Para definir a região $R$, devem ser estimados os valores de $x$, nos quais as densidades de potência $S$ na distância $x=X$, menos a densidade de potência em $x=X_{\max }^{\text {exp }}$ é maior do que 0 (zero), com probabilidade $p(X)>p_{\text {min }}:$

$$
p(X)=\operatorname{Prob}\left(S(X)-S\left(X_{\max }^{\exp }\right)>0\right)>p_{\min }
$$

em que $\mathrm{S}(x)$ é a densidade de potência no ponto $x$. A diferença entre a densidade de potência em $x=X$ e $x=X_{\text {max }}^{\text {exp }}$, em dB, é:

$$
S(X)-S\left(X_{\max }^{\text {exp }}\right)=10 \log \left(\frac{\cos ^{q}(\theta-\alpha)}{\cos ^{q}\left(\theta_{\text {max }}^{\text {exp }}-\alpha\right)}\right)-10 \gamma \log \left(\frac{d}{d_{\text {max }}^{\text {exp }}}\right)+s_{X}-s_{X \_ \text {exp _max }}
$$

Conforme a figura 5.9, $d=(H-h) \operatorname{sen}(\theta)$ e $d^{2}=X^{2}+(H-h)^{2}$. Dessa figura também se obtém a relação entre $d_{\max }^{\exp }, \theta_{\max }^{\exp }$ e $X_{\max }^{\text {exp }}$. O primeiro e o segundo termos da direita da eq. (5.12) representam a diferença do ganho da antena na direção de $X_{\max }^{\text {exp }} X$ e a diferença da perda de percurso nos pontos $X_{\max }^{\exp }$ e $X$. A componente aleatória de (5.12) é descrita pelos valores $s_{X}$ e $s_{X_{-}}$exp _max , que representam amostras de $s$ nos pontos $x=X$ e $x=X_{\text {max }}^{\text {exp }}$. 


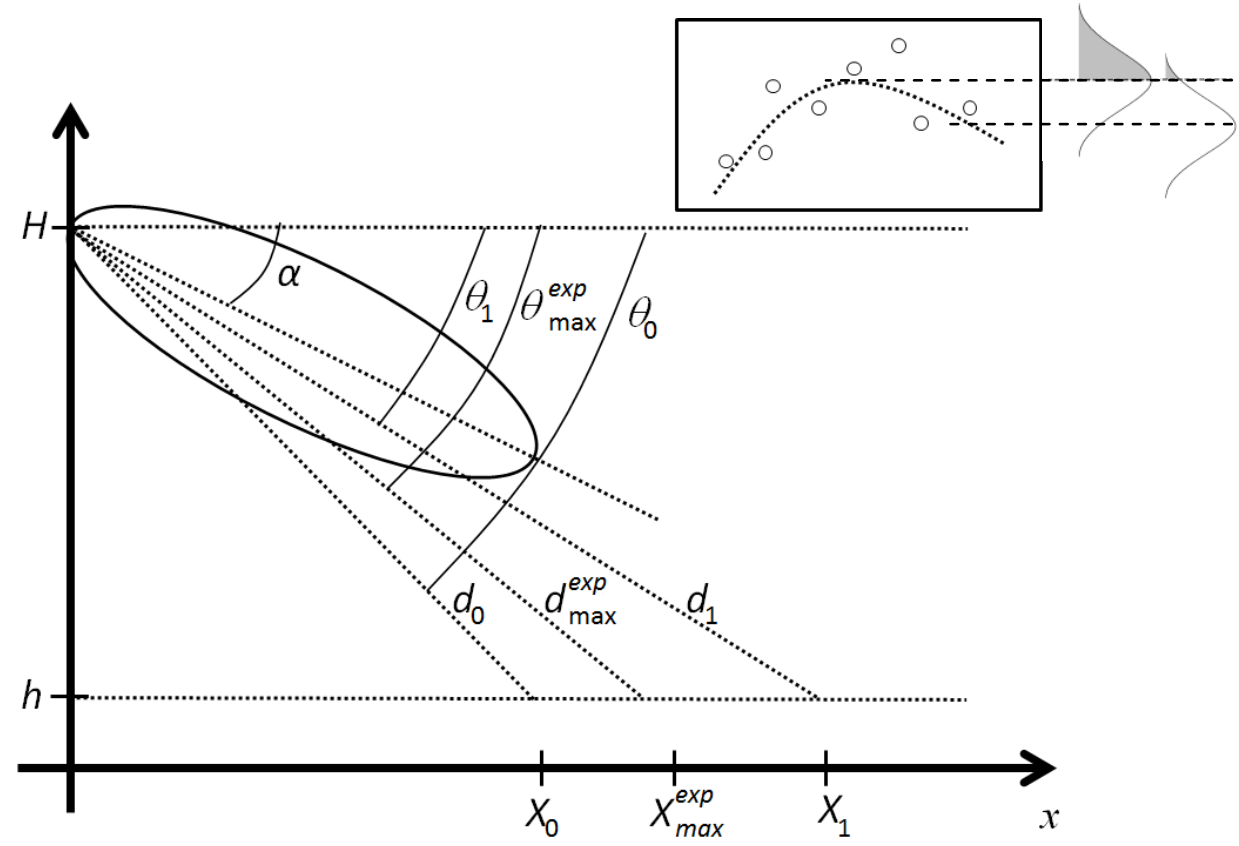

Figura 5.9: O ponto estimado de máxima exposição a CEMRF associado ao lóbulo principal é $X_{\max }^{\text {exp }}$. Devido a componente aleatória da perda de percurso, o local real de máxima exposição pode estar na região delimitada por $X_{0}$ e $X_{1}$. Em destaque estão representadas a curva teórica de densidade de potência e valores de medição (círculos).

Considerando que $s$ é uma variável aleatória gaussiana com média zero e desvio padrão $\sigma$, $v=s_{X}-s_{X \_ \text {exp _max }}$ também será uma variável aleatória gaussiana com média zero, mas com desvio padrão $\sqrt{2} \sigma$. Substituindo (5.12) em (5.11), $R$ será a região onde:

$$
p(X)=\operatorname{Prob}\left(v>10 \gamma \log \left(\frac{d}{d_{\text {max }}^{\text {exp }}}\right)-10 \log \left(\frac{\cos ^{q}(\theta-\alpha)}{\cos ^{q}\left(\theta_{\text {max }}^{\exp }-\alpha\right)}\right)\right)>p_{\text {min }}
$$

Como $v$ é uma variável aleatória gaussiana, a probabilidade definida em (5.13) é a conhecida função-Q. Logo, $R$ será a região que contém os valores de $X$ que obedece a seguinte equação:

$$
p(X)=Q\left(\frac{10 \gamma \log \left(\frac{d}{d_{\max }^{e x p}}\right)-10 \log \left(\frac{\cos ^{q}(\theta-\alpha)}{\cos ^{q}\left(\theta_{\max }^{\text {exp }}-\alpha\right)}\right)}{\sqrt{2} \sigma}\right)>p_{\text {min }}
$$

Com a eq.(5.14) é possível traçar os valores de $X$ e construir o gráfico de $p(X)$, que permite determinar a região $R$. O tamanho de $R$ depende de $\gamma, \sigma, \alpha$ e $q$. Um maior valor de $\sigma$ implica em uma região maior, enquanto maiores valores de $\gamma, \alpha$ e $q$ implicam em uma região menor. 
A Tabela 5.4 apresenta o local estimado de máxima exposição a CEMRF calculado pela eq.(5.8), a região dada pela eq.(5.14) e o ponto onde as medições indicaram o local de máxima exposição. A figura 5.10 apresenta os valores de $p(X)$ para os casos de Brasília e Aarhus (Dinamarca). Esses resultados consideram $p_{\min }=20 \%$, o que significa que fora da região $R$, a probabilidade da medida ultrapassar o valor medido em $X_{\max }^{\exp }$ é menor do que $20 \%$.

O valor de $\sigma$ usualmente varia de 6-10 dB [56]. Porém, este valor se refere a estudos realizados considerando distâncias de algumas dezenas de metros até quilômetros. No caso da exposição humana a CEMRF se está interessado em distâncias de até algumas centenas de metros, logo faz-se necessário estimar o $\sigma$ para distâncias menores. Analisando medições para cenário em visada direta feitas em Munique, Alemanha [57] e Ottawa, Canadá [53], o valor de $\sigma$ foi da ordem de 3,5 dB, que será a referência adotada nessas simulações.

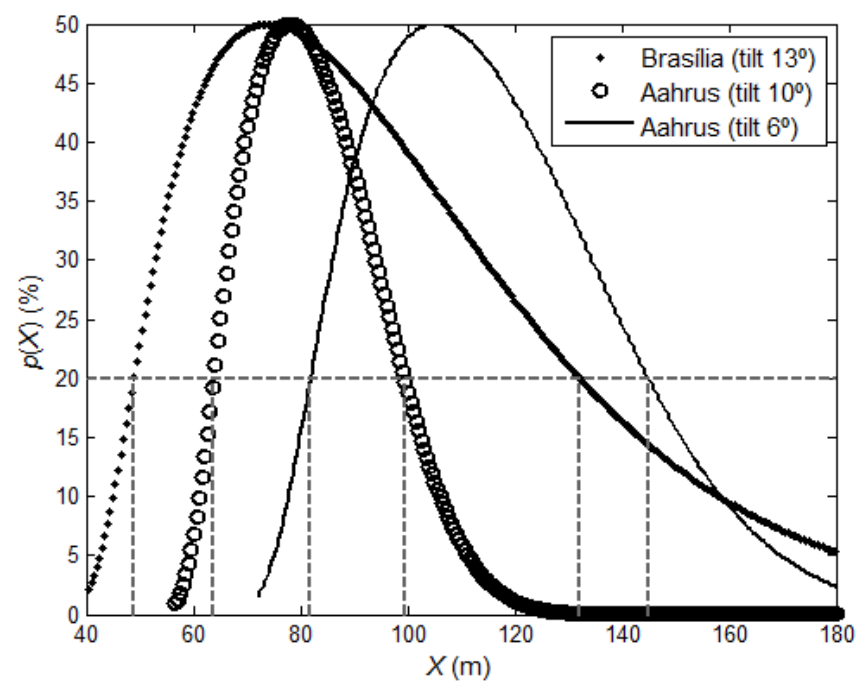

Figura 5.10: Valor de $p(X)$ para Brasília e Aahrus. $X_{\max }^{\text {exp }}$ é o local no qual $p(X)=50 \%$.

Tabela 5.4: Resultados para os locais estimados de máxima exposição $\left(X_{\max }^{\text {exp }}\right)$, região $R$ e locais medidos que apresentaram o maior valor de exposição a CEMRF.

\begin{tabular}{c|c|c|c}
\hline Cidade & $X_{\text {max }}^{\text {exp }}$ & Região $R$ & $\begin{array}{c}\text { Local medido que apresentou o maior } \\
\text { valor de exposição a CEMRF }\end{array}$ \\
\hline Brasília & $74 \mathrm{~m}$ & {$[49 \mathrm{~m}, 132 \mathrm{~m}]$} & $100 \mathrm{~m}$ \\
\hline Aarhus, $10^{\circ}$ tilt & $78 \mathrm{~m}$ & {$[64 \mathrm{~m}, 99 \mathrm{~m}]$} & $76 \mathrm{~m}$ \\
\hline Aarhus, $6^{\circ}$ tilt & $105 \mathrm{~m}$ & {$[82 \mathrm{~m}, 145 \mathrm{~m}]$} & $101 \mathrm{~m}$ \\
\hline
\end{tabular}


Adicionalmente, outros elementos podem contribuir no desvio (erro) entre as posições de máxima exposição estimada e real. Algumas dessas fontes de erro são a perturbação no diagrama de radiação da antena devido ao seu suporte e torre; precisão dos dados do datasheet, que normalmente apresentam valores inteiros de ângulo (precisão de $1^{\circ}$ ); frequência de referência, que pode não ser a frequência de operação, o que modifica o diagrama de radiação; e os próprios dados da licença para funcionamento da estação, no qual existe uma variação aceita pela regulamentação (como, por exemplo, altura da antena, tilt etc.).

Por fim, cabe enfatizar que o ponto calculado deve ser considerado como um local de referência, no qual o avaliador considerará como um ponto central em uma avaliação e buscará gradientes na intensidade de campo elétrico a fim de encontrar o local de máxima exposição.

\subsection{CONCLUSÕES}

Este capítulo apresentou a aplicação da metodologia proposta para estimar a máxima exposição a CEMRF em áreas urbanas mostrando resultados consistentes. Assim como no capítulo anterior, o foco neste capítulo foi o lóbulo principal da antena. Os resultados mostraram que o local de máxima exposição é dependente do expoente de perda de percurso.

Os resultados sugerem que em ambientes urbanos com canyon streets e LOS, o técnico deve considerar $\gamma=2,6$ para o ponto de referência e caminhar ao redor desse ponto buscando identificar o local de máxima exposição real. Nos demais casos de LOS, os resultados sugerem que o técnico deve considerar $\gamma=2$, sabendo que há maior chance de a máxima exposição ocorrer próximo à estação, sem, contudo, desconsiderar o procedimento de caminhar ao redor desse ponto.

Foi apresentado também um modelamento matemático para explicar o porquê dos desvios entre o valor estimado e o valor real, com base em uma aproximação gaussiana para modelar o desvanecimento. 


\section{EXPOSIÇÃO EM AMBIENTES INTERNOS}

\subsection{INTRODUÇÃO}

A disponibilidade de muitas opções de dispositivos móveis no mercado está mudando a interação entre as pessoas na sociedade moderna. Além disso, o estabelecimento de padrões de tecnologia sem fio incentiva a produção em larga escala de dispositivos de alta qualidade a preço baixo. No entanto, o uso de todos esses aparelhos também pode aumentar o nível total de exposição humana a CEM, devido à combinação de múltiplas fontes de RF. Isso pode levar a situações em que o público em geral pode estar exposto a níveis mais elevados de CEM, causados por dispositivos de radiação restrita em ambiente doméstico, em comparação com fontes externas de RF, mesmo que estas tenham potência radiada superior.

A motivação deste capítulo é avaliar e comparar a exposição a CEM entre uma ERB próxima a um apartamento e dispositivos de radiação restrita em ambientes domésticos, tais como dispositivos WLAN e babá eletrônica. Também será apresentada simulação de propagação de um ambiente externo para um ambiente interno, seguindo o modelo COST231. Em relação às medições, foram consideradas instalações reais, representando cenários típicos para equipamentos de radiação restrita no ambiente doméstico e um caso emblemático de ERB instalada nas proximidades de um edifício residencial. Os pontos de medição em cada local foram escolhidos para representar as condições reais que poderiam resultar em exposições mais elevadas a tais sistemas.

\subsection{PROPAGAÇÃO EM ÁREAS ABERTAS DE AMBIENTES INTERNOS}

Vários estudos mostram que a propagação em ambientes internos (indoor) possui perda de percurso seguindo uma lei de potência [48, 58-60]. No entanto, mesmo em espaços abertos de ambientes internos o modelo de espaço livre pode apresentar um desvio significativo em relação aos ambientes reais.

Sem perda de generalidade, o modelo de perda de percurso $(P L)$ para áreas abertas em ambientes internos pode ser escrito como:

$$
P L(\mathrm{~dB})=A+10 \cdot \gamma \cdot \log (d)+X
$$


em que $A$ é a perda de percurso a $1 \mathrm{~m}$ de distância; $\gamma$ é o expoente da perda de propagação; e $X$ é uma variável aleatória de média zero, que descreve o comportamento estatístico da perda de percurso.

Medições relatadas em [58-60], assim como modelos de propagação empíricos apresentados em [48], identificaram que o parâmetro $A$ possui valor maior do que o do modelo de espaço livre, e que o parâmetro $\gamma$ é aproximadamente 2, podendo ser menor, principalmente, em corredores. Em [59], é mostrado que o desvio em relação ao valor esperado diminui conforme o aumento da distância (por exemplo, $d>20 \lambda$ ). Os resultados apresentados em [62] seguiram o modelo de espaço livre, uma vez que as medições foram realizadas em câmera anecóica.

Considerando que se deve ter uma abordagem conservadora na avaliação da exposição humana a CEMRF, é razoável adotar o modelo de espaço livre em áreas abertas de ambientes internos.

\subsection{MODELO DE PROPAGAÇÃO COM FONTE EXTERNA}

O projeto COST 231 [48] propôs uma formulação empírica para o modelo de propagação, em visada direta, quando a fonte de RF está em ambiente externo, e a onda eletromagnética se propaga para dentro do prédio. Este modelo foi baseado em várias campanhas de medição para diferentes tipos de edifícios, ângulos de incidência e distâncias (até $500 \mathrm{~m}$ ), nas faixas de frequências entre 900-1.800 MHz. A perda de propagação entre uma ERB e um ponto de referência dentro do edifício, tendo somente a parede externa entre este ponto e a fonte pode ser estimada como sendo [48]:

$$
\begin{aligned}
P L=32,4+2 & \log (f)+20 \log (S+d)+W_{e}+W G_{e} \cdot\left(1-\frac{D}{S}\right)^{2}+ \\
& +\max \left[0, \alpha \cdot(d-2) \cdot\left(1-\frac{D}{S}\right)^{2}\right]
\end{aligned}
$$

em que $D$ e $d$ são, respectivamente, as distâncias perpendiculares da parede externa, ou sua projeção, à ERB e ao ponto de referência; $S$ é a distância física entre a antena da ERB e o ponto de penetração na parede; o ângulo rasante do traço de raio que se choca no ponto de penetração é dado por $\operatorname{sen}(\theta)=D / S ; W_{e}$ é a perda associada à componente perpendicular do 
sinal que ilumina a parede externa, com valores típicos entre 4-10 dB (7 dB para parede de concreto com janela de tamanho normal); $W G_{e}$ é a perda adicional para ângulo rasante de zero grau, com valor típico de $20 \mathrm{~dB}$; o parâmetro $\alpha$ é o coeficiente de atenuação indoor, com valor recomendado de $0,6 \mathrm{~dB} / \mathrm{m}$. A propagação no ambiente externo é considerada como sendo em espaço livre, com todas as distâncias em metros e frequência em gigahertz.

Os parâmetros desse modelo estão representados na figura 6.1. Com a equação (6.2), fica claro que, em distâncias curtas, a perda de penetração pode variar consideravelmente devido à variação no ângulo de incidência. $\mathrm{O}$ modelo completo considera, também, a atenuação em paredes internas, mas, nesses casos, a intensidade de campo elétrico seria irrelevante em termos da avaliação da exposição humana a CEMRF.

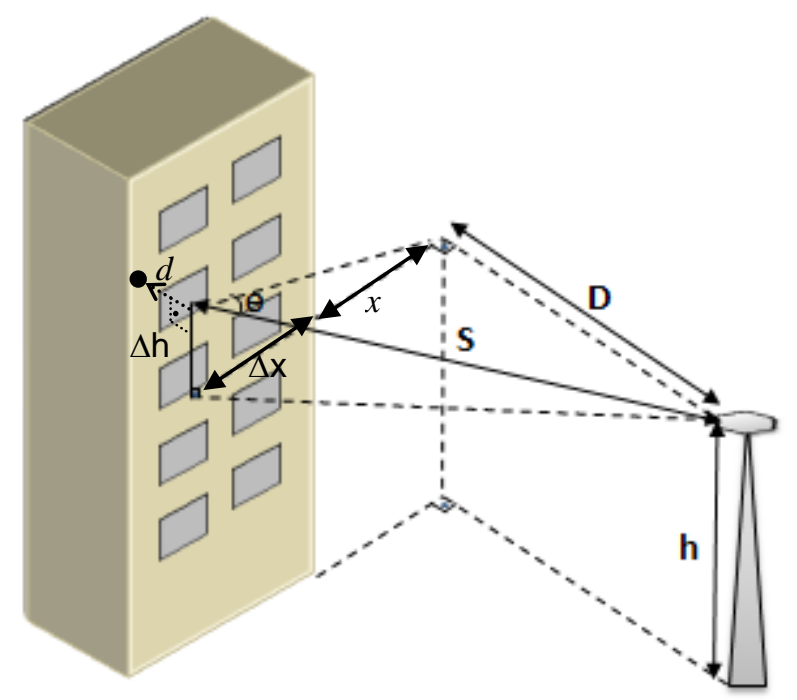

Figura 6.1: Representação esquemática de uma ERB com setor de interesse iluminando um prédio, com azimute apontando no sentido de $D$.

\subsection{EQUIPAMENTOS DE RADIAÇÃO RESTRITA}

Equipamentos de radiação restrita são dispositivos de baixa potência, geralmente operando isentos de licenciamento de estação. Esses dispositivos são amplamente utilizados na tecnologia Bluetooth (mouse, teclado, fone de ouvido etc.), RFID, babás eletrônicas, controles de garagem, WLAN e dispositivos de segurança de automóveis instalados na própria chave do veículo [63]. Neste capítulo, será avaliada a exposição a CEM associada a dois desses dispositivos: access point Wi-Fi e babá eletrônica. 


\subsubsection{Access Point Wi-Fi}

A maioria dos equipamentos WLANs é baseada em padrões IEEE 802.11, que são geralmente referidos como tecnologia Wi-Fi [64]. Dependendo da regulação nacional eles podem ser utilizados tanto em ambientes internos como em ambientes externos, bem como podem operar em diferentes faixas de frequências e limites diferenciados de potência radiada. Dispositivos Wi-Fi estão sendo largamente utilizados por operadoras para tráfego offload, bem como por usuários em ambientes de escritório ou residenciais conectados à Internet por enlaces com ou sem fio.

Dispositivos Wi-Fi operam transmitindo rajadas de pacotes de dados em faixa do espectro eletromagnético que independem de autorização de uso de RF do órgão regulador (por exemplo, 2,4 GHz e 5,8 GHz). Esta parte do trabalho tem como foco a tecnologia Wi-Fi que opera na faixa de 2.400-2.483,5 MHz. Para evitar uma avaliação superestimada da exposição a CEM, deve ser levado em conta o tempo médio ativo do dispositivo, uma vez que a exposição a um transmissor de RF contínuo operando com a mesma EIRP geraria uma exposição maior, devido ao ciclo de trabalho (duty cycle) dos dispositivos Wi-Fi [64, $65]$.

Para a medição do sistema Wi-Fi, considerou-se um caso em que o access point (AP) está na mesma mesa de trabalho do usuário, figura 6.2, mas outros usuários podem estabelecer conexões com o AP. Durante a avaliação, o desktop PC foi desligado e três laptops e um smartphone localizados fora da sala do AP estavam visualizando vídeos do YouTube.

Para a medição do sinal do Wi-Fi, a intensidade média de campo elétrico foi calculada usando a função Max-Hold do analisador de espectro. A intensidade média de campo elétrico, considerando o duty cycle do transmissor, foi assumida como [65]:

$$
E_{\text {tot }}^{\text {med }}=\sqrt{D} \cdot E_{\text {tot }}^{\text {max-hold }}(\mathrm{V} / \mathrm{m})
$$

em que $D=100 \frac{t_{\text {ativo }}}{t_{\text {tot }}}(\%)$ é a relação entre o tempo ativo $t_{\text {active }}(\mathrm{s})$ e o tempo total $t_{\text {tot }}(\mathrm{s})$ do sinal pulsante. A escolha do parâmetro $D$ foi feita com base nas avaliações apresentadas em [65]. 


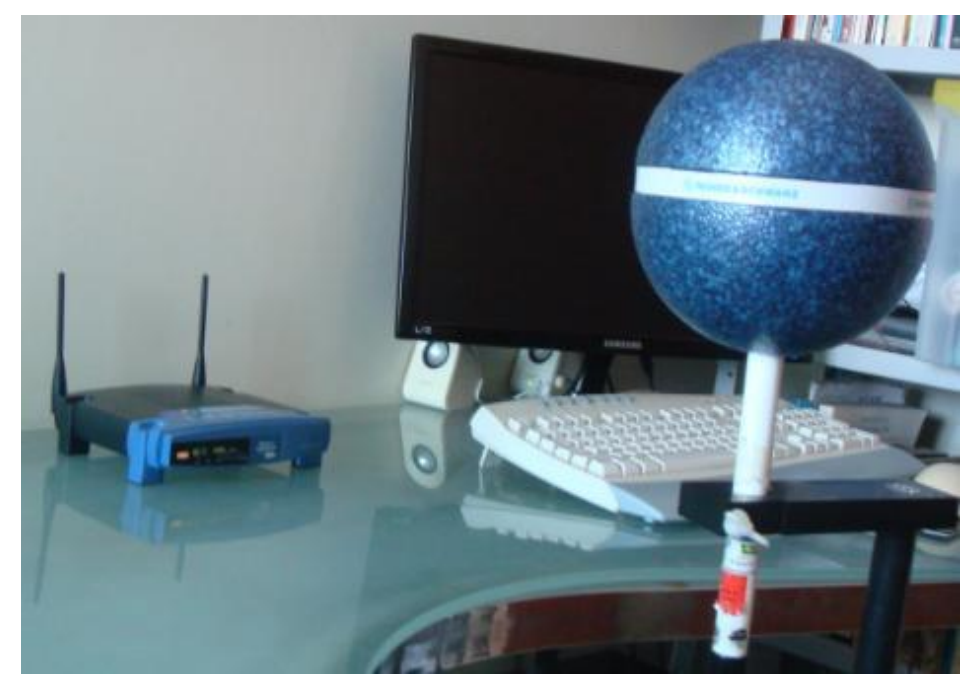

Figura 6.2: AP instalado sobre uma mesa de trabalho.

\subsubsection{Babá Eletrônica}

As babás eletrônicas são dispositivos sem fio destinados a monitorar remotamente um bebê. Há, no mercado, babás eletrônicas dotadas com funções de áudio, vídeo e/ou sensor de movimento. Esses aparelhos operam sem um padrão específico de comunicação, geralmente utilizando faixas que independem de autorização de uso de RF, em conformidade com a regulamentação nacional.

A maioria dos dispositivos de babá eletrônica opera com base em padrões proprietários [62], enquanto outros são baseados na tecnologia DECT ou em espalhamento espectral com salto em frequência. Em [62], descreve-se a avaliação de um conjunto de babás eletrônicas operando em diferentes faixas de frequências, potências radiadas e máxima distância de operação declarada. O dispositivo com maior potência radiada operava com $500 \mathrm{~mW}$ atingindo mais de $3 \mathrm{~V} / \mathrm{m}$ a $1 \mathrm{~m}$ de distância.

Para a avaliação da exposição devido à babá eletrônica, foram considerados os casos da exposição do bebê dentro do berço, assim como a exposição de um adulto na frente da câmera sem fio, como apresentado na figura 6.3. Considerando que a babá eletrônica avaliada tinha característica de sinal pulsante, o mesmo processo em (6.3) foi usado, com o parâmetro $D$ estimado a partir do Relatório de Testes da Babá Eletrônica (FCC ID: PZK280T) preparado para avaliar a conformidade com a FCC Parte 15.247 [66].

A referência [66] estabelece que sistemas com saltos em frequências operando entre 2.4002.483,5 MHz devem utilizar pelo menos 15 canais, com tempo médio de ocupação de 
qualquer canal não superior a $0,4 \mathrm{~s}$ dentro de um período de $0,4 \mathrm{~s}$ vezes o número de canais disponíveis.

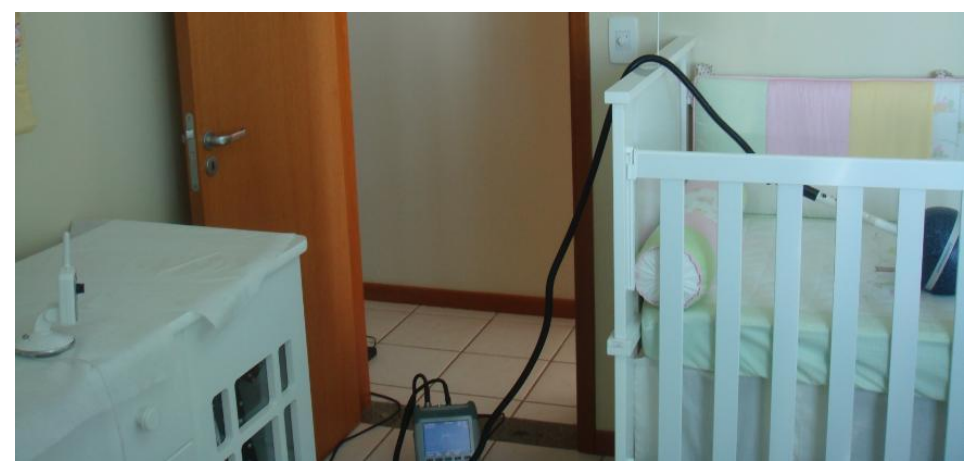

Figura 6.3: Babá eletrônica instalada perto de um berço.

\subsection{EXEMPLOS DE AVALIAÇÃO}

Para a avaliação da exposição devido aos CEMRF que se propagam para dentro do apartamento, foi considerado um apartamento novo, de um prédio recém-entregue, sem mobília, na vizinhança da ERB, como mostra a figura 6.4. O proprietário do apartamento estava preocupado com possíveis efeitos à saúde devido os CEM. É importante observar que a implantação ERB ocorreu alguns anos antes da construção do edifício.
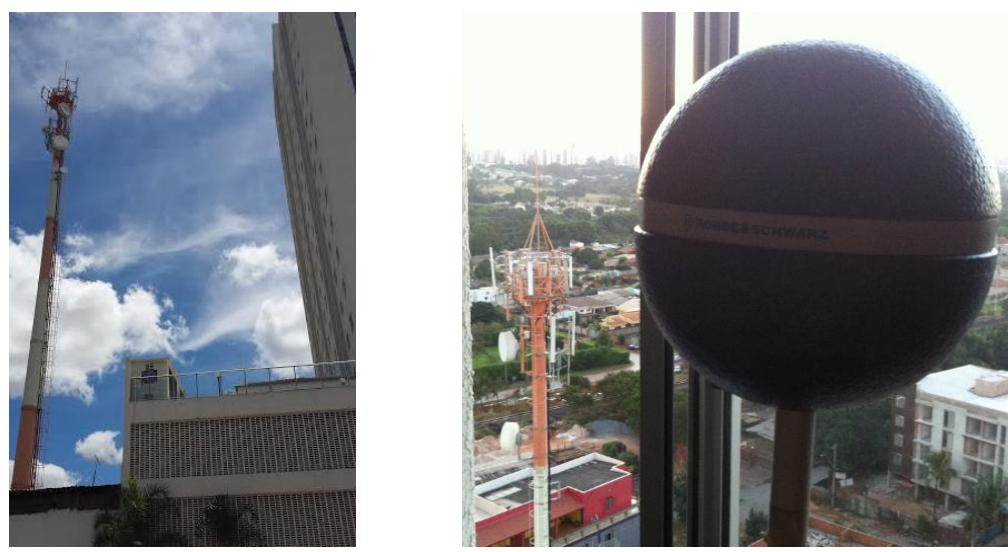

Figura 6.4: ERB próxima a um prédio residencial.

Segundo a operadora da ERB, cada setor operava com dois transceptores GSM, configurados com $43 \mathrm{dBm}$ por transmissor, ganho da antena de $17 \mathrm{dBi}$ (CommScope HBX-6516DS-VTM) e inclinação elétrica de $3^{\circ}$. As perdas em decorrência de cabo, 
conector e combinador foram estimadas em $6 \mathrm{~dB}$, logo, a EIRP máxima estimada é de 250 W por transceptor ou $500 \mathrm{~W}$ por setor GSM. Para avaliação, foi considerado apenas o nível mais elevado do canal $\mathrm{BCCH}$, que era proveniente do setor 1 .

A ERB também operava com sistemas 3G; no entanto, o analisador de espectro utilizado não possuía o módulo para medir no domínio do código, por conseguinte, apenas o sistema GSM foi avaliado.

A Tabela 6.1 apresenta a média espacial com 9 pontos para a ERB GSM. As medições foram realizadas em frente à janela, na distância de $0,4 \mathrm{~m}$, em linha de visada com a antena e no meio da sala, sem linha de visada.

Os resultados para a exposição associada à ERB são compatíveis com os valores esperados, uma vez que os locais de medição estavam fora do lóbulo principal da antena, que era muito diretiva, e com ângulos de meia-potência de $68^{\circ}$ no plano horizontal e de $7,5^{\circ}$ no plano vertical.

Tabela 6.1: Medição em uma grade 3 x 3 nas alturas de 1,1 m, 1,5 m e 1,7 m, espaçadas $0,2 \mathrm{~m}$ na horizontal, paralelamente à janela.

\begin{tabular}{|c|c|c|}
\hline & $\begin{array}{c}\text { BCCH @ 1.813 MHz } \\
\mathrm{E}(\mathrm{V} / \mathrm{m})\end{array}$ & $\begin{array}{c}\text { Extrapolação (2 Tx) } \\
\mathrm{E}(\mathrm{V} / \mathrm{m})\end{array}$ \\
\hline Janela & 0,17 & 0,24 \\
\hline Centro do quarto & 0,09 & 0,13 \\
\hline
\end{tabular}

A Tabela 6.2 apresenta as medições do AP para distâncias horizontais de 0,65 m e 0,85 m, para diferentes alturas da sonda. Foi considerado o ciclo de trabalho de 57,14\%, que é o máximo valor teórico na taxa de transmissão de $54 \mathrm{Mbps}$, no padrão IEEE 802.11g, conforme apresentado em [65]. O AP está instalado a $0,8 \mathrm{~m}$ de altura e tem EIRP de 20 $\mathrm{dBm}$. Para representar uma pessoa sentada na frente do AP, foi utilizado a média espacial com 3 pontos.

O ciclo de trabalho varia de acordo com o perfil de tráfego (como navegar em site de notícias, ver vídeos no YouTube etc), número de usuários e vazão máxima requerida. Em [65], mostra-se que, em geral, taxas de transmissão mais baixas resultam em ciclos de trabalho mais elevados (como, por exemplo, $36 \mathrm{Mbps} / 802.11 \mathrm{~g}$ em relação a 54 Mbps/802.11g). 
Tabela 6.2: Medições Wi-Fi com o AP na frente do usuário.

\begin{tabular}{|c|c|c|c|c|}
\hline $\begin{array}{c}\mathrm{X}(\mathrm{m}) \\
\text { Dist. Hor. }\end{array}$ & $\begin{array}{c}\text { Altura da sonda } \\
(\mathrm{m})\end{array}$ & $E_{\text {tot }}^{\text {max-hold }}(\mathrm{V} / \mathrm{m})$ & $E_{\text {tot }}^{\text {méd }}(\mathrm{V} / \mathrm{m})$ & $\begin{array}{c}E_{\text {tot }}^{\text {méd }}(\mathrm{V} / \mathrm{m}) \\
\text { Média Espacial }\end{array}$ \\
\hline \multirow{3}{*}{0,65} & 0,8 & 3,91 & 2,95 & \multirow{2}{*}{2,05} \\
\cline { 2 - 4 } & 1,0 & 2,26 & 1,70 & \\
\cline { 2 - 4 } & 1,2 & 1,35 & 1,02 & \multirow{2}{*}{1,29} \\
\hline \multirow{3}{*}{0,85} & 0,8 & 2,10 & 1,58 & \\
\cline { 2 - 4 } & 1,0 & 1,48 & 1,12 & \\
\cline { 2 - 4 } & 1,2 & 1,46 & 1,10 & \\
\hline
\end{tabular}

As Tabelas 6.3 e 6.4 apresentam as medições para a babá eletrônica na distância horizontal de 0,65 m e dentro do berço em distâncias horizontais variáveis. O ciclo de trabalho considerado foi de $36,9 \%$, pois o tempo médio de permanência nos canais mais baixo, mais alto e central é de 0,1476 s por canal, em um limite de 0,4 s multiplicado pelos 19 canais disponíveis. O pico de potência para dispositivos com essas características é de $125 \mathrm{~mW}$ [66], mas é comum encontrar equipamentos com potência menor [67].

Tabela 6.3: Dispositivo localizado a 1,05 m de altura.

\begin{tabular}{|c|c|c|c|c|}
\hline $\begin{array}{c}\mathrm{X}(\mathrm{m}) \\
\text { Dist. Hor. }\end{array}$ & $\begin{array}{c}\text { Altura da sonda } \\
(\mathrm{m})\end{array}$ & $E_{\text {tot }}^{\text {max-hold }}(\mathrm{V} / \mathrm{m})$ & $E_{\text {tot }}^{\text {méd }}(\mathrm{V} / \mathrm{m})$ & $\begin{array}{c}E_{\text {tot }}^{\text {méd }}(\mathrm{V} / \mathrm{m}) \\
\text { Média Espacial }\end{array}$ \\
\hline \multirow{3}{*}{0,65} & 1,05 & 1,48 & 0,9 & \multirow{2}{*}{0} \\
\cline { 2 - 4 } & 1,10 & 1,33 & 0,81 & \multirow{2}{*}{0,68} \\
\cline { 2 - 4 } & 1,50 & 0,63 & 0,38 & \\
\cline { 2 - 4 } & 1,70 & 0,78 & 0,47 & \\
\hline
\end{tabular}

Tabela 6.4: Medições com a sonda dentro do berço.

\begin{tabular}{|c|c|c|c|}
\hline $\begin{array}{c}\text { Distância Sonda }- \\
\text { Dispositivo }(\mathrm{m})\end{array}$ & $\begin{array}{c}E_{\text {tot }}^{\text {max-hold }} \\
(\mathrm{V} / \mathrm{m})\end{array}$ & $\begin{array}{c}E_{\text {tot }}^{\text {méd }} \\
(\mathrm{V} / \mathrm{m})\end{array}$ & $\begin{array}{c}E_{\text {tot }}^{\text {méd }}(\mathrm{V} / \mathrm{m}) \\
\text { Média Espacial }\end{array}$ \\
\hline 1,45 & 0,4 & 0,24 & \multirow{2}{*}{0} \\
\cline { 1 - 3 } 0 & 0,54 & 0,33 & \multirow{2}{*}{0,25} \\
\hline 1,60 & 0,22 & 0,13 & \\
\hline 1,75 & 0,45 & 0,27 & \\
\hline
\end{tabular}

Das avaliações realizadas, considerando os limites para os níveis de referência para o público em geral da ICNIRP [17], a maior exposição ocorreu devido ao AP em uma 
distância de 0,65 $\mathrm{m}(2,05 \mathrm{~V} / \mathrm{m})$, representando $0,11 \%$ do limite em termos de densidade de potência (ou 3,36\% em termos de intensidade de campo elétrico). A exposição máxima associada às emissões da babá eletrônica foi de $0,012 \%$ do limite ICNIRP a 0,65 m de distância $(1,11 \%$ em termos de intensidade de campo elétrico), enquanto que a exposição máxima devido à ERB GSM foi inferior a $0,002 \%$ do limite ICNIRP $(0,4 \%$ em termos de intensidade de campo elétrico na frente da janela).

\subsection{SIMULAÇÃO DA PROPAGAÇÃo}

Conforme explicado na Seção 6.3, no Projeto COST 231 [48] é proposta uma formulação empírica baseada em várias campanhas de medição para diferentes tipos de prédios, distâncias e ângulos de incidência. A fim de apresentar qualitativamente o comportamento esperado quando um prédio é "iluminado" por uma ERB em suas redondezas foi simulado um cenário com características similares ao ambiente apresentado na figura 6.4.

A antena foi modelada com a seguinte equação para o plano horizontal:

$$
\mathrm{F}_{\mathrm{H}}(\varnothing)=-12\left(\frac{\varnothing}{\emptyset_{3 \mathrm{~dB}}}\right)^{2}, \mathrm{~dB} \text { abaixo do ganho de referência }
$$

No plano vertical, a antena foi modelada com a seguinte equação [15], que já apresenta características de lóbulos laterais.

$$
\begin{gathered}
\mathrm{F}_{\mathrm{V}}(\theta)=\left\{\left[\frac{\operatorname{sen}[\mathrm{c} \cdot \operatorname{sen}(\theta-\alpha)]}{\mathrm{c} \cdot \operatorname{sen}(\theta-\alpha)}\right]\right\}^{2} \text {, em escala linear } \\
\mathrm{c}=\frac{1,392}{\operatorname{sen}\left(\frac{\theta_{3 \mathrm{~dB}}}{2}\right)}
\end{gathered}
$$

Os diagramas de radiação no plano vertical ou horizontal também poderiam ser modelados por meio da função $\cos ^{q}(\theta-\alpha)$, porém foram equacionados de outra forma para mostrar outras possibilidades para modelar o diagrama de radiação de antenas.

As figuras 6.5 e 6.6 apresentam a comparação do diagrama de radiação obtido com as equações (6.4), (6.5) e (6.6) com o diagrama do fabricante, para a antena modelo CommScope HBX-6516DS-VTM, de tilt elétrico de $3^{\circ}$ (porta $+45^{\circ}$ e frequência de 1.785 $\mathrm{MHz})$. 
A simulação foi executada utilizando a ferramenta Matlab R2010b considerando $W e=7$ $\mathrm{dB}$ e $W G e=20 \mathrm{~dB}$. A figura 6.7 apresenta a intensidade de campo elétrico esperada dentro dos apartamentos, a dois metros de cada janela. Nesse caso, os seguintes parâmetros foram utilizados: $h=33 \mathrm{~m}, D=25 \mathrm{~m}, x=2 \mathrm{~m}, d=2 \mathrm{~m}, f=1.813 \mathrm{MHz}$ e EIRP $=1 \mathrm{~kW}$. Aumentando a distância $D$ para $100 \mathrm{~m}$ e mantendo os outros parâmetros, tem-se o resultado apresentado na figura 6.8 .

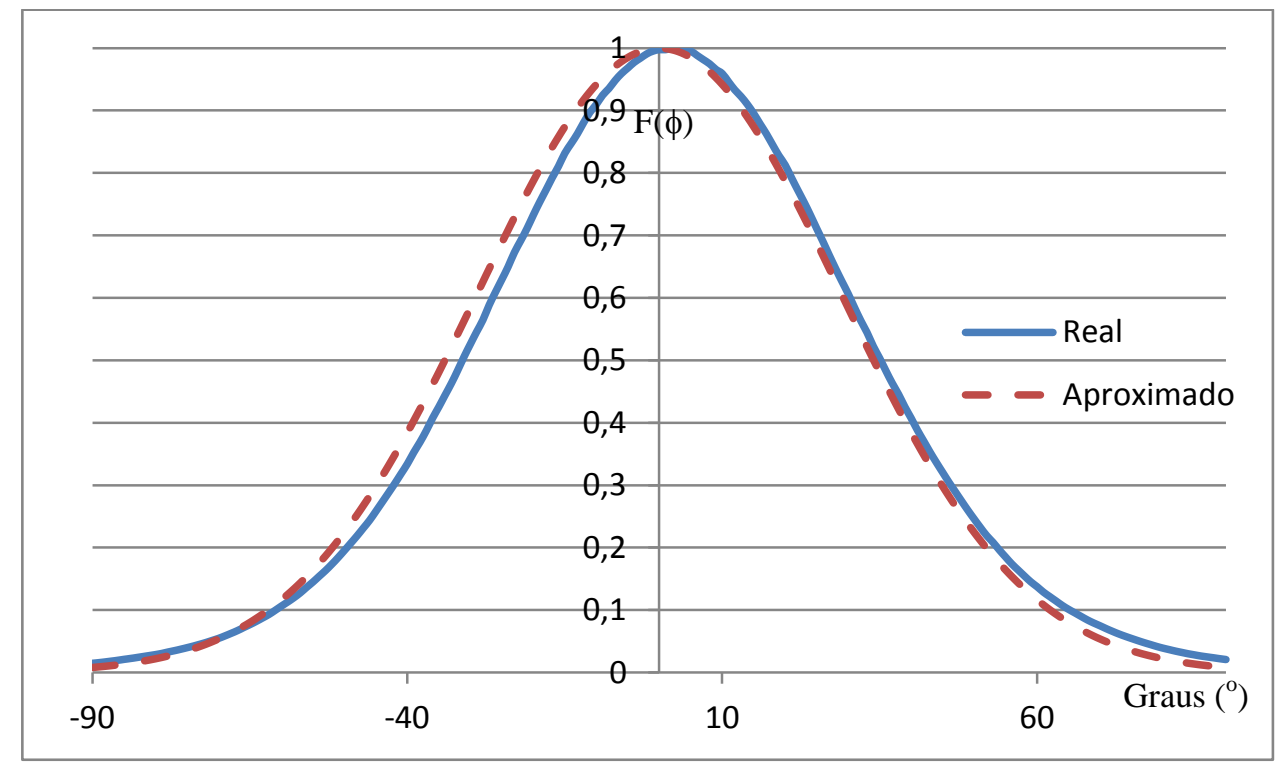

Figura 6.5: Diagrama de radiação no plano horizontal real e aproximado da antena considerada na simulação.

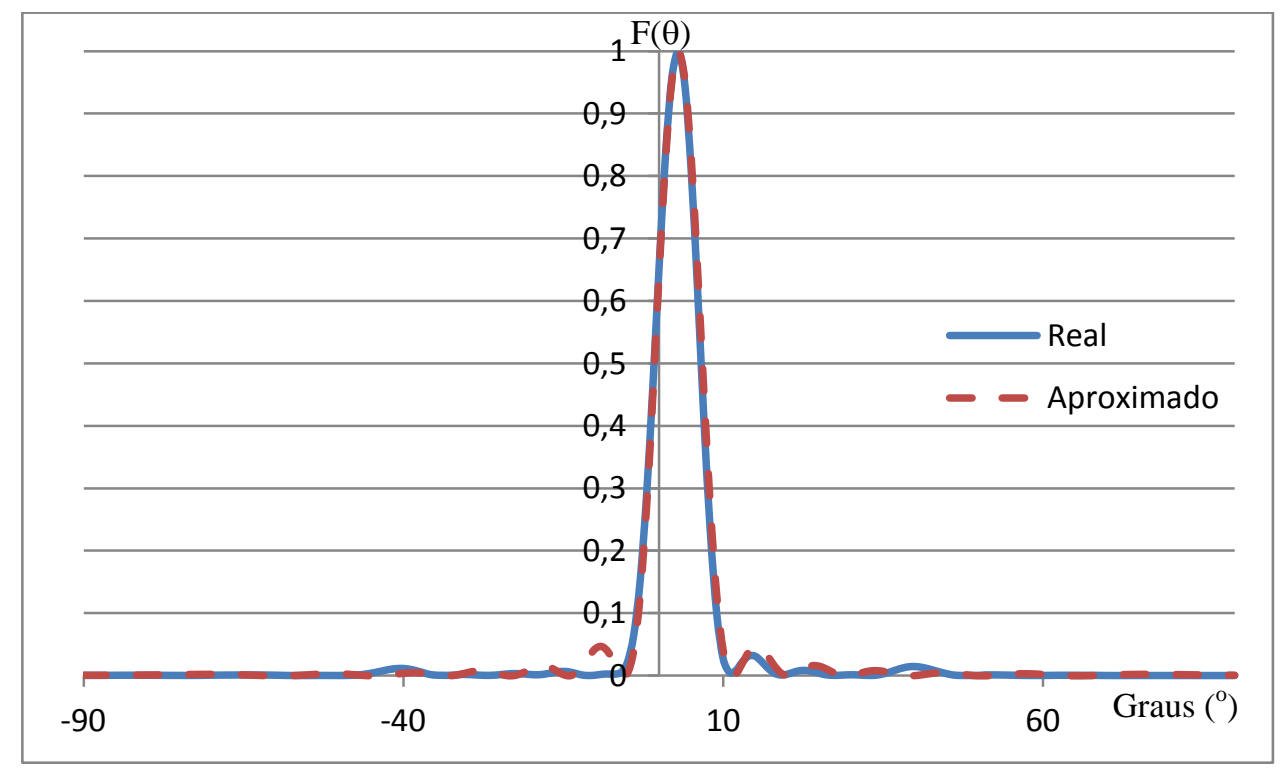

Figura 6.6: Diagrama de radiação no plano vertical real e aproximado da antena considerada na simulação. 


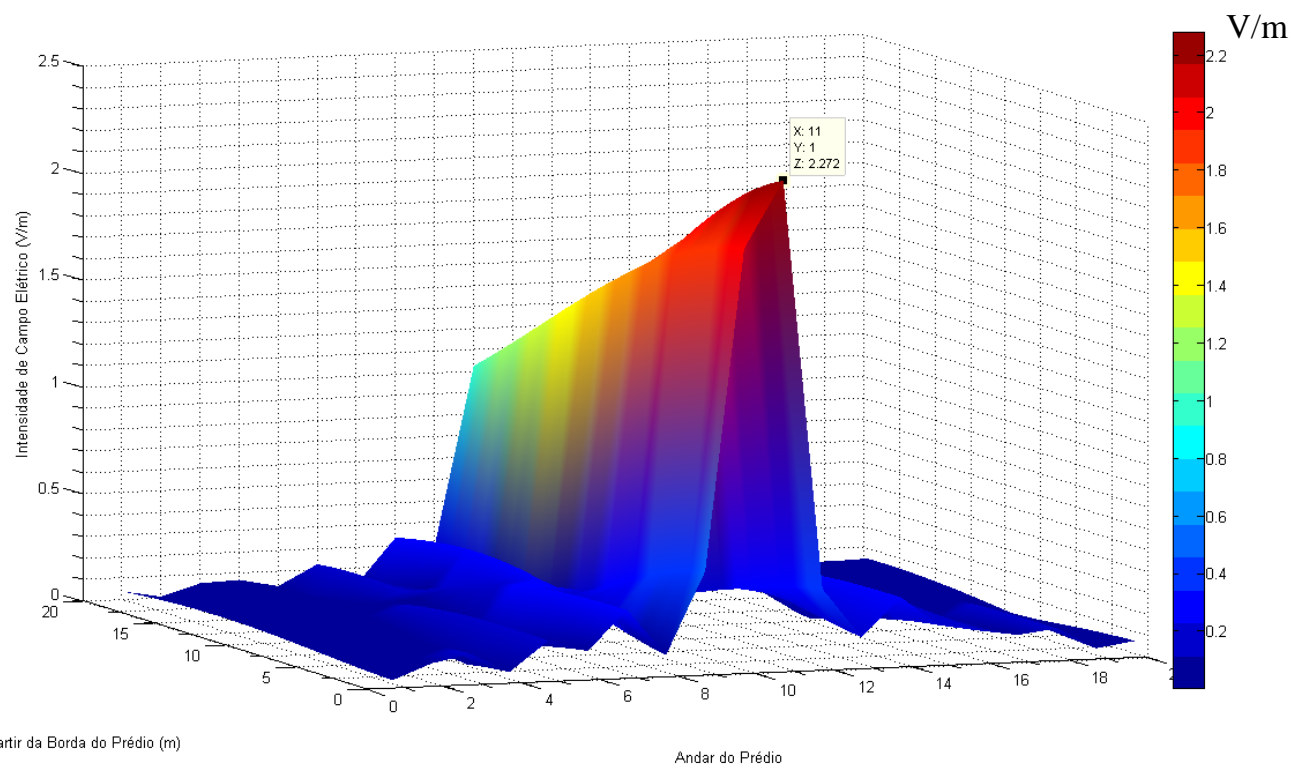

Figura 6.7: Intensidade de campo elétrico simulado dentro do apartamento, a $2 \mathrm{~m}$ da janela, com ERB a $25 \mathrm{~m}$ de distância.

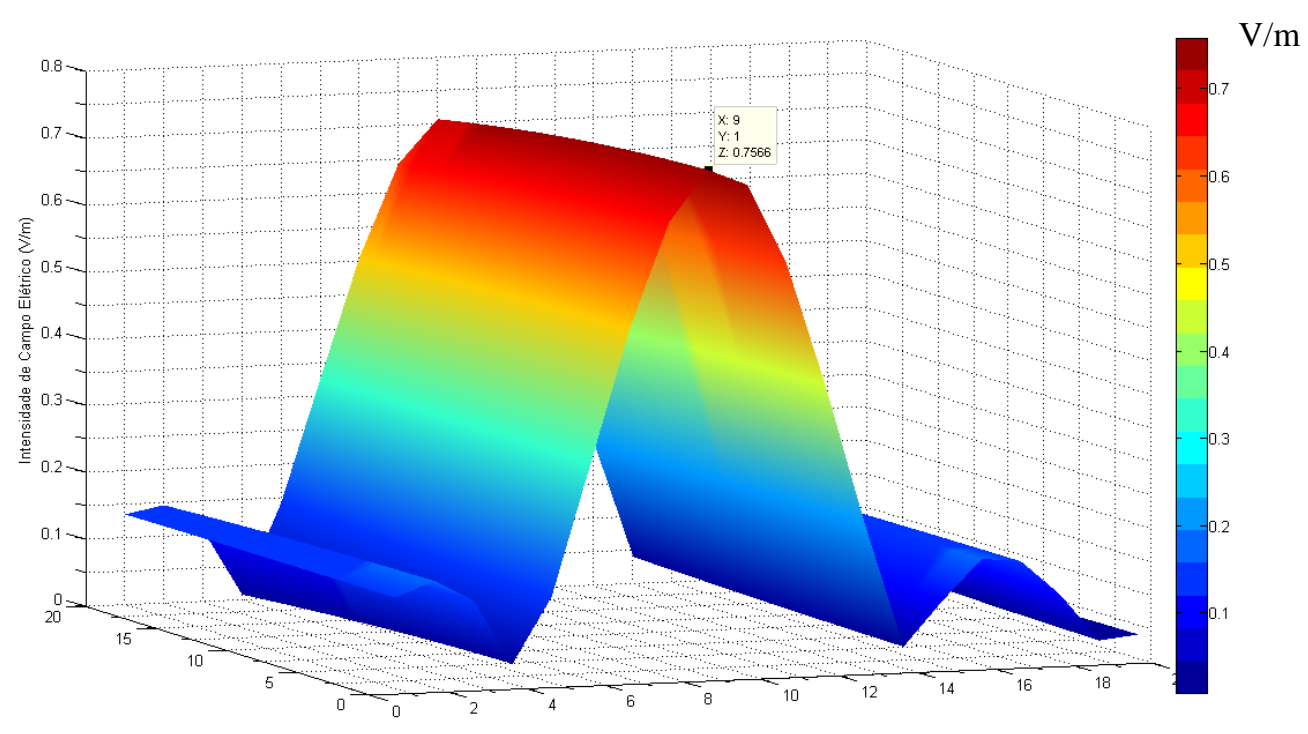

Distância a Partir da Borda do Prédio (m)

Figura 6.8: Intensidade de campo elétrico simulado dentro do apartamento, a 2 m da janela, com ERB a 100 $\mathrm{m}$ de distância.

Com as figuras 6.7 e 6.8 percebe-se a influência da distância e dos diagramas de radiação na exposição em ambientes internos com fontes de RF externas a esse ambiente. Aumentado a distância entre a fonte de RF e o ponto de interesse, além de diminuir a intensidade do sinal, a sensibilidade ao diagrama de radiação tende a diminuir. Por exemplo, na figura 6.7 fica clara a influência do plano horizontal da antena conforme aumenta a distância à borda do prédio, e isso ocorre devido duas componentes, o aumento 
do ângulo azimute (diminuindo o ganho da antena), e o aumento do ângulo de penetração no ponto de interesse (aumentando a perda de penetração). Mas, mesmo a $100 \mathrm{~m}$ de distância, ainda foram percebidos nulos da antena "iluminando" o prédio em andares mais altos e mais baixos.

\subsection{CONCLUSÕES}

Neste capítulo, foram apresentadas medições e simulações realizadas em apartamentos localizados próximos a fontes de RF. Também foi introduzida uma visão geral de diferentes tecnologias de equipamentos de radiação restrita, para mostrar a forma adequada de se realizar a avaliação de tais fontes.

Mostrou-se que, embora os dispositivos de radiação restrita sejam aparelhos de baixa potência, eles podem ser os principais responsáveis pela exposição em ambientes residênciais, mesmo quando localizadas próximas a ERBs, cuja EIRP pode ser superior a mil vezes a EIRP dos equipamentos de radiação restrita.

Em todas as medições, os valores da intensidade de campo elétrico foram muito inferiores aos limites estabelecidos pela ICNIRP. A maior exposição foi devido ao access point WiFi, porém ficando em 3,36\% do limite em termos de intensidade de campo elétrico.

As simulações referentes a uma ERB próxima a um prédio mostrou, como esperado, que a intensidade de campo elétrico varia conforme o apontamento e características direcionais da antena. A partir da equação (6.2), se percebe que a máxima exposição tende a ocorrer em apartamentos que estejam sendo iluminados frontalmente pela máxima radiação da antena, ocorrendo um decaimento da intensidade de campo elétrico com a diminuição da inclinação com que a onda eletromagnética penetra no apartamento.

Mesmo com a ERB a 100 metros, distância superior ao começo da região de campo distante, a "iluminação" do prédio não será uniforme, principalmente no plano vertical. Assim, mesmo com uma ERB nas proximidades de um prédio, a variação da intensidade de campo elétrico de um apartamento para outro, principalmente em andares diferentes, pode ser muito relevante, indicando que a distância isoladamente não é uma métrica satisfatória para fazer juízo de valor em relação a exposição humana a CEMRF. 


\section{INFLUÊNCIA DOS LÓBULOS LATERAIS DAS ANTENAS}

\subsection{INTRODUÇÃO}

Neste capítulo, são discutidas situações práticas nos quais os lóbulos laterais das antenas são responsáveis pela máxima exposição em distâncias mais próximas a ERB, mesmo transportando menos energia do que o lóbulo principal. Também são apresentadas orientações para estimar qual componente do diagrama de radiação da antena contribui com a intensidade de campo mais alta. Esta orientação pode ser utilizada quando poucas informações do sistema radiante estão disponíveis, como ganho, altura, tilt e ângulo de meia-potência, e nível de lóbulo lateral.

\subsection{AVALIAÇÃO DA ANTENA DE TRANSMISSÃO}

Para uma antena setorial instalada em uma ERB, os principais parâmetros que definem se o responsável pela máxima exposição é o lóbulo principal ou o lateral são: a diferença entre as alturas da antena e do ponto de referência, o ângulo de meia potência, o nível de lóbulo lateral e o tilt da antena. O último parâmetro é muito importante, uma vez que ângulo de meia potência é fixo, mas a variação no ângulo de inclinação é mais elevada (valores usuais de ângulo de inclinação variam de $2^{\circ}$ a $10^{\circ}$ ) do que a variação da altura da antena (valores usuais da altura da antena de uma ERB de macrocélula variam de $15 \mathrm{~m}$ a $40 \mathrm{~m}$ ) [68]. Em [4, 69, 70] há muitos exemplos da dependência do ponto de máxima exposição em relação aos principais parâmetros de antena.

A figura 7.1 apresenta a influência do tilt da antena no ponto de máxima exposição, obtida por meio do software EMF-Estimator. A simulação foi executada para tilts de $3^{\circ}, 4^{\circ}$ e $6^{\circ}$, altura da antena de transmissão de $35 \mathrm{~m}$, altura do ponto de referência de 1,5 m e ângulo de meia-potência no plano vertical de $13^{\circ}$. Para a antena com tilt de $3^{\circ}$, a exposição associada ao lóbulo lateral foi maior do que para o lóbulo principal. Percebe-se que o tilt influencia mais a exposição associada ao lóbulo principal do que associada aos lóbulos laterais. 


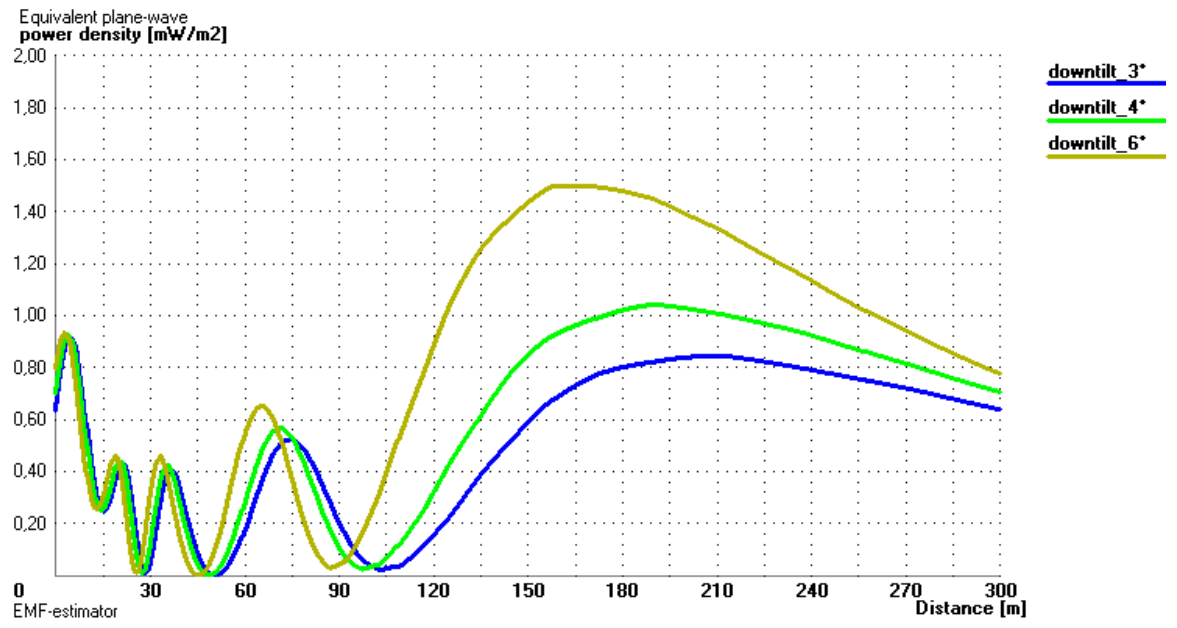

Figura 7.1: Influência do tilt da antena no ponto de máxima exposição.

A figura 7.2 apresenta a variação da distância de máxima exposição em relação a um lóbulo (principal ou lateral), em função do tilt do lóbulo e altura da antena. Aqui, o conceito de tilt do lóbulo inclui a diferença entre o ângulo dos lóbulos laterais e a linha do horizonte. Pode ser visto que, aumentando o tilt do lóbulo, a influência do ângulo de meiapotência diminui para determinação da máxima exposição local. Por outro lado, para um tilt pequeno, o ângulo de meia-potência é muito relevante para determinação do local de máxima exposição.

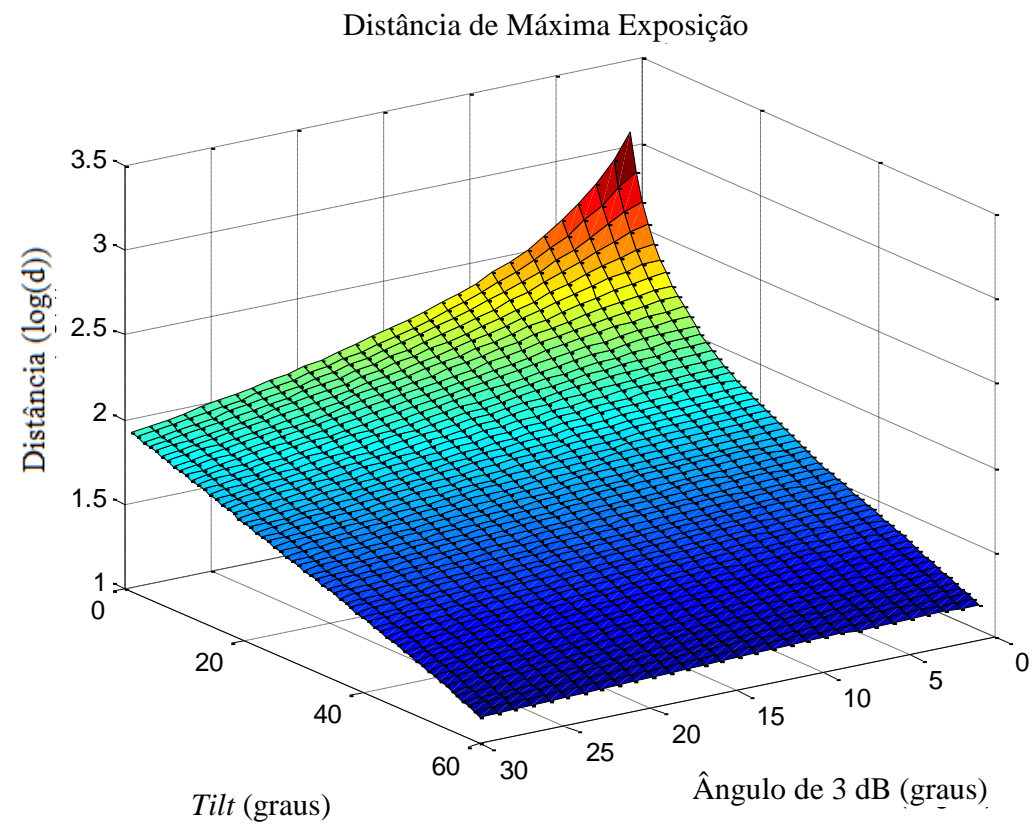

Figura 7.2: Dependência da distância de máxima exposição a qualquer lóbulo em relação ao tilt e ao ângulo de meia-potência para uma antena instalada a uma altura de $30 \mathrm{~m}$ e altura de referência de 1,5 m. 
Quando se analisa a exposição devido ao lóbulo lateral, pode ser mostrado, com alguns cálculos e fazendo uso das figuras 7.1 e 7.2, que, para um tilt de lóbulo muito alto (maiores que $50^{\circ}$ ) e ângulos de meia-potência pequenos (menores que $15^{\circ}$ ), o ponto de máxima exposição local calculado por (4.14) é aproximadamente igual a $\frac{H-h}{\operatorname{tg}(\alpha)}$ (erro igual a $1 \mathrm{~m}$ para $H-h=30 \mathrm{~m}, \alpha=50^{\circ}$ e $\left.\theta_{3 \mathrm{~dB}}=15^{\circ}\right)$.

\subsubsection{Procedimentos Práticos}

A fim de fornecer orientações sobre como estimar, a partir de características da antena como ângulo de meia-potência e tilt, qual componente é responsável pela maior exposição, os passos a seguir devem ser realizados.

1. Calcular o ponto de máxima exposição local $\left(X_{\text {main }}^{\exp }\right)$ devido ao lóbulo principal, usando (4.6), (4.8) e (4.14).

2. Se existir informação para modelar os lóbulos laterais, estimar o ponto de máxima exposição local devido aos lóbulos laterais ( $\left.X_{\text {ssl }}^{\exp }\right)$, usando (4.6), (4.8) e (4.14). Senão, utilizar (4.14) para $q=2$ (envoltória do lóbulo lateral), para encontrar $X_{\mathrm{ssl}}^{\exp }$. A equação (4.14) pode ser substituída por $\frac{H-h}{\operatorname{tg}(\alpha)}$, se as restrições já apresentadas forem obedecidas.

3. Calcular a densidade de potência (S) utilizando (4.5) ou a intensidade de campo elétrico $E$ utilizando (2.6) nos pontos $X_{\text {main }}^{\text {exp }} X_{\text {ssl }}^{\text {exp }}$.

4. Se a densidade de potência (S) (ou a intensidade de campo $E$ ) calculada em $X_{\mathrm{ssl}}^{\exp }$ for maior do que a avaliada em $X_{\text {main }}^{\text {exp }}$, então existe uma indicação de que o lóbulo lateral pode ser responsável pela máxima exposição, senão existe uma indicação de que o lóbulo principal é responsável pela máxima exposição.

Para os casos em que forem utilizados a envoltória dos lóbulos laterais, o passo 4 poderá indicar que existe a possibilidade da máxima exposição estar associada aos lóbulos laterais. No entanto, isso não necessariamente significa que o valor de pico ocorra em $X_{\text {ssl }}^{\exp }$, nem que exista grandes chances de o lóbulo principal não ser o responsável pela máxima exposição, uma vez que a consideração de envoltória superestima quase toda a região dos lóbulos laterais. 


\subsection{TESTE DO PROCEDIMENTO PROPOSTO}

Este procedimento foi testado para seis simulações com características típicas. A Tabela 7.1 mostra as informações para as primeiras três simulações, enquanto a figura 7.3 apresenta as simulações por meio do software EMF-Estimator. Aplicando o procedimento, se interpretou corretamente qual componente era responsável pela maior exposição. Todavia, nesses casos, o padrão de radiação era "bem-comportado", com o primeiro lóbulo lateral proporcionando os níveis de radiação mais elevados do que outros lobos laterais.

Tabela 7.1. Características e resultados das simulações 1, 2 e 3.

\begin{tabular}{|c|c|c|c|}
\hline \multicolumn{4}{|c|}{ Características básicas } \\
\hline \multicolumn{4}{|l|}{ Altura da antena $(H)=35 \mathrm{~m}$} \\
\hline \multicolumn{4}{|l|}{ Ganho $=15,5 \mathrm{dBi}$} \\
\hline \multicolumn{4}{|c|}{ Ângulo de meia-potência no plano vertical $=13^{\circ}$} \\
\hline \multicolumn{4}{|c|}{ Nível do lóbulo lateral (SLL) = $13 \mathrm{~dB}$} \\
\hline \multicolumn{4}{|c|}{ Frequência da portadora $=947,5 \mathrm{MHz}$} \\
\hline \multicolumn{4}{|c|}{ Altura do ponto de referência $(h)=1,5 \mathrm{~m}$} \\
\hline \multicolumn{4}{|l|}{$\mathrm{EIRP}_{\max }=888,8 \mathrm{~W}$} \\
\hline & \multicolumn{3}{|c|}{ Tilt Mecânico $(\phi)$} \\
\hline Valores Estimados & $3^{\circ}$ & $4^{\circ}$ & $6^{\circ}$ \\
\hline$X_{\text {main }}^{\text {exp }}$ & $202 \mathrm{~m}$ & $190 \mathrm{~m}$ & $167 \mathrm{~m}$ \\
\hline$S\left(@ X_{\text {main }}^{\text {exp }}, \mathrm{em} \mathrm{mW/m^{2 } )}\right.$ & 0,86 & 1,05 & 1,53 \\
\hline$X_{s s l}^{e x p}[(H-h) / \operatorname{tg}(\alpha)]$ & $4,7 \mathrm{~m}$ & $4,1 \mathrm{~m}$ & $2,9 \mathrm{~m}$ \\
\hline $\mathrm{S}_{\text {side_lobe }}\left(@ X_{s s l}^{\exp }, \mathrm{em} \mathrm{mW/ \textrm {m } ^ { 2 } )}\right.$ & 0,89 & 0,89 & 0,9 \\
\hline$X_{s s l}^{e x p}$ (envoltória) & $32 \mathrm{~m}$ & $31 \mathrm{~m}$ & $30 \mathrm{~m}$ \\
\hline $\mathrm{S}_{\mathrm{envelope}}\left(@ X_{s s l}^{\exp }, \mathrm{em} \mathrm{mW} / \mathrm{m}^{2}\right.$ & 0,87 & 0,9 & 0,96 \\
\hline
\end{tabular}




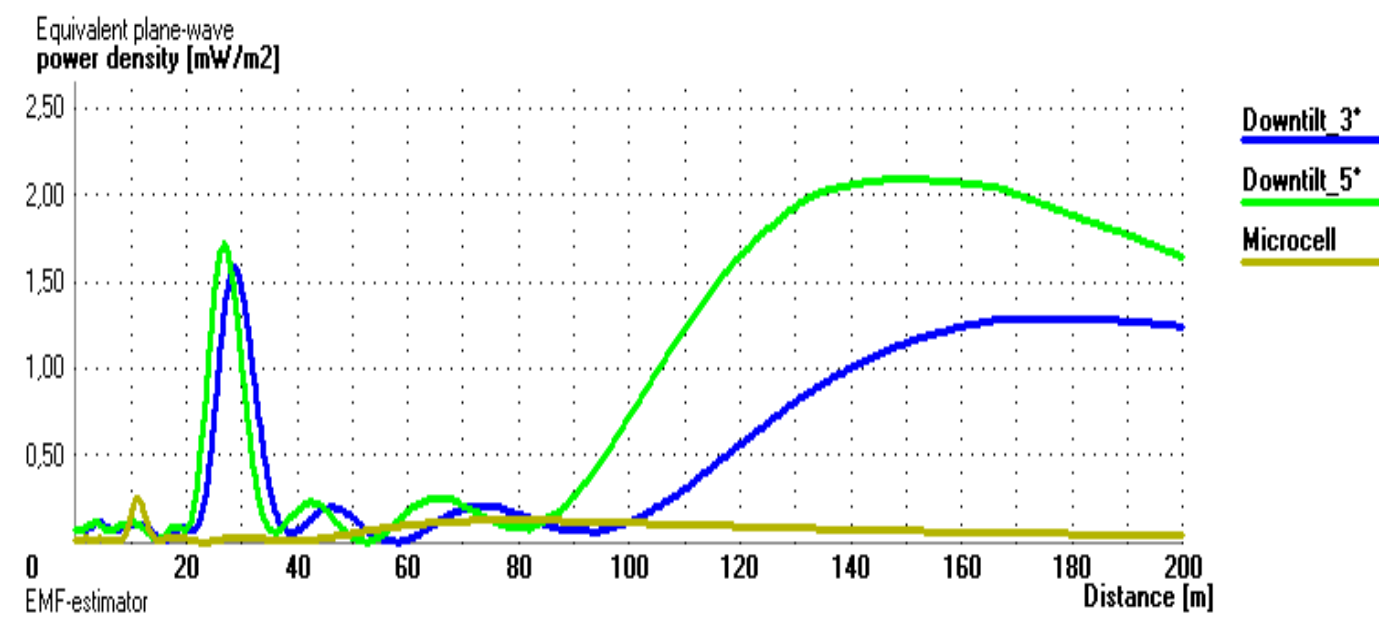

Figura 7.3: ERB de macrocélula com tilt de $3^{\circ}$ e ERB de microcélula com tilt de $1^{\circ}$ apresentaram máximo de exposição associado aos lóbulos laterais.

As outras três simulações foram executadas utilizando uma antena cujo terceiro lóbulo lateral (abaixo da linha do horizonte) fornece níveis de radiação $15 \mathrm{~dB}$ abaixo do máximo ganho, mais elevados do que outros lóbulos laterais. As informações básicas de instalação e os resultados das simulações estão apresentados na Tabela 7.2 e na figura 7.3, respectivamente. Tal como pode ser visto na figura 7.3, na modelagem de lóbulos laterais $\operatorname{com} \cos ^{q}(\theta-\alpha)$ os resultados da orientação foram precisos. No entanto, a modelagem utilizando a envoltória para os lóbulos laterais, o cálculo utilizando o tilt de 3 graus resultou em uma associação da máxima exposição com o lóbulo principal incorretamente, uma vez que a radiação verdadeira do terceiro lóbulo lateral é maior do que o valor considerado na envoltória.

Assim, pode-se dividir o procedimento em duas situações. A primeira é quando é possível recuperar informações do lóbulo lateral (SLL e ângulo de meia-potência) a partir do diagrama de radiação, de modo que os lóbulos laterais também possam ser modelados por $\cos ^{q}(\theta-\alpha)$, com resultados apresentando menor chance de erro. A segunda situação é quando apenas o nível do lóbulo lateral está disponível, no qual os resultados sugerem que a precisão desta orientação aumenta para antenas que possuem menores níveis de lóbulos laterais em ângulos superiores. 
Tabela 7.2: Características e resultados das simulações 4, 5 e 6.

\begin{tabular}{|c|c|c|c|}
\hline \multicolumn{4}{|c|}{ Características básicas } \\
\hline \multicolumn{4}{|l|}{ Ganho da Antena $=16,39 \mathrm{dBi}$} \\
\hline \multicolumn{4}{|c|}{ Ângulo de meia-potência no plano vertical $=10^{\circ}$} \\
\hline \multicolumn{4}{|l|}{ Nível de lóbulo lateral $=15 \mathrm{~dB}$} \\
\hline \multicolumn{4}{|c|}{ Frequência da portadora $=945 \mathrm{MHz}$} \\
\hline \multicolumn{4}{|c|}{ Altura do ponto de referência $(h)=1,5 \mathrm{~m}$} \\
\hline & \multicolumn{3}{|c|}{ Tilt Mecânico $(\phi)$} \\
\hline & $3^{\circ}$ & $5^{\circ}$ & $1^{\mathrm{o}}$ \\
\hline Altura da antena $(H)$ & $25 \mathrm{~m}$ & $25 \mathrm{~m}$ & $10 \mathrm{~m}$ \\
\hline $\mathrm{EIRP}_{\max }$ & $872,7 \mathrm{~W}$ & $872,7 \mathrm{~W}$ & $20 \mathrm{~W}$ \\
\hline \multicolumn{4}{|l|}{ Estimado } \\
\hline$X_{\text {main }}^{\text {exp }}$ & $175 \mathrm{~m}$ & $149 \mathrm{~m}$ & $74,5 \mathrm{~m}$ \\
\hline$S\left(@ X_{\text {main }}^{\text {exp }}, \mathrm{em} \mathrm{mW/m^{2 } )}\right.$ & 1,22 & 1,98 & 0,12 \\
\hline$X_{s s l}^{\exp }\left(\cos ^{q}(\theta)\right)$ & $28,2 \mathrm{~m}$ & $26,3 \mathrm{~m}$ & $11 \mathrm{~m}$ \\
\hline$S_{\text {side_lobe }}\left(@ X_{s s l}^{e x p}\right.$, em mW/m²) & 1,6 & 1,74 & 0,26 \\
\hline$X_{s s l}^{e x p}$ (envoltória) & $22,3 \mathrm{~m}$ & $21,5 \mathrm{~m}$ & $8,4 \mathrm{~m}$ \\
\hline $\mathrm{S}_{\text {envelope }}\left(@ X_{s s l}^{e x p}, \mathrm{em} \mathrm{mW/m^{2 } )}\right.$ & 1,1 & 1,18 & 0,18 \\
\hline
\end{tabular}

Também avaliou-se um sítio típico, tal como apresentado na figura 7.4. Neste sítio está instalada uma ERB isolada, mas com os sistemas GSM e UMTS alimentando uma antena multibanda. As informações sobre o sítio e os resultados dos cálculos são apresentadas na Tabela 7.3. A configuração básica utilizada para os testes é a mesma da apresentada na Seção 4.6. Para sinais GSM somente o canal BCCH foi medido. Para sinais de UMTS todo o canal de $5 \mathrm{MHz}(3,84 \mathrm{MHz}$ de largura de faixa de $3 \mathrm{~dB})$ foi avaliado.

A medição ocorreu no azimute com a radial em maior área aberta disponível. Nesse azimute, mediu-se 18 pontos, entre as distâncias de $5 \mathrm{~m}$ a $130 \mathrm{~m}$ até a ERB, além de um outro ponto a $210 \mathrm{~m}$ da base da torre. O ponto 19 foi medido nesta distância, porque além de $130 \mathrm{~m}$ até $200 \mathrm{~m}$ existiam árvores que obstruíam a linha de visada entre a sonda e a antena, adicionalmente, se esperava uma maior exposição devido lóbulo principal do sistema GSM.

Para o sistema UMTS a máxima exposição estava prevista para estar associada com os lóbulos laterais, sendo que o lóbulo principal atingiria o nível do chão muito além desses 
pontos de medição. As figuras 7.5 e 7.6 mostram os resultados das medições e avaliação teórica para esse sítio. Neste caso de estudo de um sistema real, a orientação apresentou uma indicação consistente sobre qual componente é responsável pela exposição máxima.

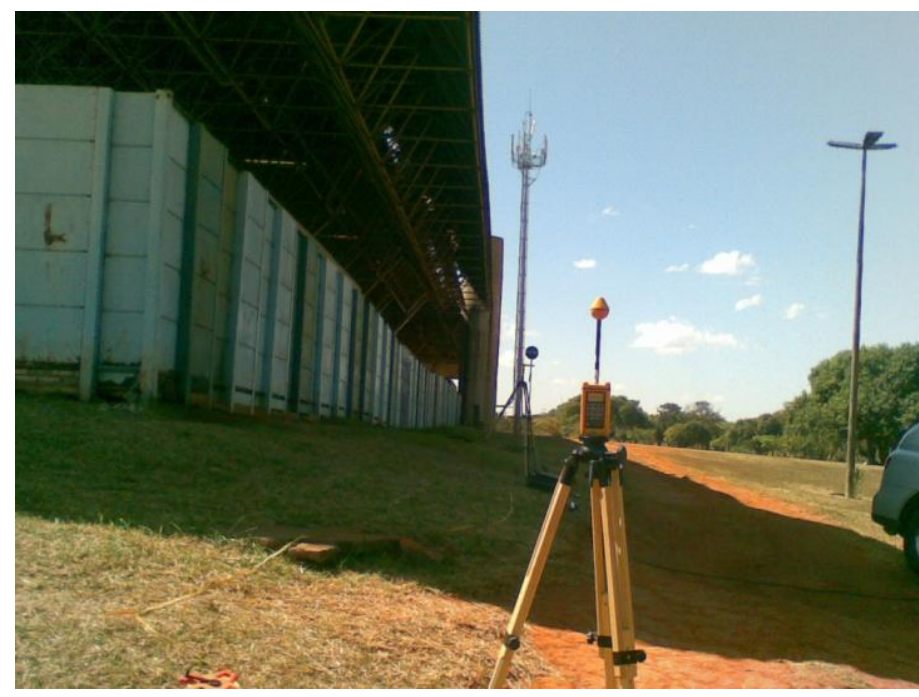

Figura 7.4: Sítio localizado no Parque da Cidade, DF, ao lado do Centro de Eventos.

Tabela 7.3: Características das fontes 1 e 2 e resultados.

Coordenadas Lat. 15 47' 51.4"; Long. 47 54' 26.4"; Azimute 220

\begin{tabular}{|c|c|c|c|}
\hline \multicolumn{2}{|c|}{ Fonte 1} & \multicolumn{2}{|c|}{ Fonte 2} \\
\hline \multicolumn{2}{|c|}{ Modelo de antena: Kathrein 742265} & \multicolumn{2}{|c|}{ Modelo de antena: Kathrein 742265} \\
\hline \multicolumn{2}{|c|}{ Altura da antena $(H)=32 \mathrm{~m}$} & \multicolumn{2}{|c|}{ Altura da antena $(H)=32 \mathrm{~m}$} \\
\hline \multicolumn{2}{|l|}{ Ganho $=15,5 \mathrm{dBi}$} & \multicolumn{2}{|l|}{ Ganho $=18,3 \mathrm{dBi}$} \\
\hline \multicolumn{2}{|l|}{ Tilt elétrico $(\phi)=7^{\circ}$} & \multicolumn{2}{|l|}{ Tilt elétrico $(\phi)=2^{\circ}$} \\
\hline \multicolumn{2}{|c|}{ Nível de lóbulo lateral $=11,2 \mathrm{~dB}$} & \multicolumn{2}{|c|}{ Nível de lóbulo lateral $=15,1 \mathrm{~dB}$} \\
\hline \multicolumn{2}{|c|}{ Ângulo de $3 \mathrm{~dB}$ no Plano $\mathrm{V}=10^{\circ}$} & \multicolumn{2}{|c|}{ Ângulo de $3 \mathrm{~dB}$ no Plano $\mathrm{V}=4,7^{\circ}$} \\
\hline \multicolumn{2}{|c|}{ Frequência do $\mathrm{BCCH}=891 \mathrm{MHz}$} & \multicolumn{2}{|c|}{ Portadora UMTS $=2157,4 \mathrm{MHz}$} \\
\hline \multicolumn{2}{|c|}{ Altura da sonda de medição $(h)=1,7 \mathrm{~m}$} & \multicolumn{2}{|c|}{ Altura da sonda de medição $(h)=1,7 \mathrm{~m}$} \\
\hline \multicolumn{2}{|c|}{$\mathrm{EIRP}_{\max } \approx 387,5 \mathrm{~W}$ (por portadora) } & \multicolumn{2}{|l|}{$\mathrm{EIRP}_{\text {max }} \approx 1.216 \mathrm{~W}$} \\
\hline \multicolumn{2}{|c|}{ Estimado } & \multicolumn{2}{|c|}{ Estimado } \\
\hline$X_{\text {main }}^{\text {exp }}$ & $165 \mathrm{~m}$ & $X_{\text {main }}^{\text {exp }}$ & $434 \mathrm{~m}$ \\
\hline E-field & $547 \mathrm{mV} / \mathrm{m}$ & E-field & $342 \mathrm{mV} / \mathrm{m}$ \\
\hline$X_{s s l}^{e x p}\left(\cos ^{q}(\theta)\right)$ & $66 \mathrm{~m}$ & $X_{s s l}^{\exp }\left(\cos ^{q}(\theta)\right)$ & $9 \mathrm{~m}$ \\
\hline E-field @ $X_{s s l}^{\exp }$ & $0,4 \mathrm{~V} / \mathrm{m}$ & E-field @ $X_{s s l}^{\exp }$ & $1,06 \mathrm{~V} / \mathrm{m}$ \\
\hline$X_{s s l}^{e x p}($ envoltória $)$ & $27 \mathrm{~m}$ & $X_{s s l}^{e x p}($ envoltória $)$ & $29,3 \mathrm{~m}$ \\
\hline E-field (envoltória) & $519 \mathrm{mV} / \mathrm{m}$ & E-field (envoltória) & $573 \mathrm{mV} / \mathrm{m}$ \\
\hline
\end{tabular}




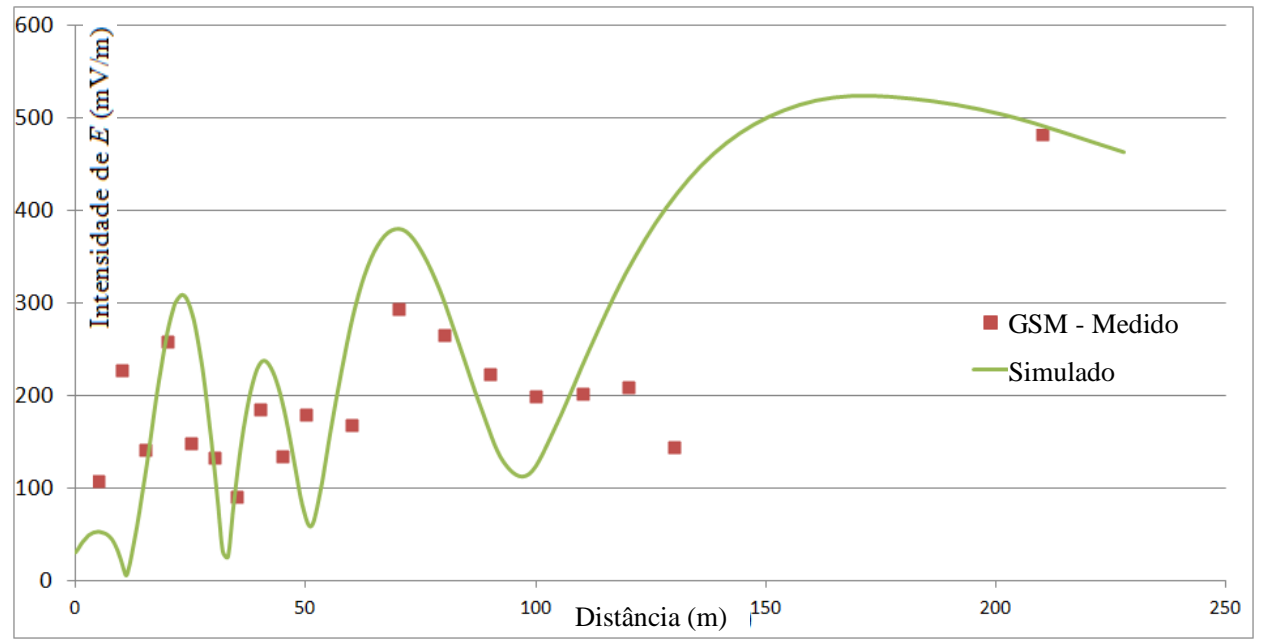

Figura 7.5: Intensidade de campo elétrico para o sistema GSM.

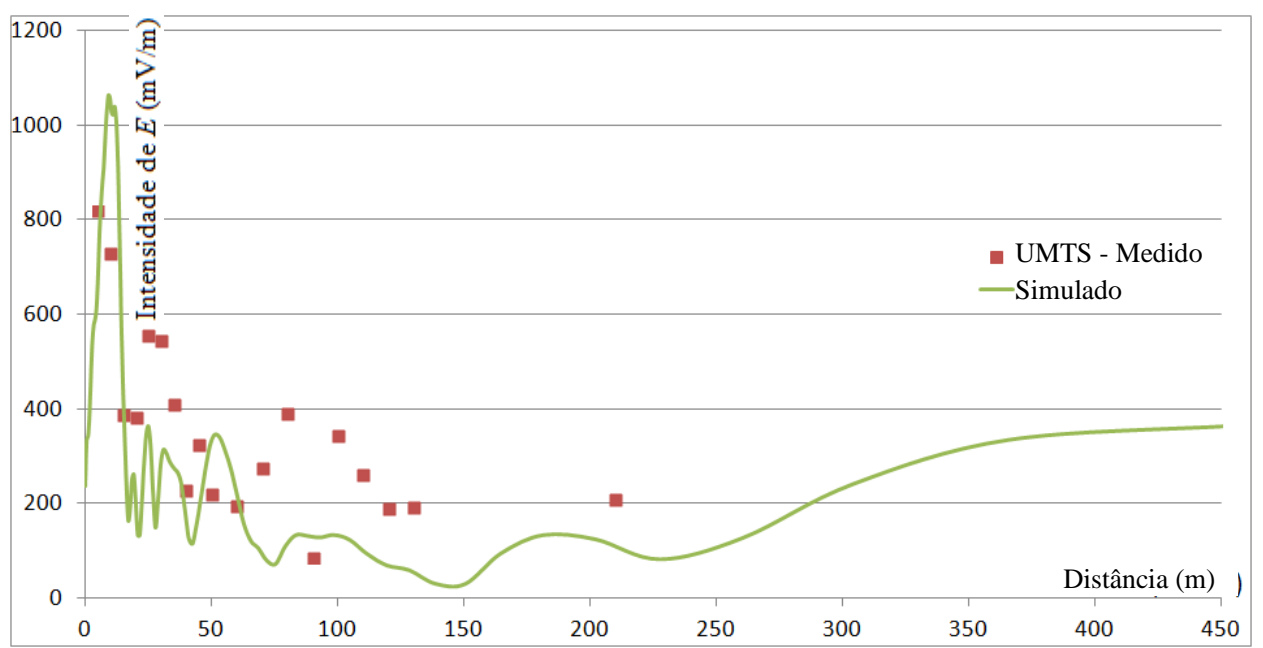

Figura 7.6: Intensidade de campo elétrico para o sistema UMTS.

\subsection{CONCLUSÕES}

Seis fontes radiantes foram simuladas e foram realizadas medições em um sítio real, representando duas fontes diferentes. Quando foi possível modelar lóbulos laterais com $\cos ^{q}(\theta-\alpha)$, a orientação resultou em oito indicações corretas em oito cenários avaliados, incluindo a região de exposição máxima. Quando apenas a informação básica estava disponível (incluindo SLL), onde lóbulos laterais foram modelados por um modelo de envoltória, a orientação resultou em sete indicações corretas em oito cenários avaliados.

Os resultados mostram que a precisão deste procedimento é proporcional à quantidade e qualidade da informação do sistema radiante instalado. Evidentemente, se o arquivo 
eletrônico com o diagrama de radiação estiver disponível, então pode ser realizada uma simulação, de modo que toda a caracterização do campo eletromagnético poderia ser realizada previamente, por conseguinte, não seria necessário aplicar este procedimento. No entanto, é relativamente fácil encontrar datasheets de antenas comerciais que fornecem informações gerais que podem ser usadas com esta orientação. Nem sempre o arquivo eletrônico do diagrama de radiação de uma antena específica é disponibilizado para o público em geral, comumente são disponibilizados para clientes e parceiros comerciais.

Quando se utiliza a envoltória dos lóbulos laterais, a precisão deste modelo aumenta para antenas que apresentam níveis de lóbulos laterais mais baixos nos ângulos mais altos. Este procedimento apresentou bons resultados para instalações típicas de ERB.

Neste estudo, não foram considerados os lóbulos laterais em ambientes urbanos com canyon street. Todavia, levando em conta que se considera o modelo de espaço livre próximo à fonte de RF e outro modelo de propagação mais adequado em distâncias maiores, como apresentado na figura 5.6, espera-se que essa metodologia possa ser aplicada em tais ambientes, com os devidos ajustes. 


\section{CONCLUSÕES E RECOMENDAÇÕES}

Este trabalho apresentou uma metodologia para estimar o local provável de máxima exposição a CEMRF associado a uma estação de radiocomunicação em qualquer tipo de ambiente com visada direta. Também apresentou elementos para auxiliar na caracterização do ambiente eletromagnético, tanto em locais internos quanto externos.

Os resultados da metodologia proposta são consistentes com as simulações e medições realizadas. Para os cenários com visada direta, o local estimado com máxima exposição é dependente do expoente de perda de percurso $(\gamma)$, porém sua influência não é crucial em pequenas distâncias, uma vez que o ponto de máxima exposição ocorre abaixo de algumas centenas de metros.

Os resultados mostraram que valores de $\gamma$ mais altos implicam em pontos de máxima exposição mais próximos da estação de radiocomunicação. Os resultados sugerem que nos casos de avaliação em ambientes com características de canyon streets e visada direta, o avaliador deva considerar $\gamma=2,6$ como um ponto de referência e, então, caminhar ao redor do local estimado para identificar o ponto que apresenta a máxima exposição associada à estação de radiocomunicação.

Em outros casos com visada direta, o avaliador deve considerar $\gamma=2$ como um ponto de referência, sabendo que há mais chances do ponto de máxima exposição ocorrer mais próximo da estação, do que mais longe. Da mesma forma, o procedimento de caminhar ao redor do local estimado deve ser executado.

Os casos de exposição em ambientes sem visada direta com a estação de radiocomunicação apresentam, usualmente, densidade de potência baixa, mesmo tendo uma qualidade de sinal satisfatória para prestação do serviço de radiocomunicação. Por isso, quando se seleciona os locais para realizar a avaliação da exposição humana a CEMRF, pontos com visada direta devem ser preferíveis em relação a pontos sem visada direta.

Foi desenvolvido um estudo sobre a influência do desvanecimento em pequena escala na avaliação da exposição humana a CEMRF mostrando a relevância da realização da média espacial, com pelo menos 3 pontos de medição, principalmente nos casos que apresentam uma não-uniformidade da intensidade do campo elétrico ao longo do corpo de uma pessoa. 
No capítulo 6 foram apresentadas medições em apartamentos que possuíam fontes de RF na proximadade do prédio (ERB) ou dentro do quarto (AP ou babá eletrônica). Adicionalmente, foram realizadas simulações para mostrar o valor esperado em ambientes que possuem ERBs em sua vizinhança, que indicaram valores compatíveis com as medições realizadas. Foi mostrado que mesmo possuindo EIRP muito inferior as das ERBs nas vizinhanças, equipamentos de radiação restrita podem ser os principais contribuintens na exposição devido à proximidade desses equipamentos em relação à pessoa exposta.

Por fim, no capítulo 7, foi aprofundado o estudo sobre as características dos lóbulos laterais de antenas setoriais, orientando sobre as chances deles serem responsáveis pelo ponto de máxima exposição. Nos casos avaliados nesse capítulo, aqueles que possuíam tilt menor ou igual a $3^{\circ}$ apresentaram a máxima exposição associada aos lóbulos laterais. Todavia, esse valor não pode ser generalizado, uma vez que antenas possuem diagramas de radiação diferentes, sendo que antenas mais novas estão mostrando uma tendência de apresentar maiores valores de SLL, inclusive a figura 4.9/Tabela 4.3 apresentou um caso de tilt de $1^{\circ}$, no qual a máxima exposição estava associada ao lóbulo principal.

Como sugestão de trabalho futuro se pode aprofundar a questão da caracterização do ambiente devido a múltiplas fontes de RF, co-localizadas ou não, além dessa caracterização em termos de exposição média para avaliações de longo prazo, como suporte a estudos epidemiológicos. 


\section{REFERÊNCIAS BIBLIOGRÁFICAS}

[1] World Health Organization - "Framework for developing health-based EMF standards".

Disponível em http://www.who.int/peh-emf/standards/framework/en/

[2] IEC Standard 62232 - "Determination of RF field strength and SAR in the vicinity of radiocommunication base stations for the purpose of evaluating human exposure".

[3] ITU-T Recommendation K-91 - "Guidance for assessment, evaluation and monitoring of human exposure to radio frequency electromagnetic fields".

[4] ITU-T Recommendation K-70 - "Mitigation techniques to limit human exposure to EMFs in the vicinity of radiocommunication stations".

[5] Agência Nacional de Telecomunicações, Resolução nº.303/2002 - "Regulamento sobre Limitação da Exposição a Campos Elétricos, Magnéticos e Eletromagnéticos na Faixa de Radiofrequências entre 9 kHz e 300 GHz”. ANATEL, 2002.

[6] ITU-T Recommendation K-100 - "Measurement of radio frequency electromagnetic fields to determine compliance with human exposure limits when a base station is put into service".

[7] World Health Organization (WHO). "Electromagnetic fields and public health: mobile phones". Fact Sheet N¹93. Genebra, Suíça; atualizado em outubro de 2014. Disponível em: http://www.who.int/mediacentre/factsheets/fs193/en/

[8] R. Baan et al. on behalf of the WHO International Agency for Research on Cancer Monograph Working Group. "Carcinogenicity of radiofrequency electromagnetic fields", The Lancet Oncology, vol. 12, no. 7, pp. 624-626, Jul. 2011.

DOI: 10.1016/S1470-2045(11)70147-4.

[9] ICNIRP SCI "Review Mobile Phones, Brain Tumours and the Interphone Study: Where are we now?", in ENVIRON HEALTH PERSPECT 119(11), pp. 1534-1538, 2011.

[10] "Non-ionizing Radiation, Part 2: Radiofrequency Electromagnetic Fields". Volume 102. Monograph by the International Agency for Research on Cancer IARC Monographs, vol. 102, 2011.

[11] "Exposure to high frequency electromagnetic fields, biological effects and health consequences $(100 \mathrm{kHz}-300 \mathrm{GHz})$ - Review of the scientific evidence on dosimetry, biological effects, epidemiological observations, and health consequences concerning exposure to high frequency electromagnetic fields (100 $\mathrm{kHz}$ to $300 \mathrm{GHz}) "$. ICNIRP 16/2009.

[12] "Estabelecendo um diálogo sobre riscos de campos eletromagnéticos". Organização Mundial de Saúde, 2002.

Disponível em: http://www.who.int/peh-emf/publications/Risk_Portuguese.pdf 
[13] “Radio Regulation", ed. of 2012. International Telecommunications Union.

[14] Agência Nacional de Telecomunicações, Resolução no.259/2002 - "Regulamento de Uso do Espectro de Radiofrequências". ANATEL, 2002.

[15] ITU-T Recommendation K-52 - "Guidance on complying with limits for human exposure to electromagnetic fields".

[16] P. A. Valberg, "Mechanistic Viewpoint on the Health Implications", in Proceedings International Workshop on Base Stations and Wireless Networks: Exposures and Health Consequences. Switzerland, Geneva, June 15-16, 2005.

[17] ICNIRP, "Guidelines for limiting exposure to time-varying electric, magnetic and electromagnetic fields (up to $300 \mathrm{GHz}$ )”, 1998.

[18] "Gestión Ambiental de los Campos Electromagnéticos en Telecomunicaciones", Módulo 2. Curso Organizado pela ITU em colaboração com o INICTEL - Instituto Nacional de Investigación y Capacitación de Telecomunicaciones (Perú). Julho de 2007.

[19] A. Linhares, A.J.M. Soares and U. S. Dias. "On the small-scale fading evaluation in human exposure assessment", in SBMO/IEEE MTTS Int. Microwave and Optoelectronics Conf. (IMOC), Rio de Janeiro, 2013.

[20] ITU-T Recommendation K-61 - "Guidance to measurement and numerical prediction of electromagnetic fields for compliance with human exposure limits for telecommunication installations".

[21] C. A. Balanis, Antenna Theory: Analysis and Design, 2nd ed., John Wiley \& Sons, Inc..

[22] W. L. Stutzman and G. A. Thiele, Antenna Theory and Design, 2nd ed., J. Wiley, 1998.

[23] ECC Recommendation (02)04 (revised Bratislava 2003, Helsinki 2007). "Measuring non-ionising Electromagnetic Radiation $(9 \mathrm{kHz}-300 \mathrm{GHz})$ ".

[24] CENELEC EN 50400: 2006 - "Basic standard to demonstrate the compliance of fixed equipment for radio transmission $(110 \mathrm{MHz}-40 \mathrm{GHz})$ intended for use in wireless telecommunication networks with the basic restrictions or the reference levels related to general public exposure to radio frequency electromagnetic fields, when put into service".

[25] Australian Communication Authority. "Guidelines on the assessment of installations against electromagnetic radiation (EMR) exposure limits". Setembro 2000 .

[26] Microwave Engineers' Handbook, vol. 2, Artech House, 1971.

[27] A. Goldsmith, Wireless Communications, Cambridge University Press, 2005. 
[28] G. Neubauer et al, "Study on the Feasibility of Future Epidemiological Studies on Health Effects of Mobile Telephone Base Stations: Dosimetric criteria for an epidemiological base station study", in Proceedings International Workshop on Base Stations and Wireless Networks: Exposures and Health Consequences. Switzerland, Geneva, June 15-16, 2005.

[29] E. Larchêveque, C. Dale, M. Wong and J. Wiart, "Analysis of electric field averaging for In Situ radiofrequency exposure assessment," IEEE Trans. on Veh. Tech., vol.54, no.4, July 2005, pp. 1245-1250.

[30] CENELEC EN 50492:2008 - "Basic standard for the in-situ measurement of electromagnetic field strength related to human exposure in the vicinity of base stations".

[31] M.D. Yacoub, "The $\kappa-\mu$ Distribution and the $\eta-\mu$ Distribution," IEEE Antennas and Propagation Magazine, vol.49, no.1, pp. 68-81, Feb. 2007.

[32] M. Sadiku, Numerical Techniques in Electromagnetics with Matlab, 3rd ed., CRC Press, pg. 535.

[33] A. Leon-Garcia, Probability and Random Processes for Electrical Engineering, 2nd ed., Addison-Wesley Publishing Company, pg.155.

[34] IEC/TR 62669:2011 (Technical Report) - Case studies supporting IEC 62232 "Determination of RF field strength and SAR in the vicinity of radiocommunication base station for the purpose of evaluating human exposure".

[35] M.D. Yacoub, “The $\alpha-\mu$ Distribution: A Physical Fading Model for the Stacy Distribution", IEEE Transaction on Vehicular Technology, vol. 56, no.1, pp. 27-34, Jan. 2007.

[36] U.S. Dias and M.D. Yacoub, "On the $\alpha-\mu$ Autocorrelation and Power Spectrum Functions: Field Trials and Validation", in IEEE Global Communications Conference - Globecom'09, 30 Nov - 4 Dec, Honolulu, HI, USA.

[37] L. Rubio, J. Reig, N. Cardona, "Evaluation of Nakagami fading behaviour based on measurements in urban scenarios", Int. J. Electron. Commun. (AEÜ) 61, pp. 135138, 2007.

[38] A.F. Toledo and A.M.D. Turkmani, "Propagation into and within Buildings at 900, 1800 and $2300 \mathrm{MHz}$ ", in Vehicular Technology Conference, 1992, IEEE 42nd, pp. 633-636 vol.2.

[39] C.L. Selvati and U.S. Dias, "On the Fading Parameters Characterization of the $\kappa-\mu$ Distribution: Measurements and Statistics", in IEEE 3rd Latin-American Conference on Communications, Oct. 24-26, 2011, Belém, Brazil.

[40] Health Protection Agency (HPA) - Mobile Telephony and Health - Exposures from Base Stations.

Disponível em: http://www.hpa.org.uk/Topics/Radiation/UnderstandingRadiation/ UnderstandingRadiationTopics/ElectromagneticFields/MobilePhones/info_BaseSta tions/ 
[41] P.H.S. Wanderley and M.A.B. Terada, "Assessment of the influence of real-world radio station antennas", Brazilian J. of Biomedical Engineering, vol. 27, sup. 1, pp. 45-51, 2011.

[42] P.H. Wanderley and M.A. Terada, "Assessment of the applicability of the Ikegami propagation model in modern wireless communication scenarios", Journal of Electromagnetic Waves and Applications, 26:11-12, pp. 1483-1491, 2012.

[43] F. Lewicki, ITU-T Technical Session on EMF - "Comparison between measurement and calculations - EMF-Estimator”, K. guide. Geneva, 27 May 2009. Disponível em: T/worksem/techsessions/com05/090527/index.html

[44] Wójcik, Dariusz. "Evaluation of near field of the GSM base station antennas in urban environment," Journal of Telecommunications and Information Technology, vol. 1, 2003.

[45] A. Linhares, M.A. Terada, and A.J. Martins Soares, "Estimating the Location of Maximum Exposure to Electromagnetic Fields Associated with a Radiocommunication Station", Journal of Microwaves, Optoelectronics and Electromagnetic Applications (JMOe), vol.12, no. 1, pp. 141-157, Jun. 2013.

[46] V. Erceg et al., "An empirically based path loss model for wireless channels in suburban environments." IEEE J. on Selected Areas of Commun., vol. 17, no. 7, pp. 1205-1211, Jul. 1999.

[47] A. Linhares; A.J.M. Soares; and M.A.B. Terada, "Determination of Measurement Points in Urban Environments for Assessment of Maximum Exposure to EMF Associated to a Base Station", International Jounal of Antennas and Propagation. Special Issue on Propagation of Electromagnetic Waves in Terrestrial Environment for Applications in Wireless Telecommunications, pp. 1-7, 2014.

[48] COST Action 231, "Digital mobile radio towards future generation systems", Final Report, tech. rep., European Communities, 1999.

[49] I. Rodriguez et al., "Path Loss Validation for Urban Micro Cell Scenarios at 3.5 GHz Compared to 1.9 GHz", in IEEE Global Commun. Conf. (Globecom), 2013.

[50] V.S. Abhayawardhana et al., "Comparison of empirical propagation path loss models for fixed wireless access systems", in Veh. Tech. Conf., 2005. VTC 2005Spring. IEEE 61st., vol. 1, 2005.

[51] I. Rodrigues et al., "A Geometrical-based Vertical Gain Correction for Signal Strength Prediction of Downtilted Base Station Antennas in Urban Areas", IEEE Vehicular Technology Conference (VTC), Fall 2012.

[52] ATDI Advanced Radiocommunications ICS Telecom, "V12 - Radio Planning and Technical Spectrum Management software".

Disponível em: http://www.atdi.com/ics-telecom/

[53] J. Whitteker, "Measurements of Path Loss at $910 \mathrm{MHz}$ for Proposed Microcell Urban Mobile Systems", IEEE Trans. on Veh. Tech., vol. 37, no. 3, Aug. 1988. 
[54] H. Barros Tercius. Distribuições Generalizadas de Desvanecimento de Curto Prazo: Medições de Campo e Validações. Dissertação de Mestrado, 2008, UnicampFEEC.

[55] L. C. Fernandes, A. Linhares, and A. J. M. Soares, "Estimation of region of maximum exposure to radiofrequency electromagnetic fields", Microwave and Optical Technology Letters (in press).

[56] J. D. Gibson, The Mobile Communications Handbook, 2nd ed., CRC Press LLC, 1999.

[57] Mannesmann Mobilfunk GmbH: "COST 231 - urban micro cell measurements and building data".

[58] A. F. de Toledo, A. M. D. Turkmani, and D. Parsons, "Estimating coverage of radio transmission into and within buildings at 900, 1800, and $2300 \mathrm{MHz}$, IEEE Personal Commun., vol. 5, pp. 40-47, Apr. 1998.

[59] C. Perez-Vega et al., "A simple and efficient model for indoor path-loss prediction”, Meas. Sci. Technol., vol. 8 pp. 1166-1173, 1997.

[60] D. Gupta et al., "RF Indoor Propagation Modelling in Buildings of Rajasthan at Frequencies of $900 \mathrm{MHz} \& 2.1 \mathrm{GHz}$ ", International Journal of Wireless and Mobile Networking (IJWAMN), vol. 1, no. 1, Nov. 2013.

[61] H. Li et al., "Modeling Wireless Signal Transmission Performance Path Loss for ZigBee Communication Protocol in Residential Houses", in Agricultural and Biosystems Engineering Presentations, Posters and Proceedings, 2009.

[62] IT'IS Foundation, "Development of Procedures for the Assessment of Human Exposure to EMF from Wireless Devices in Home and Office Environments", Final Report submitted to Swiss Federal Office of Public Health, Zurich, Switzerland, 2005 .

[63] ITU-R Report SM-2153-4 (07/2013) - "Technical and operating parameters and spectrum use for short-range radiocommunication devices".

[64] K. R. Foster, "Radiofrequency exposure from wireless LANs utilizing WI-FI technology”, Health Phys, vol. 92, pp. 280-289, Mar. 2007.

[65] W. Joseph et al., "Determination of the duty cycle of WLAN for realistic radio frequency electromagnetic field exposure assessment", Progress in Biophysics and Molecular Biology, vol. 111, no. 1, pp. 30-36, Jan. 2013.

[66] US Code of Federal Regulations, Title 47, Part 15.247. "Operation within the bands 902-928 MHz, 2400-2483.5 MHz, and 5725-5850 MHz”.

[67] A. Linhares; A.J.M Soares; and A.P. Azevedo, "Measurement of RF Field Strength in Home Environments from a Nearby Base Station and Wireless Devices". Submetido para revista. 
[68] A. Linhares; A.J.M. Soares; and M.A.B. Terada, "Side lobes from radio base station antenna in the evaluation of human exposure to EMF", in SBMO/IEEE MTTS International Microwave and Optoelectronics Conference (IMOC), 2013, Rio de Janeiro.

[69] P.H. Wanderley, “Análise de Radiação Não-Ionizante Emitida por Estações RádioBase com Perdas Calculadas pelo Modelo de Ikegami-Walfisch". Dissertação de Mestrado. Universidade de Brasília, 2009.

[70] M.A. Terada, "Análise da Intensidade de Campo Elétrico de Estações Rádio-Base", Revista Telecomunicações (Inatel), vol. 11, no. 1, Maio 2008. 